Universidade de Brasília

Faculdade de Tecnologia

Departamento de Engenharia Mecânica

\title{
ESTUDO EXPERIMENTAL EM TÚNEL DE VENTO DE TURBINAS DE EIXO HORIZONTAL
}

Marianela Machuca Macías

Orientador: Antonio C. P. Brasil Junior

Dissertação de Mestrado em Ciências Mecânicas

Publicação: ENM.DM-230 A/2016

Brasília-DF: 04/2016 
Universidade de Brasília

Faculdade de Tecnologia

Departamento de Engenharia Mecânica

\section{ESTUDO EXPERIMENTAL EM TÚNEL DE VENTO DE TURBINAS DE EIXO HORIZONTAL}

Marianela Machuca Macías

DISSERTAÇÃO SUBMETIDA AO DEPARTAMENTO DE ENGENHARIA MECÂNICA DA FACULDADE DE TECNOLOGIA DA UNIVERSIDADE DE BRASÍLIA COMO PARTE DOS REQUISITOS NECESSÁRIOS PARA OBTENÇÃO DO GRAU DE MESTRE EM CIÊNCIAS MECÂNICAS.

Aprovada por:

Antonio C. P. Brasil Junior, Prof. Dr. , UnB

(Orientador)

Aline S. de Paula, Profa. Dra., UnB

(Examinadora interna)

João N. S. Vianna, Prof. Dr., UnB-CDS

(Examinador externo)

Brasília, 12 de Abril de 2016. 


\author{
Marianela Machuca Macías \\ ESTUDO EXPERIMENTAL EM TÚNEL DE VENTO DE TURBINAS DE \\ EIXO HORIZONTAL/ Marianela Machuca Macías. - Brasil, 2016- \\ 104 p. : il. (algumas color.) ; $30 \mathrm{~cm}$. \\ Orientador: Antonio C. P. Brasil Junior \\ Dissertação (mestrado) - Universidade de Brasília - UnB \\ Faculdade de Tecnologia \\ Programa de Pós-Graduação em Ciências Mecânicas, 2016. \\ 1. ensaio em túnel de vento. 2. transposição de resultados modelo-protótipo. I. \\ Orientador. II. Universidade de Brasília. III. Faculdade de Tecnologia. IV. Ensaios \\ em túnel de vento de turbinas de eixo horizontal
}

\title{
REFERÊNCIA BIBLIOGRÁFICA
}

Macias, M. M. (2016). ESTUDO EXPERIMENTAL EM TÚNEL DE VENTO DE TURBINAS DE EIXO HORIZONTAL. Dissertação de Mestrado em Ciências Mecânicas, Publicação ENM.DM-230 A/2016, Departamento de Engenharia Mecânica, Universidade de Brasília, Brasília, DF, 102p.

\section{CESSÃO DE DIREITOS}

NOME DO AUTOR: Marianela Machuca Macias.

TÍTULO DA DISSERTAÇÃO DE MESTRADO: ESTUDO EXPERIMENTAL EM TÚNEL DE VENTO DE TURBINAS DE EIXO HORIZONTAL

GRAU/ANO: Mestre/2016.

É concedida à Universidade de Brasília permissão para reproduzir cópias desta dissertação de mestrado e para emprestar ou vender tais cópias somente para propósitos acadêmicos e científicos. O autor reserva outros direitos de publicação e nenhuma parte desta dissertação de mestrado pode ser reproduzida sem a autorização por escrito do autor.

\footnotetext{
Marianela Machuca Macías

Rua 36 Norte, lote 3350, bloco G, apt 1106 - Águas Claras

71919-180, Brasília, DF, Brasil

nelamacmac@gmail.com
} 


\section{Agradecimentos}

Ao meu marido Alex, minha filha Lola e meu filho que logo chegará por serem a alegria da minha vida.

Aos meus pais e irmãos pelo seu apoio e amor incondicional.

Ao meu orientador Antonio Brasil pela oportunidade de formar parte do seu grupo de trabalho, pela ajuda e compreensão mostradas em todas as situações e pela sua magnífica orientação e ensinamentos durante estes anos de trabalho.

Aos professor Taygoara e meus colegas do LEA, Rafael, Aramis, Paulo, Ramsay, Marcelo, Miguel, Francis, Vinicius e Eugênia, pela ajuda, apoio e por fazer os dias mais felizes no nosso trabalho. 


\section{Resumo}

O presente trabalho teve como finalidade o estudo de turbinas de eixo horizontal, tanto eólicas como hidrocinéticas. O objetivo principal do estudo foi encontrar uma lei semiempírica para realizar a transposição de resultados de desempenho de um modelo reduzido operando em ar para seu protótipo em água.

Ensaios experimentais foram realizados no interior de um túnel de vento de seção $1,2 \times 1,2$ $\mathrm{m}$ para o modelo reduzido. Foram realizados testes para as velocidades de escoamento de 8, 10 e $12 \mathrm{~m} / \mathrm{s}$. A metodologia empregada nos ensaios baseou-se em manter a velocidade do escoamento constante e variar a velocidade de rotação da turbina. Um fator importante durante os ensaios foi o controle da velocidade de rotação por meio de um controlador PID e da técnica de modulação PWM. Velocidade de rotação e torque foram medidas para o levantamento das curvas de desempenho $C_{p}$ vs $\lambda$. Foram colocados 'transition strips' sobre as pás para induzir a transição do escoamento do regime laminar para o turbulento, e correções de bloqueio tiveram que ser aplicadas sobre os resultados experimentais para diminuir os efeitos de parede do túnel de vento sobre os resultados medidos. A transposição de resultados foi realizada utilizando os dados de desempenho obtidos dos ensaios experimentais e a lei semi-empírica proposta. A equação de transposição proposta depende exclusivamente dos números de Reynolds do modelo e do protótipo e de um fator de escala, m. Este fator de escala é calculado a partir das equações da metodologia BEM, relacionando os coeficientes de potência com os fatores de indução axial e radial. Simulações numéricas CFD e BEM foram realizadas para modelo, em ar, e protótipo. No modelo reduzido, as simulações foram validades com os dados experimentais de $C_{p}$ obtidos durante os ensaios em túnel de vento. Por outro lado, as simulações do protótipo foram usadas para validar os resultados obtidos da transposição de resultados. Por meio destes resultados, as metodologias numéricas e experimental foram validades. Cabe ressaltar, que a lei semi-empírica proposta é robusta, confiável e consistente para a turbina estudada neste trabalho.

Palavras-chaves: ensaios em túnel de vento. simulações CFD. simulações BEM. turbinas de eixo horizontal. 


\section{Abstract}

The aim of this work was to study the horizontal axis hydrokinetic and wind turbines. The main objective of this study was to find a semi empirical law to make the transposition of the performance results of a small turbine, in air, to the prototype, in water.

Experimental tests were carried out in a wind tunnel of $1,2 \times 1,2 \mathrm{~m}$ of section to the small turbine. The tests were realized at wind speed of 8,10 and $12 \mathrm{~m} / \mathrm{s}$. The methodology used in the tests was based in keep constant the wind speed and to varying the rotation velocity of the turbine. A key element of the methodology was the control of the rotation velocity using a PID controller and the modulation technique PWM. During the test torque and rotation velocity were measured. To achieve the expect results were located on the blades transition strips to force the transition from laminar flow to turbulent, and blockage effect of the wind tunnel wall was removed from the measured power data applying a blockage correction method. The transposition of results was carried out using the performance data obtained with the experimental tests and the semi empirical law proposed. The proposed equation dependence of the Reynolds numbers and a scale factor. The scale factor, $\mathrm{m}$, is calculate using the equations of BEM method, which relates the power coefficients with axial and radial induction factors. CFD and BEM numerical simulations were realized to the small turbine, in the air, and the prototype, in water. In the case of the small turbine, the numerical simulations were validated with the $C_{p}$ experimental data in the wind tunnel. For the other hand, the prototype simulations were used to validate the results obtained with the transposition of results. All that results validate the numerical and experimental methodology used. It should be noted that the semi empirical law proposed is robust for the turbine studied in this case.

Key-words: wind tunnel tests. CFD simulations. BEM simulations. horizontal axis turbines. 


\section{Lista de ilustrações}

Figura 1 - Participação(\%) por fonte na produção mundial de eletricidade em 20132

Figura 2 - Turbina eólicas comerciais: (a) HAWT-Duas pás; (b) HAWT- Trés pás; (c) HAWT-Com difusor; (d) VAWT-tipo Savonius; (e) VAWT-tipo Darrieus; (f) VAWT-tipo Savonius e Darrieus. . . . . . . . . . . . . . . . 4

Figura 3 - Turbina hidrocinéticas comerciais: (a) HAWT-Turbina marinha de dois pás; (b) HAWT- Trés pás de Verdant Power; (c) HAWT-Trés pás de Hammerfest; (d) HAWT-Multipás de Lunar Energy ; (e) HAWTMultipás de UEK; (f) H-Darrieus de Alternative Hydro. . . . . . . . . . 5

Figura 4 - Capacidade energética de sistemas eólicos e hidrodinâmicos $(\mathrm{Cp}=0,35) \quad 6$

Figura 5 - Esquema do disco atuador e do tubo de velocidade . . . . . . . . . 13

Figura 6 - (a) Trajetória de uma partícula de ar no passo pelo rotor. (b) Rotor de três pás de raio $\mathrm{f} \ldots \ldots \ldots \ldots \ldots$

Figura 7 - Triângulo de velocidades mostrando a velocidade induzida . . . . . . . 18

Figura 8 - Comparação do coeficiente de potência ótimo de Glauert de uma turbina incluindo efeitos de rotação com o limite de Betz. Representação do

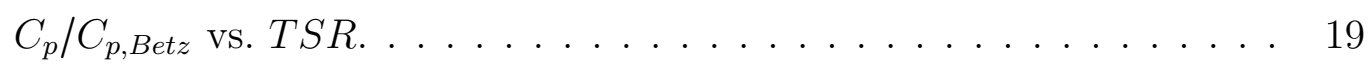

Figura 9 - Tubo de corrente anular através do rotor . . . . . . . . . . . 20

Figura 10 - Discretização na pá pelo método BEM . . . . . . . . . . . . . . . . 21

Figura 11 - Triângulo de velocidades na pá. . . . . . . . . . . . . . . . . . 22

Figura 12 - Forças locais na pá . . . . . . . . . . . . . . . . . . 24

Figura 13 - Variação do $C_{T}$ com o fator de indução axial $a$. - Teoria BEM; •: Correção empírica de Glauert . . . . . . . . . . . . . . . . . . . 27

Figura 14 - Cálculo de $\alpha_{\text {opt }}$ a partir da curva de $C_{L} / C_{D}$ vs $\alpha \ldots \ldots$. . . . . . 29

Figura 15 - Ponto de inflexão para o cálculo do $\alpha_{\text {opt }}$ da curva polar $C_{L}$ vs $C_{D} \ldots 30$

Figura 16 - Separação da camada limite, reversão do fluxo e estol em um perfil aerodinâmico. . . . . . . . . . . . . . . 32

Figura 17 - Curva $C_{L}$ vs $\alpha$. Regiões pré (a) e pós-estol (b) . . . . . . . . . 32

Figura 18 - Linhas de corrente em volta do perfil aerodinâmico: (a) Região pré-estol da curva $C_{L}$ vs $\alpha$. Camada limite colada ao corpo; (b) Região pós-estol da curva $C_{L}$ vs $\alpha$. Descolamento da camada limite e reversão do fluxo.

Figura 19 - Camada limite: (a) Baixo número de Reynolds. Separação completa da camada limite e estol. (b) Alto número de Reynolds. Transição laminar-turbulenta. . . . . . . . . . . . . . . . 33

Figura 20 - Curvas $C_{L}$ vs $\alpha$ para vários números de Reynolds (NACA 65(3)618). Simulações XFOIL com $N_{\text {crit }}=9$, para os casos de $R e=5 \cdot 10^{6} \mathrm{e}$ $R e=5 \cdot 10^{5}$, e $N_{\text {crit }}=5$ para $R e=5 \cdot 10^{4} \ldots \ldots \ldots \ldots$ 
Figura 21 - Curvas $C_{D}$ vs $\alpha$ para vários números de Reynolds (NACA 65(3)618). Simulações XFOIL com $N_{\text {crit }}=9$, para os casos de $R e=5 \cdot 10^{6} \mathrm{e}$

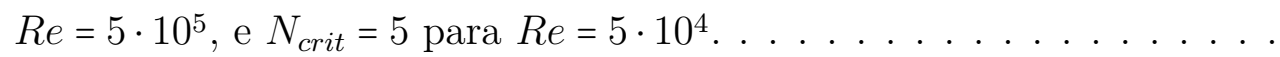

Figura 22 - Curva $C_{L}$ vs $\alpha$ (NACA 65(3)618). Simulações XFOIL com $N_{\text {crit }}=5$. : 'transition strip' em $20 \%$ da corda; - - : Sem 'transition strip' . . . . .

Figura 23 - Vistas acotadas (m) do túnel de vento do Laboratório de Energia e Ambiente da Faculdade de Tecnologia da UnB . . . . . . . . . . . . .

Figura 24 - Túnel de vento do Laboratório de Energia e Ambiente da Faculdade de Tecnologia da UnB . . . . . . . . . . . . . . . . . . . . 39

Figura 25 - Modelo reduzido no interior do túnel de vento. . . . . . . . . . . . . . . . 41

Figura 26 - Esquema do modelo reduzido . . . . . . . . . . . . . . . . 41

Figura 27 - Detalhe da montagem do motor em balanço sobre a estrutura . . . . 42

Figura 28 - Esquema do ensaio experimental do modelo reduzido . . . . . . . . . . . 43

Figura 29 - Tubo de Pitot no interior do túnel de vento e manômetro de coluna

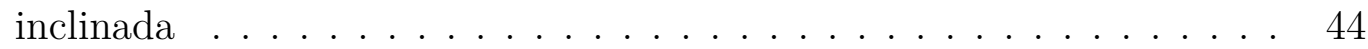

Figura 30 - Detalhe da célula de carga e o braço metálico e do sensor de proximidade indutivo . . . . . . . . . . . . . . . . . . . . . . . 44

Figura 31 - Esquema dos sensores utilizados no modelo reduzido para medidas de velocidade e torque . . . . . . . . . . . . . . . . . . 45

Figura 32 - Esquema do circuito elétrico para modulação da carga aplicada ao rotor 46 Figura 33 - Modulação por largura de pulso (PWM) . . . . . . . . . . . . . . . 47

Figura 34 - Diagrama de blocos do sistema de controle da velocidade PID . . . . . 48

Figura 35 - Esquema do modelo do disco atuador com as velocidades do escoamento em várias seções . . . . . . . . . . . . . . . . . . . . . . . . 51

Figura 36 - Relação entre os coeficientes de potência, para protótipo e modelo, $C_{p_{\text {prot }}} / C_{p_{\text {mod }}}$, com $T S R$ para o raio médio da pá. . . . . . . . . 55

Figura 37 - Rotor simplificado usado nas simulações do protótipo . . . . . . . . 58

Figura 38 - Domínio computacional usado na simulação do modelo reduzido . . . . 59

Figura 39 - Malha no domínio computacional com $7,5 \cdot 10^{6}$ nós . . . . . . . . . . 60

Figura 40 - Detalhe do refinamento da malha a montante e a jusante no rotor . . . 60

Figura 41 - Detalhe do refinamento da malha no rotor e na pá . . . . . . . . . . . 61

Figura 42 - Condições de contorno usadas na simulação . . . . . . . . . . . . . 62

Figura 43 - (a) Montagem inicial do modelo; (b) Montagem melhorada para reduzir o sombreamento nas pás . . . . . . . . . . . . . . . . . . 65

Figura 44 - Detalhe do 'transition strips' em uma pá . . . . . . . . . . . . . . . . . 65

Figura 45 - Curvas experimentais de $C_{p}$ vs. $\lambda$. •: Montagem inicial; $\mathbf{~}$ : Montagem melhorada; $\mathbf{\nabla}$ : Transition Strips. (a) $8 \mathrm{~m} / \mathrm{s}$; (b) $10 \mathrm{~m} / \mathrm{s}$; (c) $12 \mathrm{~m} / \mathrm{s}$. .

Figura 46 - Curvas experimentais de $C_{p}$ vs. $\lambda$ para $12 \mathrm{~m} / \mathrm{s}$. $\square$ : Curva experimental Transition Strips; $\mathbf{\nabla}$ : Curva experimental - Correção de bloqueio . . . 
Figura 47 - Curva de desempenho $C p$ vs. $\lambda$ do modelo reduzido. $\boldsymbol{\nabla}$ : CFD; Experimental-Correção bloqueio. . . . . . . . . . . . . . 71

Figura 48 - Curva de desempenho $C p$ vs. $\lambda$ do modelo reduzido. $\bullet$ : BEM; $\boldsymbol{\nabla}$ : CFD. 71

Figura 49 - Curva de desempenho $C p$ vs. $\lambda$ do protótipo. •: BEM; $\mathbf{\nabla}$ : CFD. . . . 72

Figura 50 - Linhas de correntes sobre as pás e em volta do perfil aerodinâmico médio das mesmas para o modelo reduzido (a) $\lambda=2,8$; (b) $\lambda=3,9$; (c)

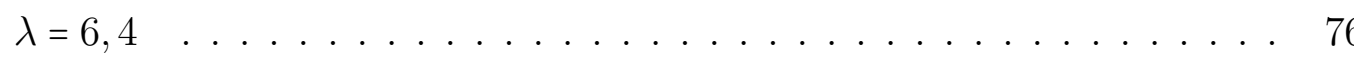

Figura 51 - Linhas de correntes sobre as pás e em volta do perfil aerodinâmico médio das mesmas para o protótipo (a) $\lambda=2,8$; (b) $\lambda=3,9$; (c) $\lambda=6,477$

Figura 52 - Velocidade axial do escoamento em volta da turbina para modelo reduzido (esquerda) e protótipo (direita) para varios valores de $\lambda$ (a) $\lambda=2,8$; (b) $\lambda=3,9 ;$ (c) $\lambda=6,4 \ldots \ldots \ldots \ldots \ldots$

Figura 53 - Energia cinética de turbulência do escoamento em volta da turbina para modelo reduzido (esquerda) e protótipo (direita) para varios valores de $\lambda$ (a) $\lambda=2,8$; (b) $\lambda=3,9$; (c) $\lambda=6,4 \ldots \ldots \ldots$

Figura 54 - Comparação das curvas de $C p$ vs. $\lambda$ numérica e experimental após aplicar a correção de bloqueio. • : Transposição modelo-protótipo; •: Experimental - Correção bloqueio; •: CFD-modelo; n: CFD-protótipo . 83

Figura 55 - Aerofólio NACA 65(3)618 usado nas pás . . . . . . . . . . . . . . . . 94

Figura 56 - Modelo tridimensional da pá . . . . . . . . . . . . . . . . . . . 94

Figura 57 - Haste móvel e tubo de Pitot usados na medida dos perfis de velocidade 96

Figura 58 - Perfil de velocidade na linha central para as velocidades média de 8,8

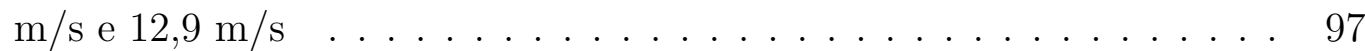

Figura 59 - Montagem experimental do anemômetro de fio quente para medição da intensidade de turbulência . . . . . . . . . . . . . . . . . . . . . 98

Figura 60 - Intensidade de turbulência para diferentes velocidades do escoamento . 99

Figura 61 - Calibração do túnel de vento $y=0,079 x-0,045 \ldots \ldots$. . . . . . 100

Figura 62 - Calibração do anemômetro de fio quente $y=0,058 x+5,49 \ldots$. . . . . 101

Figura 63 - Calibração da célula de carga $y=0,998 x+0,125 \ldots \ldots$. . . . . . . 101 


\section{Lista de tabelas}

Tabela 1 - Tabela de sintonização de Ziegler-Nichols para o cálculo dos parâmetros do PID . . . . . . . . . . . . . . . . . . 48

Tabela 2 - Estudo de convergência de malha. . . . . . . . . . . . . . 61

Tabela 3 - Dados da geometria da pá para o protótipo . . . . . . . . . . . 95

Tabela 4 - Dados da geometria da pá para o modelo. Escala $1 / 20$. . . . . . . . 95 


\section{Lista de símbolos}

\section{Símbolos latinos}

\begin{tabular}{|c|c|c|}
\hline$A$ & Área & {$\left[m^{2}\right]$} \\
\hline$a$ & Fator de indução axial & \\
\hline$a^{\prime}$ & Fatoro de indução tangencial & \\
\hline$B$ & Número de pás & \\
\hline$c$ & corda & \\
\hline$C_{D}$ & Coeficiente de arrastro & \\
\hline$C_{L}$ & Coeficiente de sustentação & \\
\hline$C_{M}$ & Coeficiente de momento & \\
\hline$C_{n}$ & Força normal adimensional & \\
\hline$C_{p}$ & Coeficiente de potência & \\
\hline$C_{t}$ & Coeficiente de empuxo & \\
\hline$C_{T}$ & Força tangencial adimensional & \\
\hline$D$ & Diâmetro do rotor & \\
\hline$F_{D}$ & Força de arrastro por unidade de longitude & {$[\mathrm{N} / \mathrm{r}$} \\
\hline$F_{L}$ & Força de sustentação por unidade de longitude & {$[\mathrm{N} / \mathrm{r}$} \\
\hline$F$ & Fator total de correção & \\
\hline$F_{h u b}$ & Fator de correção de perdas no hub & \\
\hline$F_{t i p}$ & Fator de correção de ponta de pá de Prandtl & \\
\hline$g$ & Aceleração da gravidade & {$[\mathrm{m} / \mathrm{s}$} \\
\hline$\dot{m}$ & Vazão mássica & {$[k g /$} \\
\hline$m$ & Parâmetro de escala & \\
\hline$M$ & Momento angular & ? \\
\hline
\end{tabular}




$\begin{array}{llr}p & \text { Pressão } & {[\mathrm{Pa}]} \\ p_{n} & \text { Força normal por unidade de longitude } & {[\mathrm{N} / \mathrm{m}]} \\ p_{t} & \text { Força tangencial por unidade de longitude } & {[\mathrm{N} / \mathrm{m}]} \\ P & \text { Potência } & {[\mathrm{W}]} \\ r & \text { Raio } & {[\mathrm{m}]} \\ R & \text { Raio na ponta da pá } & {[\mathrm{m}]} \\ R e & \text { Número de Reynolds } & {[-]} \\ T & \text { Empuxo axial } & {[\mathrm{kgm}]} \\ u & \text { Velocidade do escoamento } & {[\mathrm{m} / \mathrm{s}]} \\ u^{*} & \text { Velocidade do escoamento corrigida } & {[\mathrm{m} / \mathrm{s}]}\end{array}$

\section{Símbolos gregos}

$\begin{array}{llr}\alpha & \text { Ângulo de ataque } & {[-]} \\ \beta & \text { Ângulo de torção da pá } & {[-]} \\ \lambda & \text { Velocidade de ponta de pá } & {[-]} \\ \lambda^{*} & \text { Velocidade de ponta de pá corrigida } & {[-]} \\ \lambda_{r} & \text { Velocidade de ponta de pá local } & {[-]} \\ \omega & \text { Velocidade angular } & {[\mathrm{rad} / \mathrm{s}]} \\ \phi & \text { Ângulo de entrada do escoamento } & {[\mathrm{rad} / \mathrm{s}]} \\ \rho & \text { Densidade } & {\left[\mathrm{kg}^{*} / \mathrm{m}^{3}\right]} \\ \sigma & \text { Solidez } & {[-]} \\ \delta & \text { Erro experimental } & {[-]} \\ \tau & \text { Torque } & {[\mathrm{Nm}]} \\ \theta & \text { Ângulo de passo } & {[-]}\end{array}$

\section{Subscritos}

$\infty \quad$ Ecoamento não perturbado

d Escoamento no disco atuador 


$\begin{array}{ll}w & \text { Escoamento a jusante da turbina } \\ \theta & \text { Escoamento tangencial } \\ \text { disp } & \text { Disponível } \\ \text { mec } & \text { Mecânica } \\ \text { mod } & \text { Modelo } \\ \text { opt } & \text { Ótimo } \\ \text { prot } & \text { Protótipo } \\ \text { rel } & \text { Relativo }\end{array}$

Siglas

BEM Blade Element Methodology

BF Blockage Factor

BR Blockage Ratio

CFD Compute Fluid Dinamics

HAWT Horizontal Axis Wind Turbine

VAWT Vertical Axis Wind Turbine

IEA International Energy Agency

LEA Laboratório de Energia e Ambiente

NACA National Advisory Committee for Aeronautics

NASA National Aeronautics and Space Administration

NREL National Renewable Energy Laboratory

NWTC National Wind Technology Center

PWM Pulse Width modulation

RANS Reynolds-Averaged Navier-Stokes

SST Shear Stress Transport Model

TSR Tip Speed Ratio

UnB Universidade de Brasília 


\section{Sumário}

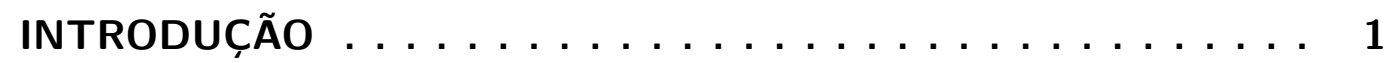

1.1 Contextualização $\ldots \ldots \ldots \ldots \ldots \ldots \ldots \ldots$

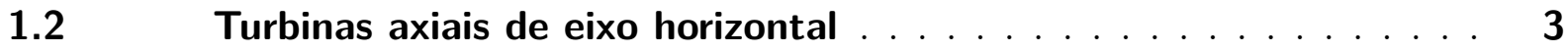

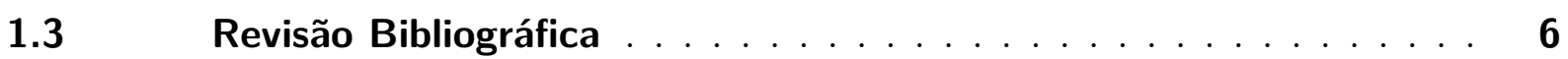

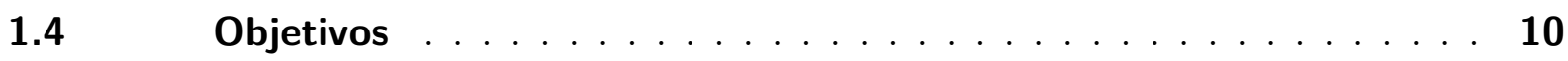

1.4.1 Objetivos Gerais . . . . . . . . . . . . . . . . . . . . . 10

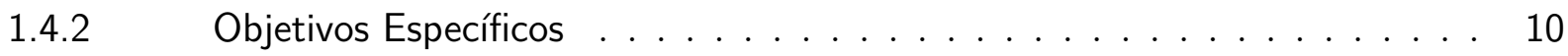

$1.5 \quad$ Organização da dissertação $\ldots \ldots \ldots \ldots \ldots \ldots \ldots \ldots \ldots$

2 HIDRODINÂMICA DE TURBINAS DE EIXO HORIZONTAL . . . 12

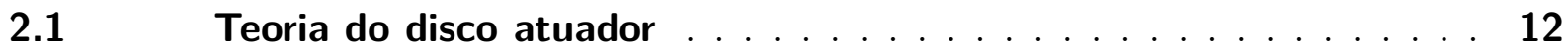

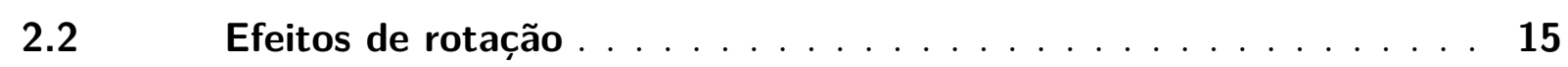

2.3 Teoria BEM (Blade Element Moment) $\ldots \ldots \ldots \ldots \ldots$

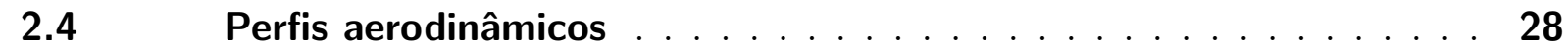

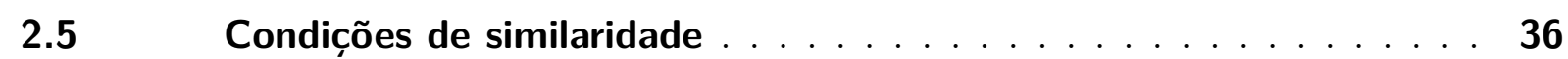

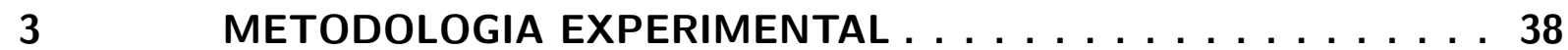

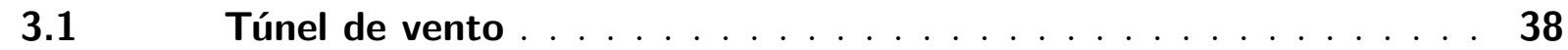

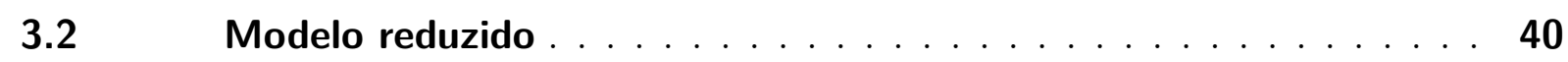

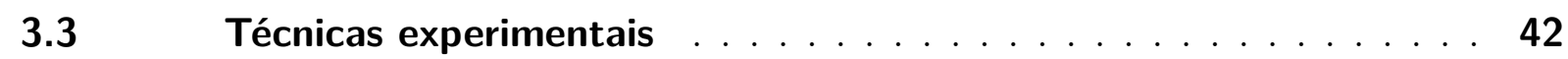

3.3.1 Medidas de Pressão, Temperatura e Velocidade do escoamento livre . . . . 43

3.3.2 Medida de Torque . . . . . . . . . . . . . . . . . . . . . 44

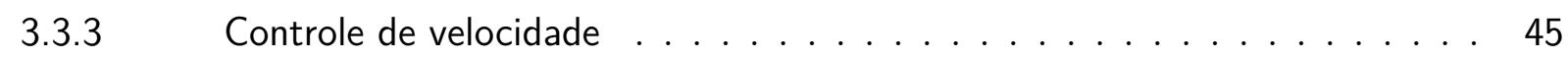

$3.4 \quad$ Ensaio do modelo reduzido no túnel de vento . . . . . . . . 48

$3.5 \quad$ Correções de Bloqueio . . . . . . . . . . . . . . . . . 49

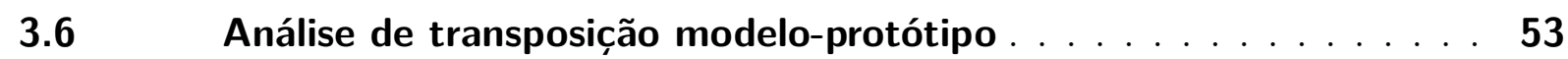

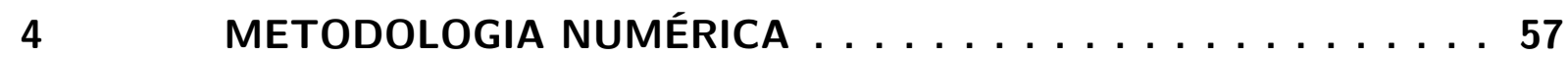

$4.1 \quad$ Modelo geométrico $\ldots \ldots \ldots \ldots \ldots \ldots \ldots$

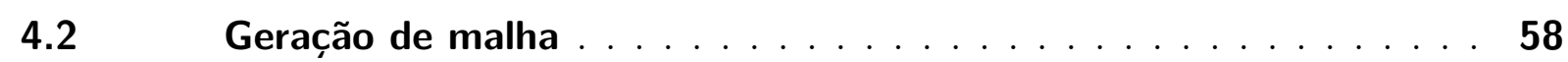

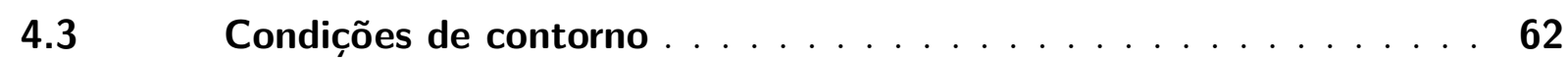

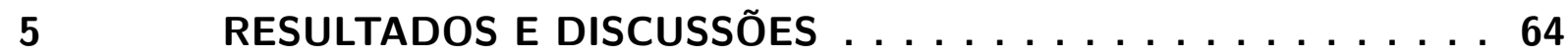

$5.1 \quad$ Estudo de curvas de desempenho (modelo e protótipo) . . . . . . 64

5.2 Características hidrodinâmicas do escoamento (modelo e protótipo) 74

5.3 Transposição Modelo-Protótipo . . . . . . . . . . . . . 82 


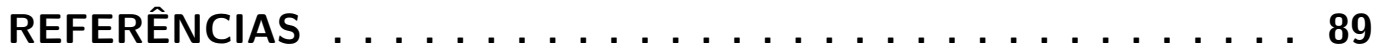

APÊNDICE A - CARACTERIZAÇÃO GEOMÉTRICA DA PÁ . . 94 APÊNDICE B - CARACTERIZAÇÃO DO PERFIL DE VELOCIDADES DO TÚNEL DE VENTO $\ldots \ldots \ldots 96$

APÊNDICE C - ESTIMAÇÃO DA INTENSIDADE DE TURBULENCIA NO TÚNEL DE VENTO . . . . . . . 98

APÊNDICE D - CALIBRAÇÃO DO TÚNEL DE VENTO E DOS

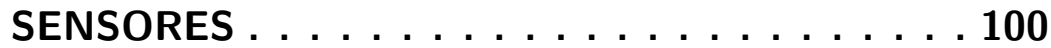

APÊNDICE E - PROPAGAÇÃO DE INCERTEZAS . . . . . 102 


\section{Introdução}

\subsection{Contextualização}

A energia é fundamental para a prosperidade global, já que serve de base para o desenvolvimento econômico, social e a redução da pobreza. Desde a revolução industrial vem se observando a contribuição da disponibilidade de energia para o crescimento econômico mundial. Infelizmente esta interdependência está também relacionada com o aumento de impactos ambientais tais como aumento das emissões e uso intensivo de recursos naturais.

$\mathrm{Na}$ atualidade mais de $80 \%$ da energia global é proveniente da queima de combustíveis fósseis. Estes são apontados como a principal causa das mudanças climáticas do planeta devido à crescente demanda de energia e apresentam uma grande variação de preço no mercado tornando-se uma forte componente de crises econômicas mundiais. $\mathrm{O}$ investimento em energias renováveis vem sendo essencial para mudar a matriz energética atual por fontes limpas, e a ação dos governos, empresas, comunidades e indivíduos é fundamental neste esforço de mudança tecnológica.

Segundo o relatório IEA STATISTICS: Key Renewables Trends elaborado em 2015 pela Agencia Internacional da Energia (IEA), no ano 2013, fontes de energia renováveis representaram 21,7 \% da produção de eletricidade mundial, após carvão $(41,2 \%)$ e gás natural (21,8\%). Pode-se observar na Figura 1 que a hidroelétrica contribui com 16,3\% da eletricidade mundial e que também é responsável pelo $75,1 \%$ do total de eletricidade geradas pelas energias renováveis. Embora crescendo rapidamente as energias geotérmica, solar e eólica foram responsáveis por apenas 3,7\% da produção total de eletricidade em 2013. Desconsiderando a energia hidroelétrica, o resto de fontes renováveis usadas na produção de eletricidade cresceram de 1,3\% em 1990 a 5,4\% em 2013. As energias solar fotovoltaica e eólica se encontram em destaque com maiores taxas de crescimento (IEA, 2015). 


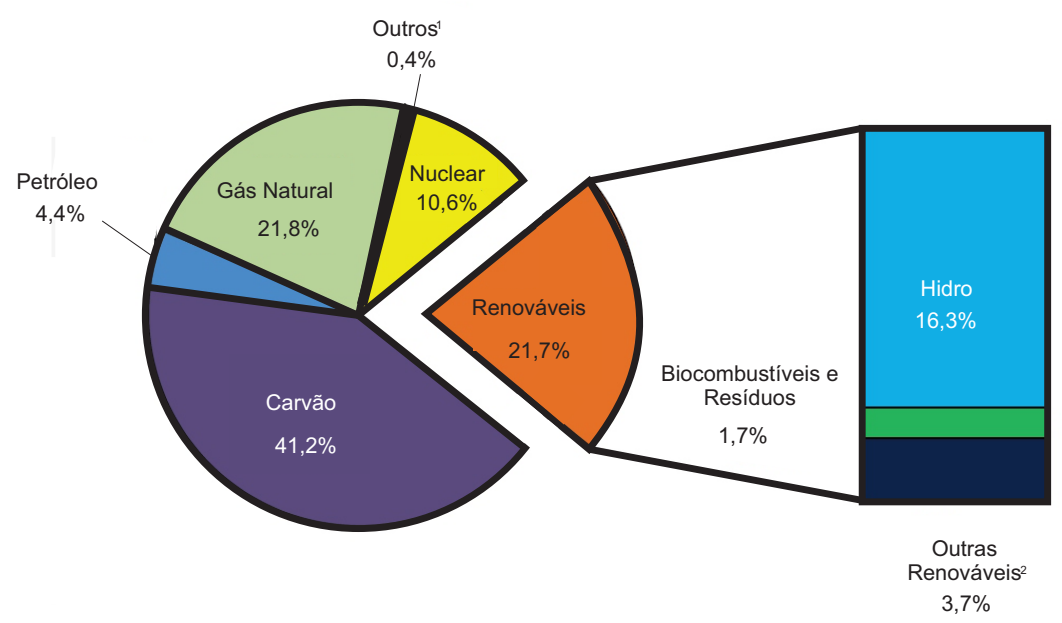

1. Inclui fontes como resídudos não renováveis, xisto, calor químico, entre outros.

2. Inclui geotérmica, eólica, solar e marés.

Figura 1 - Participação(\%) por fonte na produção mundial de eletricidade em 2013

Fonte: (IEA, 2015)

Nos últimos tempos, grandes esforços foram feitos pelas entidades privadas que operam no setor e pelos governos em termos de financiamento, que permitiram o desenvolvimento de avanços tecnológicos e melhorias na eficiência das turbinas eólicas. O constante estudo nesta área, avanços aerodinâmicos , estruturais e a introdução de métodos computacionais de simulação, tem tornado a tecnologia mais competitiva se comparada às fontes tradicionais como os combustíveis fósseis (CAMPAGNOLO, 2013).

Baseada nos mesmos princípios que a energia eólica, a energia hidrocinética contida em correntes aquáticas (rios) é considerada uma fonte de energia renovável que pode ser utilizada para produzir energia elétrica (KHAN et al., 2009). De fato, o aproveitamento do fluxo de água em turbinas hidrocinéticas está se tornando uma atraente fonte de energia devido à alta densidade de energia da água corrente, à sua boa previsibilidade e ao baixo impacto ambiental e humano. A tecnologia de turbinas hidrocinéticas está se desenvolvendo de forma rápida com diferentes conceitos e protótipos desenvolvidos em vários países(KINSEY et al., 2011).

O estudo de turbinas hidrocinéticas de eixo horizontal ainda é muito incipiente e grande parte de sua concepção é feita em analogia com as turbinas eólicas. Essa similaridade também é reproduzida em ensaios experimentais, devido a complexidade e custo de desenvolvimento de bancadas de ensaio adequadas para operação desses rotores. Atualmente, devido ao progresso tecnológico de técnicas computacionais, primeiro é feito 
um estudo numérico e posteriormente inicia-se a construção de protótipos e análises experimentais (SILVA, 2014).

Com este trabalho pretende-se contribuir para o desenvolvimento de máquinas eólicas e hidrocinéticas, mediante os ensaios realizados em túnel de vento de modelos de turbinas hidrocinéticas de eixo horizontal, viabilizando-se a realização da transposição dos resultados entre o modelo reduzido e seu protótipo.

\subsection{Turbinas axiais de eixo horizontal}

As turbinas de fluxo livre (eólicas e hidrocinéticas) transformam a energia cinética contida no movimento de uma massa de ar ou água em energia mecânica no eixo que, subsequentemente, através do gerador, é transformada em energia elétrica. A conversão de energia é parametrizada classicamente por:

$$
P=\frac{1}{2} \rho A u^{3} C_{p}
$$

onde $P$ é a potência mecânica extraída pela turbina $[W], \rho$ é a densidade do fluído $\left[\mathrm{kg} / \mathrm{m}^{3}\right], A$ é a área desenvolvida pelo rotor $\left[\mathrm{m}^{2}\right], u$ a velocidade do fluido $[\mathrm{m} / \mathrm{s}]$, e $C_{p}$ é o coeficiente de potência, uma medida de eficiência fluido-dinâmica da turbina.

A viabilidade econômica de uma turbina eólica é baseada na maximização da conversão de energia minimizando os custos de fabricação e construção. A análise do comportamento da aerodinâmica de rotores de turbinas de eixo horizontal se iniciou com a teoria do disco atuador, um modelo simplificado desenvolvido por R. E. Froude e W.J.M. Rankine, e estendido para turbinas eólicas por Betz (GLAUERT, 1959). Betz determinou que o $C_{\text {pmax }}$ de uma turbina era igual a 16/27, conhecido como o limite de Betz. Glauert mostrou como estes supostos são conservativos e o atual limite é ligeiramente menor que o limite de Betz (MANWELL; MCGOWAN; ROGERS, 2002; MCWILLIAM, 2008).

As turbinas eólicas modernas constam de um conjunto de pás rotativas conectadas a um eixo. Se o eixo é vertical ao escoamento, a máquina é denominada de turbina axial de eixo vertical (VAWT), e se o eixo é horizontal,paralelo ao escoamento, a turbina é denominada de turbina axial de eixo horizontal (HAWT) (HANSEN, 2008).

Na era moderna, o mercado tem centrado seu interesse em três configurações de turbina eólica. As turbinas axiais de eixo horizontal (HAWT), turbinas de hélice onde a força impulsora é a sustentação. As turbinas tipo Darrieus, turbinas de eixo vertical, onde igual as HAWT, a força predominante é a sustentação, e finalmente, as turbinas com rotor tipo Savonius, turbinas de eixo vertical onde o movimento é baseado na força de arrasto (AKON, 2012). A maior parte das turbinas eólicas comerciais são do tipo HAWT, devido a sua eficiência e robustez. 
A tecnologia de turbinas hidrocinéticas é semelhante a energia eólica. A principal diferença entre as duas tecnologias reside no fluido de trabalho, ar para energia eólica e água para hidrocinética.

No caso das turbinas hidrocinéticas,a maior parte dos protótipos que estão sendo construídos na atualidade usam rotores de eixo horizontal (como as turbinas eólicas modernas) ou rotores de eixo vertical (como as turbinas eólicas tipo Darrieus) (KINSEY et al., 2011).

Nas Figura 2 e Figura 3 apresentam-se alguns modelos de turbinas eólicas e hidrocinéticas comercializadas na atualidade.

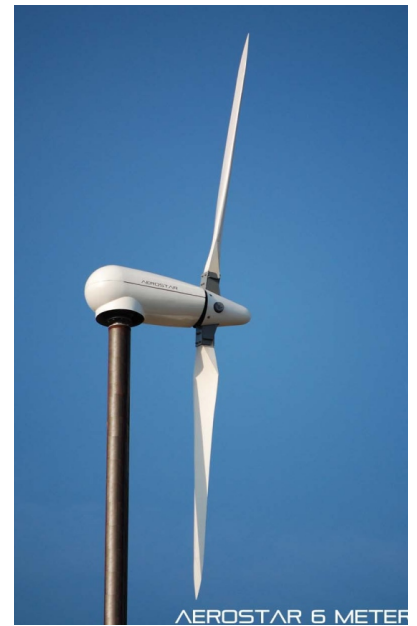

(a)

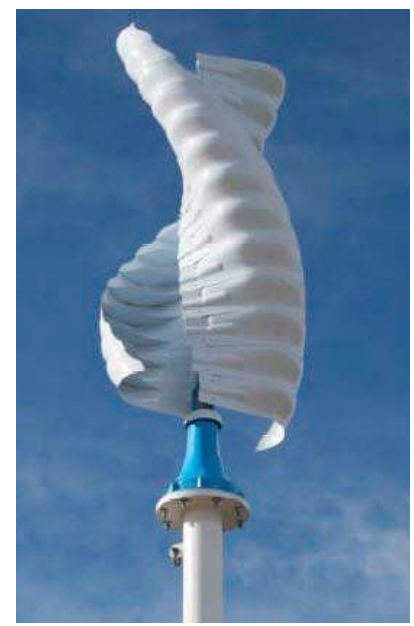

(d)

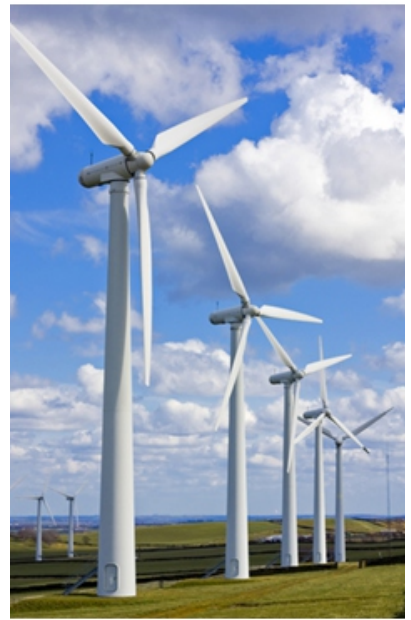

(b)

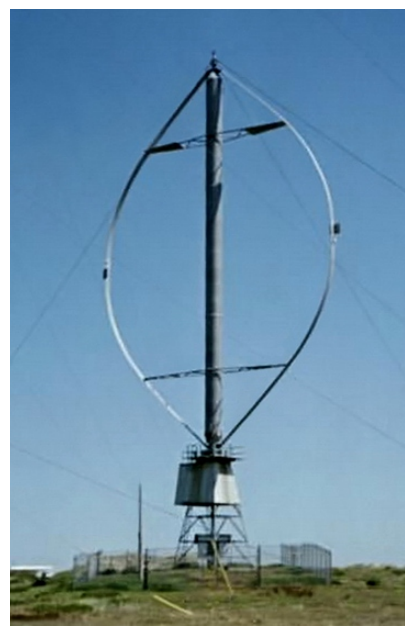

(e)

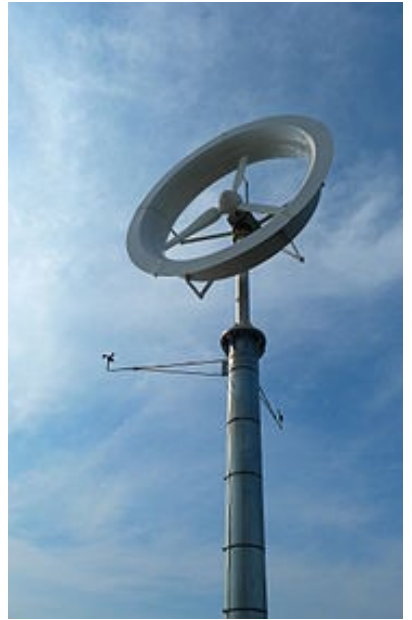

(c)

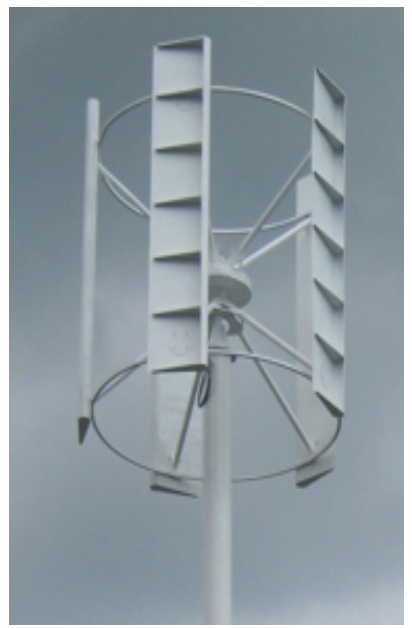

(f)

Figura 2 - Turbina eólicas comerciais: (a) HAWT-Duas pás; (b) HAWT- Trés pás; (c) HAWT-Com difusor; (d) VAWT-tipo Savonius; (e) VAWT-tipo Darrieus; (f) VAWT-tipo Savonius e Darrieus. 


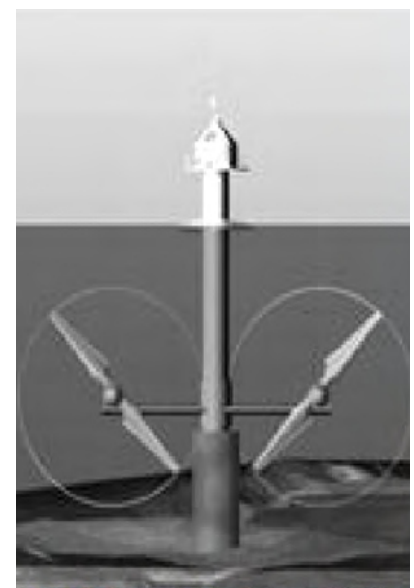

(a)

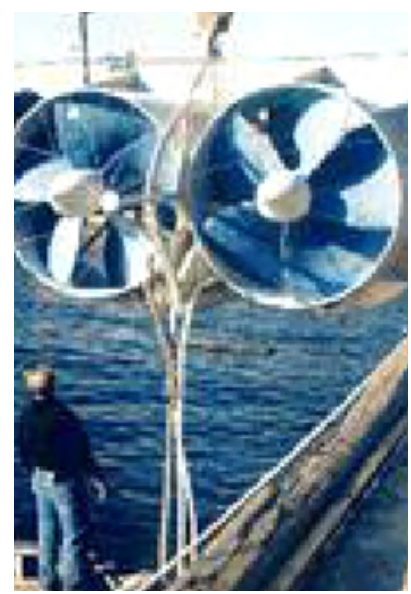

(d)

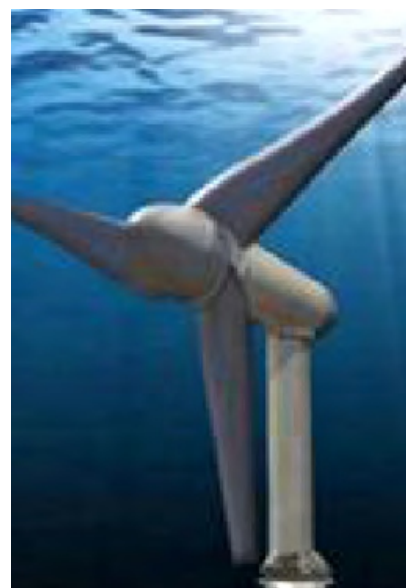

(b)

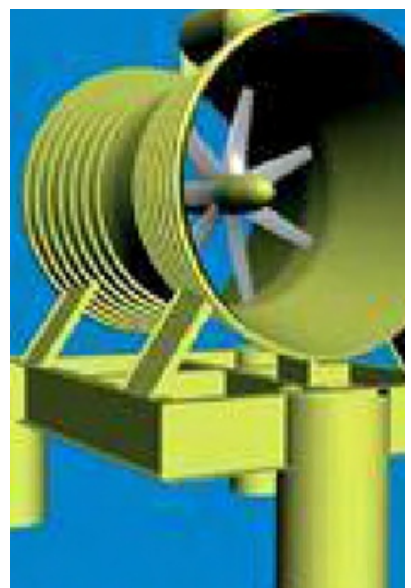

(e)

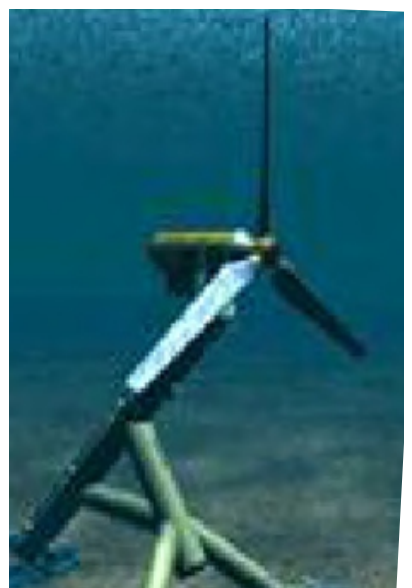

(c)

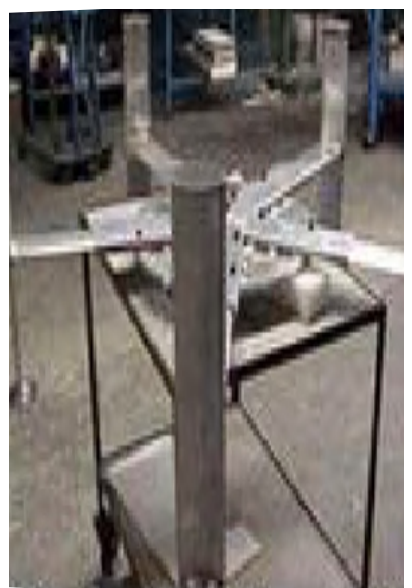

(f)

Figura 3 - Turbina hidrocinéticas comerciais: (a) HAWT-Turbina marinha de dois pás; (b) HAWT- Trés pás de Verdant Power; (c) HAWT-Trés pás de Hammerfest; (d) HAWT-Multipás de Lunar Energy ; (e) HAWT-Multipás de UEK; (f) H-Darrieus de Alternative Hydro.

Na Figura 4 apresentam-se as capacidades energéticas dos sistemas eólicos e hidrocinéticos. As turbinas eólicas são desenhadas para operar com velocidades entre 11-13 $\mathrm{m} / \mathrm{s}$. Por outro lado, as turbinas hidrocinéticas que trabalham em rios são desenhadas, normalmente, para velocidades da água entre 1,7-2,5 m/s. Para turbinas do mesmo tamanho, uma turbina hidrocinética em um rio oferece maior capacidade de energia que uma turbina eólica (KHAN; IQBAL; QUAICOE, 2008). Em geral, as velocidades de correntes de água (rios ou oceanos) são bem menores que as do vento atmosférico. No entanto, observa-se que a massa específica da água é bem superior à do ar (Equação 1.1), o que faz com que o potencial de energia disponível em correntes de água proporcione um potencial que pode ser economicamente aproveitado em situações de velocidades de fluxo relativamente baixas. 

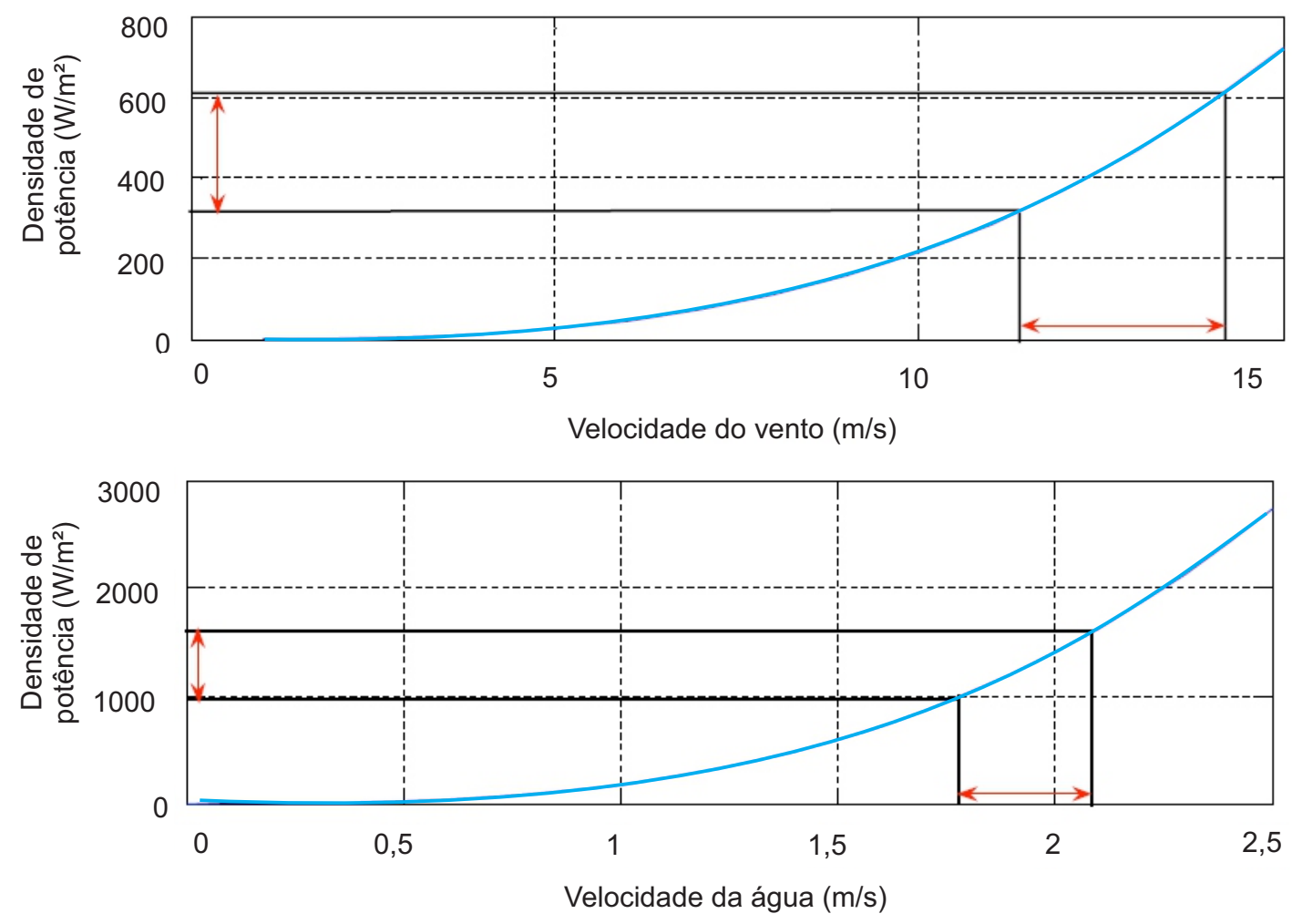

Figura 4 - Capacidade energética de sistemas eólicos e hidrodinâmicos $(\mathrm{Cp}=0,35)$ Fonte: (KHAN; IQBAL; QUAICOE, 2008)

O baixo impacto ambiental é um dos principais fatores que favorecem a aplicação de turbinas de eixo horizontal para conversão de energia, sejam eólicas ou hidrocinéticas. No caso de países em desenvolvimento, com comunidades pequenas e remotas situadas ao longo de rios com águas de corrente a instalação de turbinas hidrocinéticas vem sendo uma solução para produção de eletricidade (VAN ELS; BRASIL JUNIOR, 2015).

\subsection{Revisão Bibliográfica}

A extração da energia cinética, contida no escoamento do fluido, pelo rotor depende da hidrodinâmica da turbina. Inúmeros estudos analíticos, experimentais e computacionais têm sido desenvolvidos ao longo das últimas décadas para o entendimento do fluxo nas proximidades do rotor da turbina e a extração da potência. Em muitas ocasiões, para ajudar e/ou complementar os estudos de turbinas em campo, são realizados testes em túnel de vento usando modelos em escala reduzida. 
Considerando que o foco do presente trabalho é direcionado para estudos experimentais em modelos de turbinas de eixo horizontal, a revisão bibliográfica é voltada, principalmente, para os ensaios em túneis de vento e os problemas de escala.

Motivados pelo desconhecimento de vários fenômenos aerodinâmicos, tais como estol, fluxo dinâmico e efeitos de torre, entre outros, no começo dos anos 80, várias instituições começaram a direcionar seus esforços na pesquisa e o desenvolvimento de sistemas eólicos de grande porte.

Em 1974, surgiu a IEAwind, uma ramificação da IEA (International Energy Agency). No começo de 1980 foram publicados os primeiros resultados sobre energia eólica no (Task XI Base Technology Information Exchange) . Em 1992, várias instituições europeias estabeleceram um acordo de cooperação, (IEAwind Annex XIV 'Fiel Rotor Aerodynamics), que permitiu a criação de uma extensa base de dados de medidas aerodinâmicas de turbinas eólicas para validação e desenvolvimento de modelos. Nos documentos IEAwind Annex XIV e XVIII 'Fiel Rotor Aerodynamics' foram apresentadas as primeiras medições em campo para uma turbina eólica de 25 m de diâmetro (SCHEPERS et al., 1997) .

Desde 1987, estudos experimentais focados na aerodinâmica de turbinas de eixo horizontal vem acontecendo pelo National Renewable Energy Laboratory (NREL) no National Wind Technology Center (NWTC) em Colorado. Estes testes, como os acontecidos na Europa (SCHEPERS et al., 1997), demonstraram que as turbinas eólicas sofrem fenômenos aerodinâmicos muito complexos quando operam em ambiente de campo. Isto devido ao fluxo turbulento, efeitos de rotação e anomalias no escoamento dificilmente controláveis, entre outros (HAND D.A. SIMMS; LARWOOD, 2001).

Os testes em túnel de vento deram a oportunidade de ter um ambiente livre das fortes anomalias no fluxo, com, maior controle sob as condições de entrada. Portanto, ensaios em túnel de vento têm sido desenvolvidos obtendo dados estruturais e aerodinâmicos representativos de turbinas eólicas.

Entre 1986 e 1992, um dos primeiros ensaios em túnel de vento foi realizado por uma cooperação sueco-chinesa. Foi usado um perfil NACA $44 t t$ com $t t=14-22 \%$ e uma pá de 2,65 m. A principal conclusão foi a confirmação do stall-delay nas seções próximas ao hub (SCHAFFARCZYK, 2014).

Nas últimas décadas, muitas experiências têm sido realizadas com o objetivo de melhorar o desempenho das turbinas eólicas.

No relatório técnico NREL Phase VI (HAND D.A. SIMMS; LARWOOD, 2001), é apresentado o ensaio em túnel de vento de uma turbina de $10 \mathrm{~m}$ de diâmetro e duas pás. Este túnel de vento é localizado no NASA Ames Research Center at Moffett Field, Califórnia e sua seção de testes tem 24,4 m x 36,6 m . O foco deste estudo foi a coleta de dados experimentais para aprofundar no conhecimento dos vários fenômenos aerodinâmicos 
que acontecem durante o funcionamento das turbinas, tais como, os efeitos do estol e de rotação. Este estudo experimental tem se tornado referência para a compreensão de fenômenos aerodinâmicos em turbinas eólicas e para validação de modelos e simulações numéricas.

Pouco tempo depois, em 2006, um projeto Europeu-Israeli ocorreu no maior túnel de vento da Europa, o $D N W-L L F$, com seção de 9,5 m x 9,5 m. Foi testada uma turbina de 4,5 m de diâmetro e três pás. Este projeto foi chamado de 'MEXICO' e uma grande quantidade de dados foi coletada e compartilhada com os membros participantes do projeto. Mais tarde, um modelo em escala reduzida do rotor 'MEXICO' foi testado no Korea Aerospace Research Institute para baixas velocidades do escoamento, destacando na influência do número de Reynolds na performance aerodinâmica (SCHAFFARCZYK, 2014).

Testes em grande escala são desejáveis já que oferecem resultados mais realistas. No entanto, muitas vezes não são possíveis devido a seu elevado custo. Embora os resultados de testes experimentais com modelos contenham efeitos de escala e de bloqueio, eles têm maior viabilidade que as experiências em protótipos e oferecem importantes informações da aerodinâmica e da performance da turbina em grande escala. Os testes com modelos em escalas menores contribuem na flexibilidade dos ensaios e o desenvolvimento de metodologias experimentais mais robustas. Campagnolo (2013) considera que testes em modelos não substituem nem simulações nem testes em campo, mas contribuem no objetivo de validação e ampliação de conhecimento do problema em estudo.

Whale et al. (1996) realizou um estudo da esteira usando o método de PIV Particle Image Velocitimetry para uma turbina em grande escala e para seu modelo reduzido em túnel de vento. O autor concluiu como alentadores os resultados encontrados para prever a performance de uma turbina em grande escala com o estudo de PIV em uma pequena turbina. Por outro lado, discrepâncias entre modelo e protótipo foram encontrados e atribuídos a (a) bloqueio no túnel, ou (b) incertezas na experiência do protótipo.

O trabalho de revisão de Vermeer, Sørensen e Crespo (2003) apresentou uma lista de 19 pesquisas em túneis de vento com modelos. O foco desta pesquisa foi o estudo do desenvolvimento da esteira para uma e/ou várias turbinas. Outros estudos na área de aerodinâmica em túnel de vento para modelos de turbina são relatados na literatura. Mais recentemente, Adaramola e Krogstad (2011) estudaram a performance de um modelo de turbina com um rotor de $0,9 \mathrm{~m}$ de diâmetro. Os testes experimentais foram validados por simulação numérica no CFD. Além deste trabalho, analisaram a esteira colocando duas turbinas, como a já mencionada, no interior de um túnel de vento obtendo informações sobre a interferência entre elas.

Monteiro et al. (2013) realizaram testes em túnel de vento de uma turbina de 1,2 $\mathrm{m}$ de diâmetro. Os resultados obtidos foram comparados com dois códigos BEM (QBlade 
e $\left.W T_{P e r f}\right)$.

Um dos procedimentos fundamentais na análise dos resultados obtidos no interior do túnel é aplicar a correção pelos efeitos de bloqueio devidos às paredes do túnel de vento ${ }^{1}$. O primeiro método de correção foi desenvolvido por Glauert (1933). Glauert analisou os efeitos de bloqueio em túnel de vento fechado durante os testes de uma hélice. Um método mais recente é o proposto por Mikkelsen e Sørensen (2002), especificamente concebido para efeitos de bloqueio em túnel de vento para turbinas. Este método é baseado na teoria de momentos axial. Bahaj et al. (2007) desenvolveram um método para corrigir o efeito de bloqueio da esteira, um processo iterativo baseado no modelo de Mikkelsen e Sørensen (2002). Por outro lado, Ryi et al. (2015) usaram o algoritmo proposto por Glauert para correção do bloqueio. Neste caso foi testado um modelo de turbina eólica utilizando túneis de vento de três tamanhos diferentes.

Analogamente aos ensaios em túnel de vento, testes em túneis de água para modelos de turbinas hidrocinéticas são realizados pelos pesquisadores para estudar os efeitos que influenciam no desempenho destas. Milne et al. (2013) realizou um conjunto de testes em túneis de água para estudar os fenômenos de instabilidade hidrodinâmica em turbinas marinhas. Bahaj et al. (2007) e Batten et al. (2008) pesquisaram os efeitos de cavitação de turbinas em túnel de água. Outras experiências similares são relatadas por Jo et al. (2012), Connor et al. (2007), Myers, Galloway e Bahaj (2011), Maganga et al. (2010), Doman et al. (2015). Os dados obtidos dos testes com modelos em pequena escala são usados para validação e calibração de modelos preditivos de performance de turbinas, e para o desenvolvimento de novas ideias com custos muito menores que para modelos em grande escala (MCWILLIAM, 2008).

A análise adimensional das variáveis do problema proporciona as leis de escala que permitem transpor resultados de um pequeno modelo a um grande protótipo. A teoria de similaridade diz que uma máquina somente terá o comportamento similar ao seu modelo se forem respeitados os três tipos possíveis de homogeneidades: dimensional, cinemática e dinâmica.

Vários autores relatam as dificuldades da transposição de resultados de modelo para protótipo devido às limitações impostas pela escala. A similaridade dinâmica é mais um sonho que uma realidade, já que a equivalência entre os números de Reynolds do modelo e protótipo pode ser apenas alcançada para propriedades do fluido inusuais. De fato, os modelos são testados, normalmente, em água ou ar, sendo portanto, quase impossível reproduzir uma total similaridade.

Mason-Jones et al. (2012) mostraram como a performance de uma turbina hidrocinética de eixo horizontal pode ser quantificada unicamente por parâmetros adimensionais,

1 Nota: O fenômeno de bloqueio é devido à interferência que as paredes do túnel de vento produzem sobre o rotor causando o aumento das variáveis mesuradas durante os ensaios. 
e que no caso de números de Reynolds maiores que $5 \cdot 10^{5}$, os resultados obtidos são independentes do número de Reynolds para a geometria em estudo. Na sua tese doutoral, Campagnolo (2013) formulou um conjunto específico de leis de escala para entender como a inércia e as propriedades estruturais e aerodinâmicas de uma turbina em grande escala devem ser escaladas. Nos trabalhos de Bottasso, Campagnolo e Petrovic (2014) e Doman et al. (2015) os efeitos do número de Reynolds na similaridade entre protótipo e modelo são também discutidos.

Em todos os estudos para transposição de escalas, fica claro que as leis semiempíricas, dependentes do número de Reynolds, não podem ser generalizadas.

A transposição entre resultados de modelos para protótipo depende de uma série de fatores inerentes à hidrodinâmica do escoamento sobre pás girantes, que está associada a complexos fenômenos tais como transição laminar-turbulenta, descolamento da camada limite, etc. Portanto, leis de escala, tais como são propostas em outras turbomáquinas, tem aplicabilidade restrita ao estudo específico analisado.

Atualmente outra forma de prever a performance de uma turbina é utilizando a dinâmica dos fluidos computacional (CFD). Estes softwares permitem um maior entendimento dos fenômenos físicos presente no problema, apresentando uma abordagem mais complexa do funcionamento de turbinas (MO; LEE, 2012; MOSHFEGHI; SONG; XIE, 2012; OGGIANO, 2014; SILVA, 2014; MENDES, 2015; SORENSEN; MICHELSEN; SCHRECK, 2002). No presente trabalho, os ensaios experimentais realizados em túnel de vento para o modelo em escala reduzida foram estudados através de simulações CFD, compondo assim uma abordagem robusta de validação cruzada de resultados.

\subsection{Objetivos}

\subsubsection{Objetivos Gerais}

O objetivo principal do presente trabalho é o estudo de uma turbina de eixo horizontal. O estudo pretende ampliar o conhecimento na predição do desempenho de uma turbina em grande escala a partir das informações de um modelo reduzido de turbina (mais fácil de operar e com menor custo). Com este fim, vamos realizar a transposição de resultados experimentais de $C_{p}$ vs. $\lambda$ obtidos no túnel de vento, a partir de um modelo reduzido de turbina de eixo horizontal, para conhecer a performance de um protótipo operando em água.

\subsubsection{Objetivos Específicos}

- Concepção e construção do modelo reduzido de turbina axial de eixo horizontal 
- Ensaio da turbina (modelo) em túnel de vento

- Simulação da turbina (modelo e protótipo) utilizando a metodologia BEM (Blade Element Method)

- Simulação da turbina (modelo e protótipo) CFD

- Desenvolvimento de uma metodologia para o cálculo do fator de escala que permitirá a transposição entre resultados modelo-protótipo, para um caso específico

- Validação da metodologia numérica utilizando dados experimentais obtidos no ensaio em túnel de vento

- Validação da curva de desempenho obtida para o protótipo por meio da transposição usando os resultados da simulação numérica para o protótipo

\subsection{Organização da dissertação}

O capítulo 2 contém uma revisão dos principais estudos sobre hidrodinâmica em turbinas de eixo horizontal, teoria do disco atuador, efeitos de rotação na esteira, teoria BEM e perfis aerodinâmicos. No capítulo 3 apresentam-se as técnicas experimentais empregadas para a realização dos testes do modelo reduzido de turbina no túnel de vento, assim como a análise de transposição entre modelo-protótipo. As simulações CFD, usando o software ANSYS CFX R16.1, realizadas para validação dos resultados experimentais e de transposição modelo-protótipo são apresentados no capítulo 4. Os resultados do trabalho são discutidos no capítulo 5. Neste são apresentadas as curvas de $C_{p}$ vs. $\lambda$ do modelo, numéricas e experimentais, e os resultados da transposição modelo-protótipo. O capítulo 6 contem conclusões, sugestões e observações. 


\section{Hidrodinâmica de turbinas de eixo horizon-}

\section{tal}

A hidrodinâmica é a parte da mecânica dos fluidos que se ocupa do estudo de fluidos em movimentos. No presente trabalho a formulação do escoamento em uma turbina é dada por modelos simplificados baseados em equações de conservação da massa e quantidade de movimento expressas em forma integral. Os modelos diferencias, descrição Euleriana, poderão ser resolvidos usando CFD baseados nas equações de conservação diferenciais.

No caso das turbinas de eixo horizontal, o estudo hidrodinâmico permite a descrição do escoamento em volta das mesmas (campo de velocidades e pressão). Isto leva à obtenção da análise de desempenho da máquina $\left(C_{p}\right.$ vs. $\left.\lambda\right)$ e de técnicas de projeto das pás da turbina.

\subsection{Teoria do disco atuador}

O modelo do disco atuador é o mais simples modelo hidrodinâmico para HAWT, onde a turbina é substituída por um disco circular permeável chamado disco atuador. Nesta abordagem considera-se apenas o processo de conversão de energia sem qualquer informação geométrica da turbina. A teoria do disco atuador assume algumas simplificações tais como fluxo incompressível, constante e uniforme a montante do disco, com irrotacionalidade e velocidade constante através do disco atuador.

A teoria do disco atuador é baseada na teoria de conservação da quantidade de movimento linear e usa como volume de controle um tubo de corrente, como ilustrado na Figura 5. O disco atuador oferece uma resistência ao fluxo de ar que sofre uma diminuição na velocidade, e portanto, um aumento na pressão. Quando o escoamento passa através do disco origina uma descontinuidade de pressão no fluxo ar. Na Figura 5 pode ser observado como antes do disco há um aumento de pressão e logo en seguida a pressão cai subitamente para um valor inferior que a pressão ambiente. Na região a jusante do disco, a esteira, ocorre a recuperação gradual da pressão até a pressão ambiente. Porém, a velocidade nunca volta a ser a mesma devido à extração de energia cinética pela turbina. Portanto, pela conservação da massa, acontece a expansão do tubo de corrente. Pode-se observar que a montante do rotor o tubo de velocidade tem área de seção menor que a jusante.

As velocidades axiais do fluxo são definidas como, $u_{\infty}$, velocidade a montante do disco no escoamento não perturbado, $u_{w}$ velocidade a jusante do disco atuador, na esteira e $u_{d}$ velocidade no disco . Assume-se a conservação da massa através do rotor, portanto, 


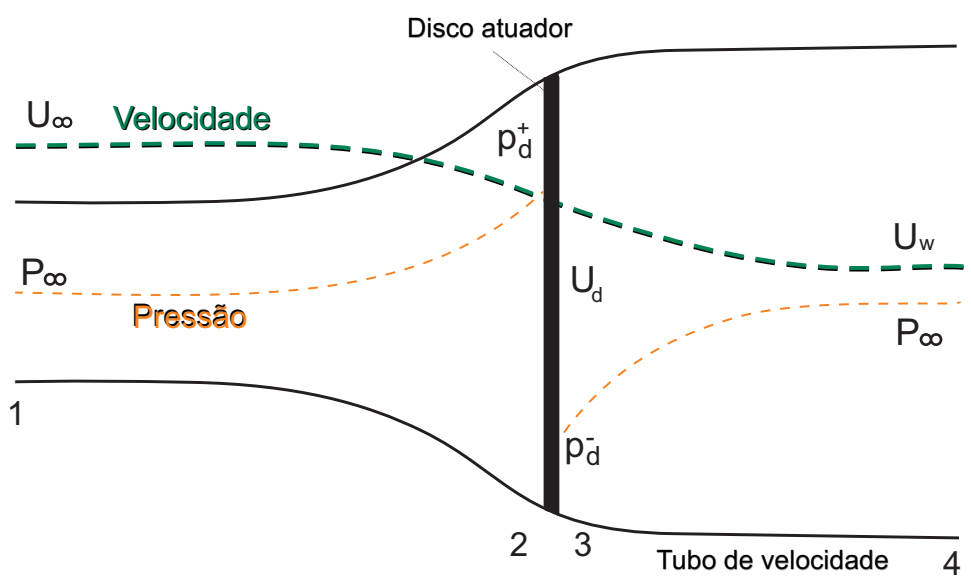

Figura 5 - Esquema do disco atuador e do tubo de velocidade

Fonte: (BURTON et al., 2001, p. 43)

$u_{d^{+}}=u_{d^{-}}=u_{d}$. Pela equação de continuidade ao longo do volume de controle temos que

$$
\rho A_{\infty} u_{\infty}=\rho A_{d} u_{d}=\rho A_{w} u_{w}
$$

onde $\rho$ é a densidade do fluido, $A_{\infty}$ a área da seção de entrada ao tubo de corrente, $A_{d}$ a área do disco atuador e $A_{w}$ a área da seção do tubo de corrente que corresponde à região da esteira.

A vazão mássica, $\dot{m}$, através do rotor, em regime estacionário é dada por

$$
\dot{m}=\rho A_{d} u_{d}
$$

Para o cálculo da força axial atuante no disco aplica-se a equação de conservação de momento axial, $\mathrm{T}$

$$
T=\dot{m}\left(u_{\infty}-u_{w}\right),
$$

Essa força causa a variação do momento, que é equivalente à diferença de pressão através do disco vezes a área, tal que

$$
\left(p_{d^{+}}-p_{d^{-}}\right) A_{d}=\dot{m}\left(u_{\infty}-u_{w}\right)=\rho A_{d} u_{d}\left(u_{\infty}-u_{w}\right),
$$

e portanto,

$$
\Delta p=\left(p_{d^{+}}-p_{d^{-}}\right)=\rho u_{d}\left(u_{\infty}-u_{w}\right) .
$$


A diferença de pressões no disco atuador é obtida a partir da equação de Bernoulli considerando que o escoamento é invíscido e irrotacional, entre 1-2 e 3-4. A equação é aplicada separadamente em duas regiões do tubo de velocidades, isto ocorre porque, o total da energia a jusante do rotor é diferente da energia a montante tendo em vista que a turbina extrai energia do sistema.

A região 1-2 da Figura 5 é referida na equação (2.6),

$$
p_{\infty}+\frac{1}{2} \rho u_{\infty}^{2}=p_{d^{+}}+\frac{1}{2} \rho_{d} u_{d^{+}}^{2},
$$

e a região 2-2 na equação $(2.7)$

$$
p_{w}+\frac{1}{2} \rho u_{w}^{2}=p_{d^{-}}+\frac{1}{2} \rho_{d} u_{d^{-}}^{2} .
$$

Subtraindo a equação (2.7) de (2.6),

$$
\left(p_{d}^{+}-p_{d}^{-}\right)=\frac{1}{2} \rho\left(u_{\infty}^{2}-u_{w}^{2}\right)
$$

e substituindo (2.8) em (2.5),

$$
u_{d}=\frac{1}{2}\left(u_{\infty}+u_{w}\right)
$$

Por outro lado, a potência extraída pelo disco atuador, P, é igual ao produto da força axial definida na Equação 2.3 e a velocidade no disco ,

$$
P=T u_{d}=\dot{m}\left(u_{\infty}-u_{w}\right) u_{d}
$$

Combinando as equações $(2.2),(2.9)$ e (2.10),

$$
P=2 \rho A_{d} u_{d}^{2}\left(u_{\infty}-u_{d}\right)
$$

Definindo o fator de indução axial, $a$, variável adimensional que toma valores entre $[0,1]$

$$
a=\frac{u_{\infty}-u_{d}}{u_{\infty}}
$$

O fator de indução axial quantifica a interferência da turbina na velocidade do escoamento. Se $a=0$ implica que $u_{\infty}=u_{d}$, e portanto, a turbina não gera nenhuma alteração no escoamento. Já para $a=1$ implica que $u_{d}=0$, é dizer, o total bloqueio do escoamento causado pela turbina. 
Combinando agora as equações (2.12) e (2.11), tem-se que

$$
P=2 \rho A_{d} u_{\infty}^{3} a(1-a)^{2}
$$

Uma estimativa da eficiência de uma turbina é descrita pelo coeficiente de potência $C_{p}$, que representa a relação entre a potência extraída pelo rotor (Equação 2.13), sendo

$$
C p=\frac{P_{\text {extraída }}}{P_{\text {disponível }}} \text {. }
$$

A potência disponível no escoamento na área de seção $A_{d}$ é calculada como,

$$
P_{\text {diponível }}=\frac{1}{2} \rho A_{d} u_{\infty}^{3}
$$

e portanto,

$$
C p=\frac{2 \rho A_{d} u_{\infty}^{3} a(1-a)^{2}}{\frac{1}{2} \rho u_{\infty}^{3} A_{d}}
$$

Manipulando Equação 2.16, observa-se como o coeficiente de potência pode ser expressado unicamente em função do fator de indução tal que

$$
C p=4 a(1-a)^{2}
$$

Derivando a Equação 2.17 em função do fator de indução, obteremos para que valor de $a$ teremos o valor máximo de $C_{p}$.

$$
\frac{\partial C p}{\partial a}=4(1-a)^{2}-8 a(1-a)=4\left(1-4 a+3 a^{2}\right)=0
$$

Resolvendo a Equação 2.18 obtêm-se que $C_{p_{\max }}=16 / 27 \approx 0,593$ para um valor de $a=1 / 3$. Este valor máximo para o $C_{p}$ é conhecido como o limite de Betz (1926) e representa o valor máximo de eficiência atingido para quaisquer turbina de eixo horizontal e fluxo livre.

\subsection{Efeitos de rotação}

A teoria do disco atuador deve ser complementada introduzindo os efeitos de rotação do fluido na esteira, para trabalhar com um modelo mais realista. Ocorre que o torque exercido no eixo da turbina é transmitido ao fluxo de ar como um torque igual e de sentido oposto. Consequentemente, este torque reativo, causa uma rotação no escoamento na direção oposta à rotação do rotor. 
A jusante da turbina o escoamento ganha um momento angular e o campo de velocidades passa ter uma componente tangencial, além da axial. A variação na velocidade tangencial é parametrizada em termos do fator de indução axial, $a^{\prime}$. A montante da turbina e fora do tubo de velocidade a velocidade não tem componente tangencial, portanto, $a^{\prime}=0$. Após o escoamento passar pela turbina, as pás induzem uma velocidade tangencial nele, e portanto, o momento angular deixa de ser nulo.

Da mesma forma que a velocidade axial do escoamento após o rotor era definida pelo fator de indução axial, $a$, a velocidade tangencial é expressada em termos da do fator de indução tangencial, $a^{\prime}$, tal que

$$
u_{\theta}=2 a^{\prime} \omega r
$$

onde $r$ é a distância radial ao centro da turbina e $\omega$ a velocidade de rotação da turbina. Na Figura 6a pode-se observar a trajetória de uma partícula do ar no passo pelo rotor.

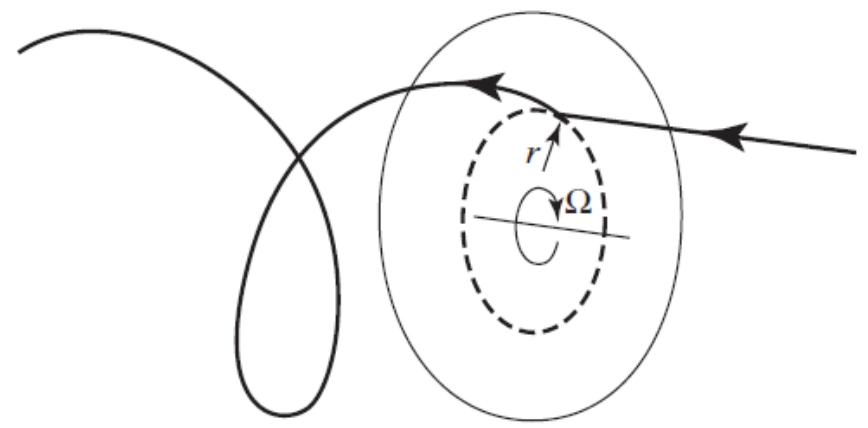

(a)

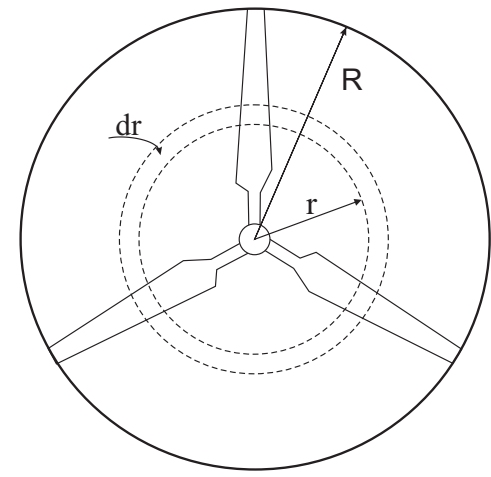

(b)

Figura 6 - (a) Trajetória de uma partícula de ar no passo pelo rotor. (b) Rotor de três pás de raio $R$

Fontes: (a) (BURTON et al., 2001, p. 47), (b) (HANSEN, 2008, p. 24)

A potência aproveitada pela rotor é menor se considerarmos o efeito de rotação, já que uma parte da energia cinética é consumida pela componente tangencial do campo de velocidades não podendo ser aproveitada pelo turbina.

A potência será calculada como torque vezes velocidade de rotação, sendo o torque igual à taxa de variação do momento angular do fluxo de ar que passa pela turbina. Os cálculos serão feitos sobre um elemento infinitesimal $d r$, como apresentado na Figura 6b . Neste caso, o torque será igual à taxa de variação do momento angular que passa através 
deste anel infinitesimal, o que pode ser equacionado por

$$
d M=\rho d A_{d} u_{d} u_{\theta} r
$$

onde $d M$ é a taxa de variação do momento angular no elemento $d r, \rho$ a densidade do fluido, $d A_{d}=2 \pi r d r, u_{d}=u_{\infty}(1-a)$ e $u_{\theta}=2 \omega a^{\prime} r$. E portanto, a potência , dP, é

$$
d P=d M \omega
$$

sendo $\omega$ a velocidade de rotação.

Relacionando as equações 2.20 e 2.21 tem-se que

$$
d P=2 \pi \rho \omega^{2} u_{\infty} a^{\prime}(1-a) r^{3} d r
$$

A potência total será calculada como a integral de $d P$ em todos os elementos $d r$,

$$
P=4 \pi \rho \omega^{2} u_{\infty} \int_{0}^{R} a^{\prime}(1-a) r^{3} d r
$$

Portanto, $C p$ pode ser escrito como

$$
C p=\frac{8 \omega^{2}}{R^{2} u_{\infty}^{2}} \int_{0}^{R} a^{\prime}(1-a) r^{3} d r
$$

A Equação 2.24 pode ser escrita em forma adimensional usando a razão de velocidades de ponta de pá (TSR ou $\lambda$ ). Esse parâmetro é uma variável adimensional que relaciona a velocidade de rotação na ponta da pá e a velocidade do escoamento não perturbado.

$$
\lambda=\frac{\omega R}{u_{\infty}}
$$

onde R é o raio do rotor. Para reescrever a Equação 2.24 precisa-se definir um TSR local (2.26) onde $r$ representa um raio do rotor adimensional

$$
\lambda_{r}=\frac{\omega r}{u_{\infty}}
$$

portanto,

$$
C p=\frac{8}{\lambda^{2}} \int_{0}^{\lambda} a^{\prime}(1-a) \lambda_{r}^{3} d \lambda_{r}
$$

Após considerar os efeitos de rotação na esteira foi obtida uma nova expressão do $C_{p}$ dada pela Equação 2.27, função de $a$ e $a^{\prime}$. Tal e como foi feito para a teoria do disco 
atuador,pretende-se obter o máximo valor possível de $C_{p}$ e para quais valores dos fatores de indução, axial e radial, isto acontece.

Para conhecer o valor máximo do coeficiente de potência temos que maximizar a função $f\left(a, a^{\prime}\right)=a^{\prime}(1-a)$. Sabendo que $a^{\prime}=f(a)$

$$
\begin{gathered}
\frac{d}{d a} a^{\prime}(1-a)=0 \\
\frac{d a^{\prime}}{d a}=\frac{a^{\prime}}{(1-a)}
\end{gathered}
$$

precisamos conhecer qual é a relação entre $a, a^{\prime}$ para conhecer o $C p_{\text {máx }}$. Estas variáveis serão relacionadas a partir das relações 2.30 e 2.31 obtidas do triângulo de velocidades por meio do ângulo $(\phi)$. (Figura 7 e Figura 11).

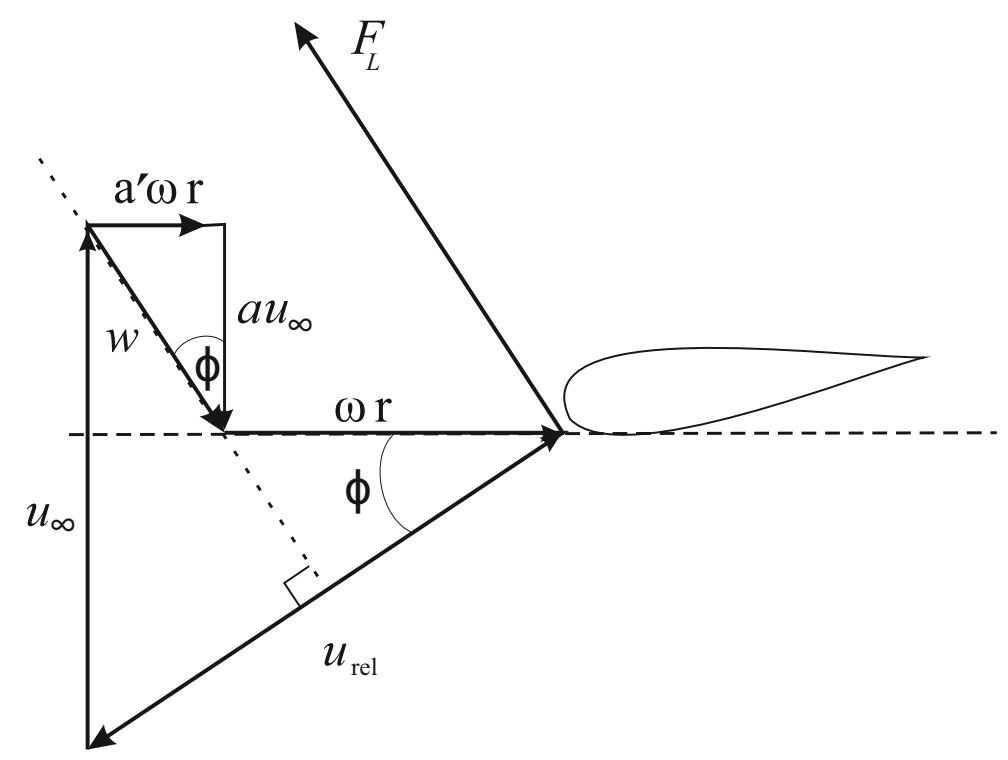

Figura 7 - Triângulo de velocidades mostrando a velocidade induzida Fonte: Adaptado de (HANSEN, 2008, p. 38)

$$
\operatorname{tg}(\phi)=\frac{(1-a) u_{\infty}}{\left(1+a^{\prime}\right) \omega r}
$$

e,

$$
\operatorname{tg}(\phi)=\frac{a^{\prime} \omega r}{a u_{\infty}}
$$


Igualando as equações 2.30 e 2.30 encontra-se uma relação entre a , a' e $\lambda_{r}$, tal q

$$
\lambda_{r}^{2} a^{\prime}\left(1+a^{\prime}\right)=a(1-a)
$$

Derivando esta equação em função $a$, tem-se que

$$
\lambda_{r}^{2}\left(1+2 a^{\prime}\right) \frac{d a^{\prime}}{d a}=a(1-2 a)
$$

Combinando as equações 2.29, 2.32 e 2.33, chega-se à relação ótima entre $a$ e $a^{\prime}$

$$
a^{\prime}=\frac{1-3 a}{4 a-1}
$$

Glauert (1935) descreveu a equação acima relacionando os fatores de indução axial e tangencial para o maior valor de Cp possível em uma turbina. O valor ótimo foi encontrado para $a=1 / 3$, o que é consistente com a teoria do disco atuador. Glauert comparou o coeficiente de potência ótimo calculado com o limite Betz (16/27), que não considera os fenômenos rotativos. Vide Figura 8.

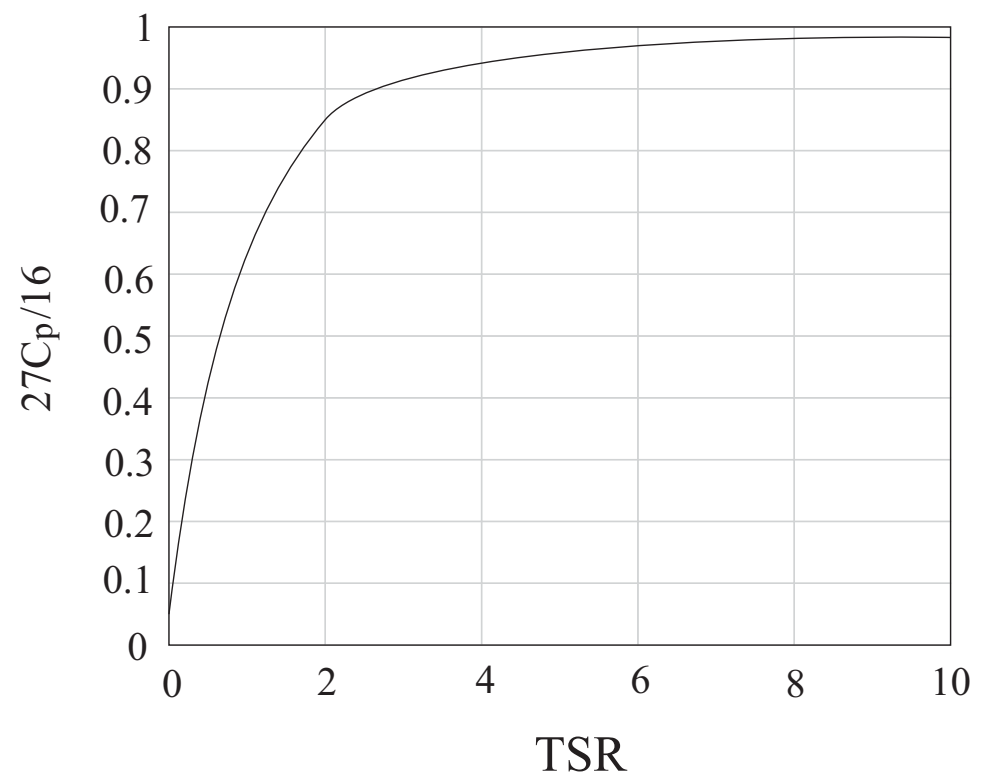

Figura 8 - Comparação do coeficiente de potência ótimo de Glauert de uma turbina incluindo efeitos de rotação com o limite de Betz. Representação do $C_{p} / C_{p, \text { Betz }}$ vs. $T S R$.

Fonte: Adaptado de (HANSEN, 2008, p. 40) 


\subsection{Teoria BEM (Blade Element Moment)}

Até o momento, o rotor da turbina era considerado como um disco onde a conservação da quantidade de movimento era aplicada. A teoria BEM passa a considerar as pás da turbina e combina as equações de conservação da quantidade de movimento com a "Blade Element Theory". Esta última examina as forças geradas em várias seções das pás. A teoria BEM é a mais antiga e usada teoria para definir as forças exercidas pelo escoamento no rotor pelo cálculo iterativo dos fatores de indução.

O BEM assume que um elemento radial da pá pode ser analisado independentemente e que as forças aerodinâmicas atuantes nas pás são constantes em cada elemento anular. Sendo tudo isto aplicável para um rotor com um numero infinito de pás. Mais tarde uma correção conhecida como Prandtl's tip loss factor corrige a formulação considerando os efeitos de ponta de pá.

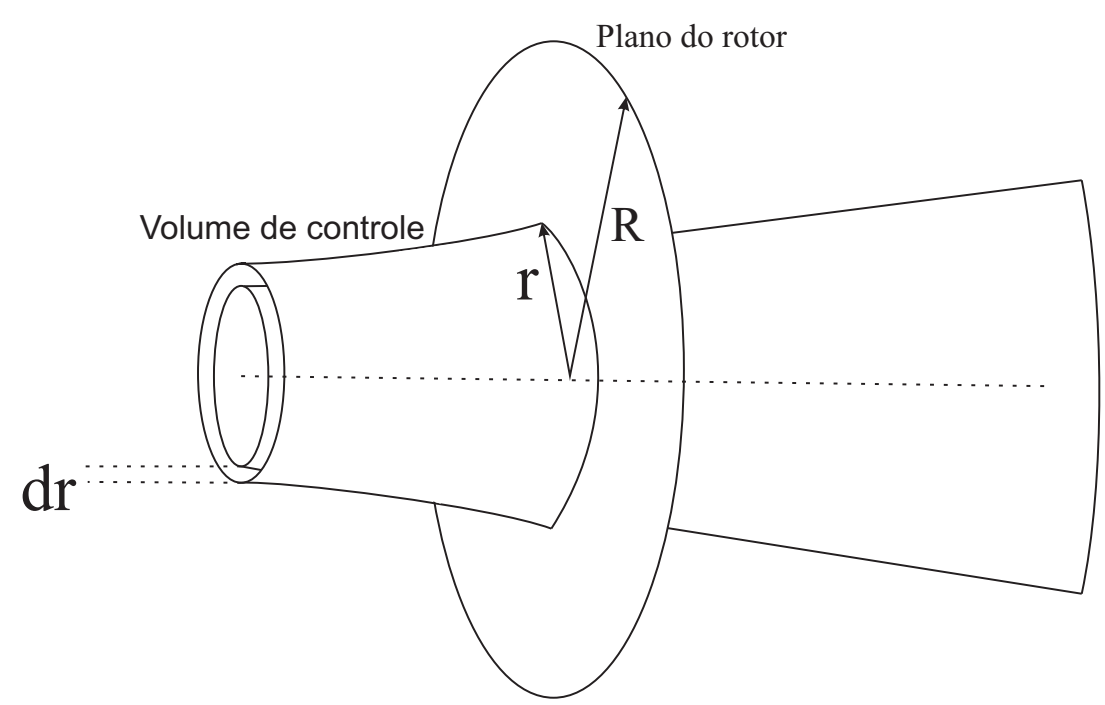

Figura 9 - Tubo de corrente anular através do rotor

Fonte: Adaptado de (HANSEN, 2008, p. 45)

Considerando o tubo de corrente anular apresentado na Figura 9. A força axial atuante no disco, $d T$, de área $2 \pi r d r$, no plano do rotor, é obtida a partir da equação integral da conservação da quantidade de movimento tal que,

$$
d T=\left(u_{\infty}-u_{w}\right) d \dot{m}=2 \pi r \rho u_{d}\left(u_{\infty}-u_{w}\right) d r .
$$

O torque, $d M$, é equivalente à taxa de variação do momento angular no elemento 
anular $d r$, de forma que

$$
d M=\rho d A_{d} u_{d} u_{\theta} r
$$

Após substituir as equações 2.12 e 2.19, que definem os fatores de indução axial e radial, nas equações 2.35 e 2.36 , tem-se que

$$
d T=4 \pi r \rho u_{\infty}^{2} a(1-a) d r
$$

e,

$$
d M=4 \pi r^{3} \rho u_{\infty} \omega a^{\prime}(1-a) d r
$$

Baseado na teoria BEM a pá do rotor é dividida em $\mathrm{N}$ seções, assumido que não existe interação entre os elementos da pá e que as forças atuantes sobre as seções são calculadas mediante os coeficientes de arrastro e sustentação, considerando o ângulo de ataque em cada seção da pá.

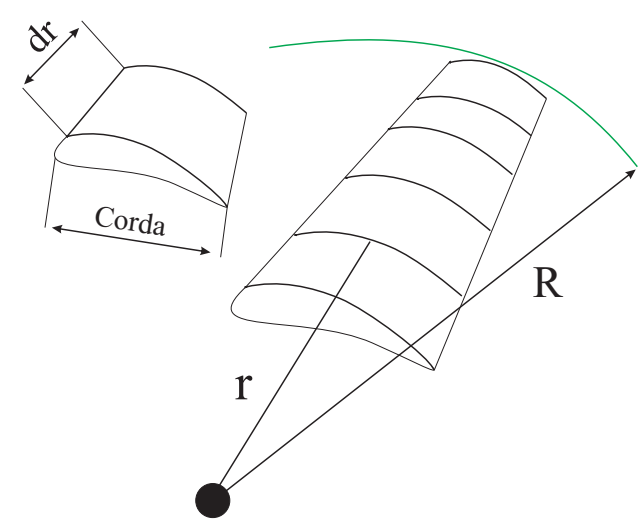

Figura 10 - Discretização na pá pelo método BEM

Fonte: Adaptado de (KULUNK, 2011)

As forças atuantes sobre as seções são calculadas mediante os coeficientes de arrastro e sustentação considerando o ângulo de ataque em cada seção da pá. A interação entre os elementos da pá não é considerada neste método. A força axial, ou empuxo, e o torque podem ser calculados por este método.

A figura Figura 11 apresenta o triângulo de velocidades em um perfil da pá, de forma que

$$
\alpha=\phi-\theta
$$


e,

$$
\tan \phi=\frac{(1-a) u_{\infty}}{\left(1+a^{\prime}\right) \omega r}
$$

sendo $\theta$ o ângulo de passo, pitch, situado entre a corda e o plano do rotor, $\phi$ o ângulo de entrada do escoamento localizado entre o plano de rotação e a velocidade relativa $u_{\text {rel }}$ e $\alpha$ o ângulo de ataque.

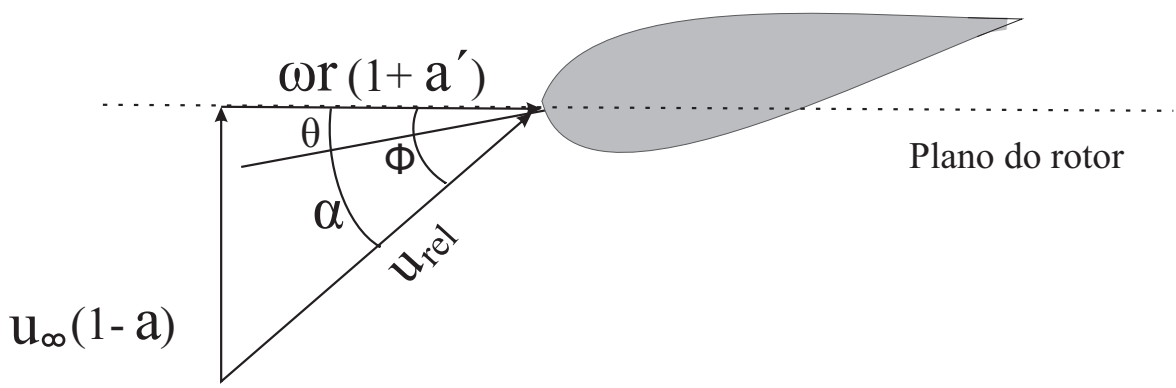

Figura 11 - Triângulo de velocidades na pá.

Fonte: Adaptado de (HANSEN, 2008, p. 47)

As forças aerodinâmicas que o escoamento exerce sobre o aerofólio, em 2-D, são a sustentação, $F_{L}$, perpendicular à velocidade vista pelo aerofólio, $u_{r e l}$, e o arrasto, $F_{D}$, paralela à dita velocidade. Se os coeficientes de sustentação, $C_{L}$, e arrastro, $C_{D}$ são conhecidos, as forças por unidade de longitude podem ser equacionadas como,

$$
F_{L}=\frac{1}{2} \rho u_{r e l}^{2} c C_{L}
$$

e,

$$
F_{D}=\frac{1}{2} \rho u_{r e l}^{2} c C_{D}
$$

onde $c$ é a corda do aerofólio na posição r.

As forças normal e tangencial por unidade de longitude no plano do rotor são determinadas pelas projeções das forças de sustentação e arrastro nessas direções tal que,

$$
p_{n}=F_{L} \cos \phi+F_{D} \sin \phi,
$$


e,

$$
p_{t}=F_{L} \sin \phi-F_{D} \cos \phi
$$

As equações 2.43 e 2.44 são escritas de forma adimensional de forma que,

$$
C_{n}=C_{L} \cos \phi+C_{D} \sin \phi
$$

e,

$$
C_{t}=C_{L} \sin \phi-C_{D} \cos \phi
$$

onde,

$$
C_{n}=\frac{p_{n}}{\frac{1}{2} \rho u_{r e l}^{2} c}
$$

e,

$$
C_{t}=\frac{p_{t}}{\frac{1}{2} \rho u_{r e l}^{2} c}
$$

Da Figura 12 são obtidas as relações geométricas,

$$
u_{r e l} \sin \phi=u_{\infty}(1-a)
$$

e

$$
u_{r e l} \cos \phi=\omega r\left(1+a^{\prime}\right) .
$$




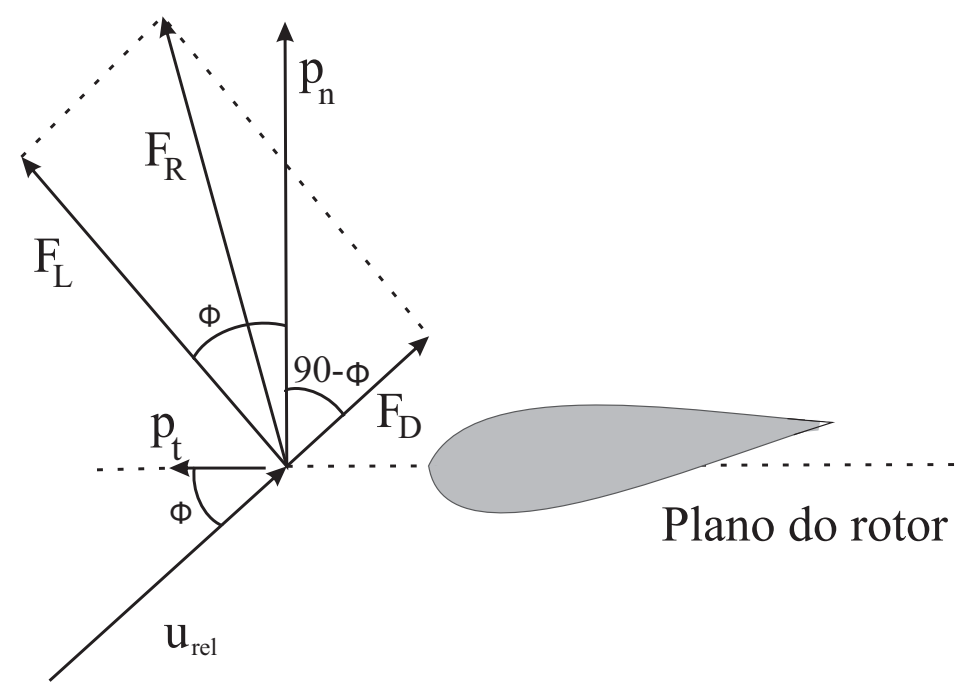

Figura 12 - Forças locais na pá

Fonte: Adaptado de (HANSEN, 2008, p. 48)

A força axial e o torque de um elemento infinitesimal $d r$ no volume de controle podem ser calculadas como

$$
d T=B p_{n} d r
$$

e

$$
d M=r B p_{t} d r
$$

onde B é o número de pás e r a posição radial no volume de controle.

Combinando as equações 2.47, 2.49 e 2.51 a força axial pode ser expressada como

$$
d T=\frac{1}{2} \rho B \frac{u_{\infty}^{2}(1-a)^{2}}{\sin ^{2} \phi} c C_{n} d r
$$

Analogamente, combinando as equações $2.48,2.50$ e 2.52 o torque pode ser expressado como

$$
d M=\frac{1}{2} \rho B \frac{u_{\infty}(1-a) \omega r\left(1+a^{\prime}\right)}{\sin \phi \cos \phi} c C_{t} d r
$$


Igualando as duas equações obtidas para $d T, 2.37$ e 2.53, é obtida uma expressão para o fator de indução axial $a$,

$$
a=\frac{1}{\frac{4 \sin ^{2} \phi}{\sigma C_{n}}+1},
$$

onde $\sigma$ é a solidez definida como a fração da área anular no volume de controle que é coberta pelas pás,

$$
\sigma(r)=\frac{c(r) B}{2 \pi r}
$$

com $c(r)$ a corda local, $r$ a posição radial do volume de controle e $B$ o número de pás do rotor.

Se as equações 2.38 e 2.54 são igualadas, uma equação para $a^{\prime}$ é obtida

$$
a^{\prime}=\frac{1}{\frac{4 \sin \phi \cos \phi}{\sigma C_{t}}-1} .
$$

Uma vez obtidas as equações do modelo BEM o algoritmo básico para análise de desempenho do rotor é apresentado a seguir.

1. Valores iniciais para $a$ e $a^{\prime}$. Tipicamente $\mathrm{a}=\mathrm{a}^{\prime}=0$.

2. Calcular o valor do ângulo $\phi$ pela Equação 2.40 .

3. Calcular o valor do ângulo de ataque $\alpha$ pela Equação 2.39.

4. Tomar os valores conhecidos dos coeficientes $C_{L}(\alpha)$ e $C_{D}(\alpha)$ das curvas polares .

5. Calcular $C_{n}$ e $C_{t}$ das equações 2.45 e 2.46 .

6. Calcular $a$ e $a^{\prime}$ das equações 2.55 e 2.57 .

7. Se a variação de $a$ e $a^{\prime}$ é maior que uma tolerância dada, voltar ao passo (2) senão ir ao passo (8)

8. Calcular os carregamentos locais ao longo das pás.

Algumas correções como, a correção de ponta de pá (Prandtl's tip loss factor) e a correção de Glauert, podem ser adicionadas ao método BEM desenvolvido até o momento para obter melhores resultados. Na literatura podem ser encontrados métodos BEM mais robustos (ANDRIAMPARANY, 2015). 
Observação 1: A correção de ponta de pá de Prandtl considera que o rotor tem um número finito de pás e que o sistema de vórtices na esteira é diferente que no caso de um rotor com um número infinito de pás. O fator corretor $F_{\text {tip }}$ é definido como

$$
F_{\text {tip }}=\frac{2}{\pi} \cos ^{-} 1\left(e^{-f_{t i p}}\right)
$$

onde

$$
f_{t i p}=\frac{B}{2} \frac{R-r}{r \sin \phi}
$$

$B$ é o número de pás, $R$ o raio total do rotor, $r$ o raio local e $\phi$ o ângulo do escoamento.

Observação 2: O fator de correção de perdas no hub é introduzido para corrigir os efeitos dos vórtices perto da região do hub do rotor:

$$
F_{h u b}=\frac{2}{\pi} \cos ^{-} 1\left(e^{-f_{h u b}}\right),
$$

onde

$$
f_{h u b}=\frac{B}{2} \frac{r-R_{h u b}}{R_{h u b} \sin \phi} .
$$

O fator de correção total vem definido como,

$$
F=F_{\text {tip }} F_{\text {loss }}
$$

As equações 2.37 e 2.38 corrigidas ficam como

$$
d T=4 \pi r \rho u_{\infty}^{2} a(1-a) F d r
$$

e,

$$
d M=4 \pi r^{3} \rho u_{\infty} \omega a^{\prime}(1-a) F d r
$$

Usando as equações 2.63 e 2.64 as expressões para os fatores de indução $a$ e $a^{\prime}$ são

$$
a=\frac{1}{\frac{4 F \sin ^{2} \phi}{\sigma C_{n}}+1}
$$


e,

$$
a^{\prime}=\frac{1}{\frac{4 F \sin \phi \cos \phi}{\sigma C_{t}}-1} \text {. }
$$

No algoritmo de resolução apresentado acima deve ser introduzido o cálculo do fator de correção de ponta de pá e calcular os coeficientes $a$ e $a^{\prime}$ pelas equações acima.

Observação 3: A correção de Glauert é usada quando o fator de indução axial a toma valores maiores que 0,4 já que a teoria de momentos nesse caso não funciona. Glauert desenvolveu uma correção para o coeficiente de empuxo, $C_{T}$, baseada em dados experimentais válida para valores de $a>0,4$. Na Figura 13 é apresentado a variação do $C_{T}$ em função de $a$ segundo a teoria de momentos e a correção empírica de Glauert.

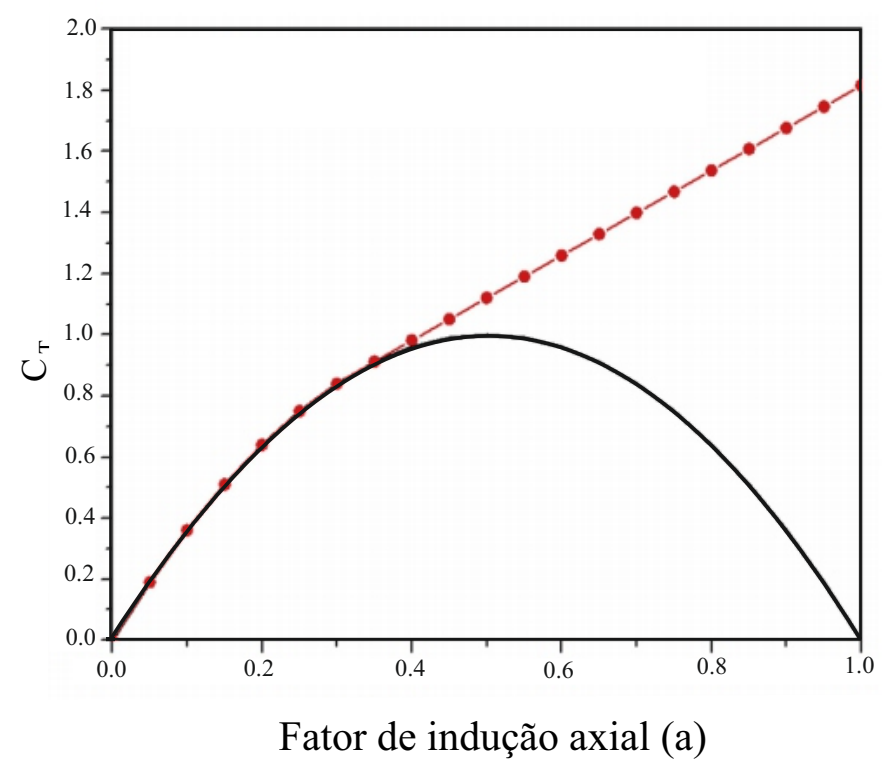

Figura 13 - Variação do $C_{T}$ com o fator de indução axial a. - Teoria BEM; •: Correção empírica de Glauert

Fonte: (RYI et al., 2015) 


\subsection{Perfis aerodinâmicos}

Para resolver as equações da teoria BEM é preciso conhecer o valor das forças atuantes nas pás. Elas são obtidas a partir do estudo bidimensional dos perfis aerodinâmicos. Desta análise, normalmente são obtidos os denominados coeficientes aerodinâmicos de sustentação, arrastro e momento, $C_{L}, C_{D}$ e $C_{M}$, em função do ângulo de ataque, $\alpha$. As curvas que apresentam a variação dos coeficientes aerodinâmicos em função do ângulo de ataque são denominadas curvas polares.

Na literatura exite uma grande disponibilidade de informação referente aos coeficientes de sustentabilidade e arrasto em aerofólios padrões para vários números de Reynolds. Esses resultados foram obtidos mediante ensaios experimentais em túnel de vento para as mais variadas famílias de aerofólios (ABBOTT; DOENHOFF; STIVERS, 1945; MILEY, 1982; VITERNA; CORRIGAN, 1982). Ao longo dos anos, foram também realizadas simulações numéricas para retratar fenômenos físicos em aerofólios, destacando o método dos painéis (HESS; SMITH, 1966) também conhecido como método de singularidades. Mais recentemente, tem sido muito utilizadas as simulações numéricas CFD com aerofólios.

Vários autores (BERTAGNOLIO et al., 2001; MONTGOMERIE, 2004; LEE et al., 2004; LANZAFAME; MESSINA, 2012) tem trabalhado em melhorar, interpolar e extrapolar as curvas polares obtidas de forma experimental para obter resultados mais precisos. Uma informação mais precisa sobre os coeficientes levará a melhores resultados de desempenho da metodologia BEM e evitará problemas de instabilidade numérica.

O software livre XFOIL (DRELA, 1989), que usa o método dos painéis acoplado a uma formulação de camada limite, é uma das ferramentas mais usadas para gerar informações sobre os aerofólios. Dada as coordenadas do aerofólio em 2-D, o número de Reynolds e o número de Match, o XFOIL calcula o campo de pressões em volta do aerofólio e portanto, os coeficientes de sustentação, arrastro e momento, as curvas polares.

Como foi colocado anteriormente, para o cálculo das equações BEM é necessário conhecer os valores dos coeficientes $C_{L}(\alpha)$ e $C_{D}(\alpha)$ obtidos a partir das curvas polares do aerofólio. Portanto, os códigos BEM utilizam normalmente uma interface com o software XFOIL para ter acesso às informações do aerofólio. As informações das curvas polares, obtidas no XFOIL, são usadas tanto para projetos de turbinas como para a simulação de desempenho destas pelo método BEM.

$\mathrm{Na}$ análise de dependência de escalas hidrodinâmicas exitem três pontos que devem ser fortemente considerados devido à importância sobre a transposição de resultados modelo-protótipo: (a) Condição de ângulo de ataque ótimo para o projeto hidrodinâmico; (b) Comportamento da camada limite e estol sobre o aerofólios; e (c) Dependência do comportamento do escoamento sobre aerofólios do número de Reynolds.

A escolha do ângulo de ataque ótimo, $\alpha_{\text {opt }}$, é uma decisão de projeto que depende de 
cada tipo de aerofólio. Na literatura de projetos de aeronaves ,turbomáquinas, e turbinas eólicas várias abordagens são propostas para o cálculo do $\alpha_{\text {opt }}$. Neste texto apresentam-se duas das mais utilizadas.

a) O ângulo de ataque ótimo escolhido corresponde ao maior desempenho aerodinâmico associado ao ponto máximo da curva $C_{L} / C_{D}$.

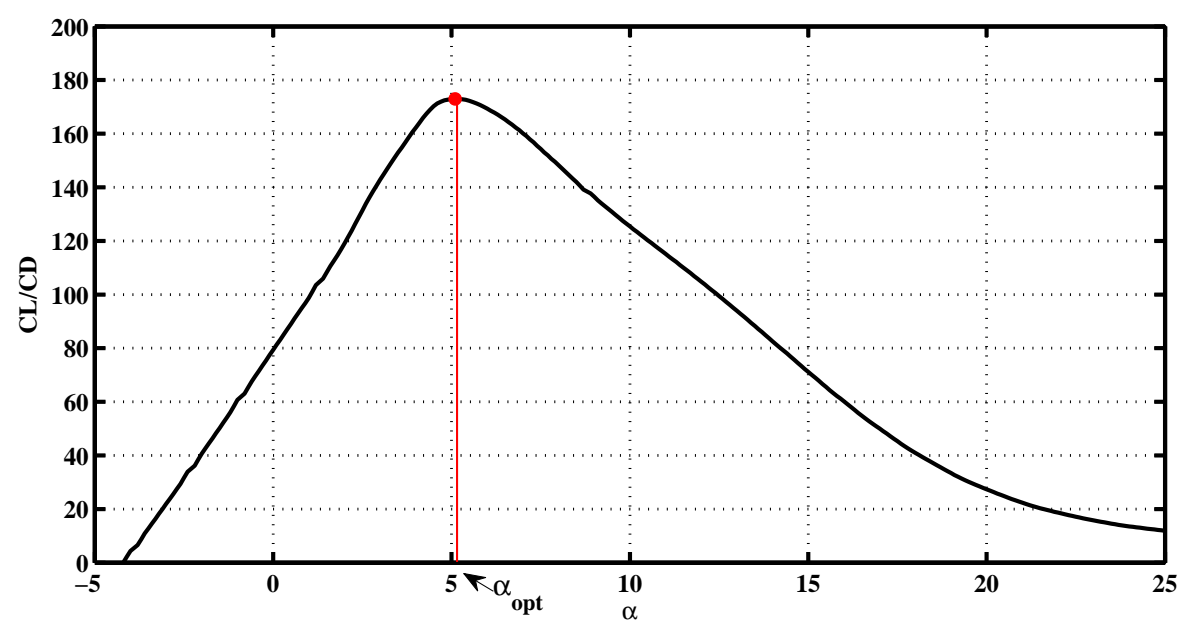

Figura 14 - Cálculo de $\alpha_{\text {opt }}$ a partir da curva de $C_{L} / C_{D}$ vs $\alpha$

b) Ponto de inflexão na curva $C_{L}$ vs $C_{D}$.

Glauert definiu a eficiência aerodinâmica de um elemento da pá, $\eta$, como la razão entre a energia absorvida pelo elemento em forma de trabalho útil pelo empuxo no mesmo, de forma que

$$
\eta=\frac{1-\tan \gamma \cot \phi}{1+\tan \gamma \cot \phi}
$$

A Figura 15 ilustra a curva polar $C_{L}$ vs $C_{D}$. Nela é representado o ângulo $\gamma$ como o formado pela linha reta, traçada desde o origem, tangente à curva e pelo eixo de ordenadas, de forma que

$$
\tan \gamma=\frac{C_{D}}{C_{L}},
$$




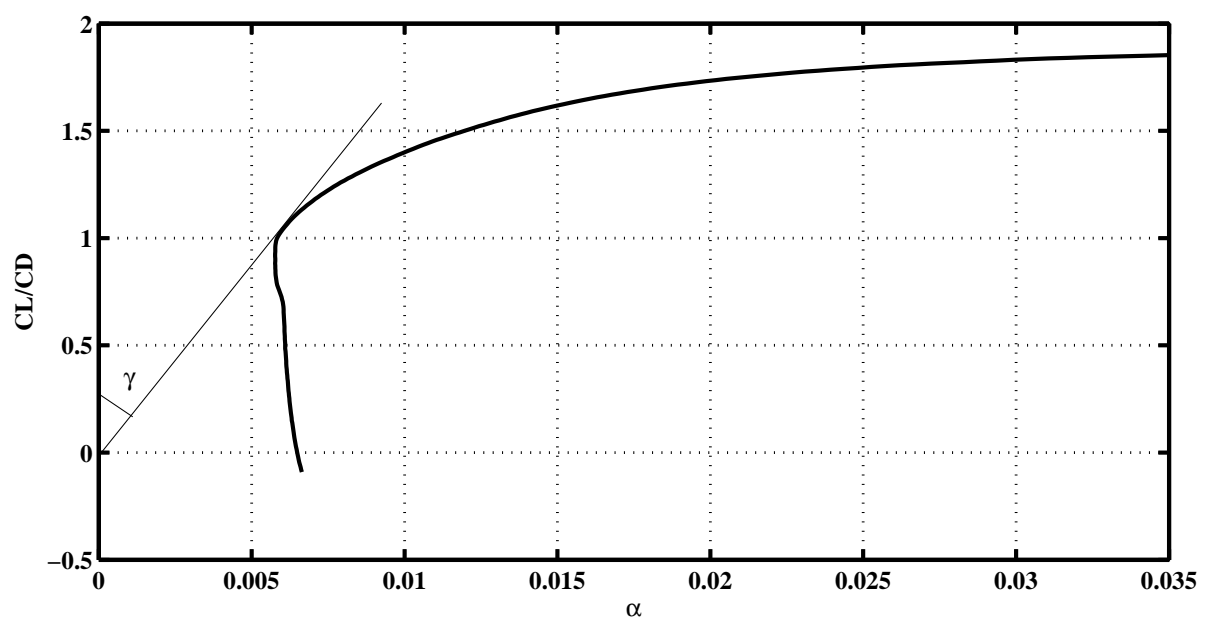

Figura 15 - Ponto de inflexão para o cálculo do $\alpha_{\text {opt }}$ da curva polar $C_{L}$ vs $C_{D}$

A Figura 15 apresenta que tan $\gamma$ é mínimo para o ângulo de ataque, $\alpha$, correspondente ao ponto de inflexão da curva (MAALAWI; BADAWY, 2001). Portanto, para este valor de $\alpha$ a eficiência alcançará valores máximos, e consequentemente também, o desempenho da turbina. $\mathrm{O}$ valor do ângulo de ataque ótimo, é determinado da relação apresentada por Maalawi e Badawy (2001),

$$
\alpha=\frac{C_{L}}{\frac{\partial C_{L}}{\partial \alpha}}+\alpha_{0},
$$

onde $\alpha_{0}$ corresponde ao valor de $\alpha$ para o coeficiente de sustentação igual a 0 e $\frac{\partial \mathrm{C}_{\mathrm{L}}}{\partial \alpha}$ é a inclinação da curva $C_{L}$ vs $\alpha$ (Vide Figura 17). Por outro lado, a relação entre $C_{D}$ e $C_{L}$, em condições de não estol, pode ser aproximada pelo polinômio de segundo grau

$$
C_{D}=C_{D 0}+K_{1} C_{L}+K_{2} C_{L}^{2}
$$

sendo $C_{D 0}$ o coeficiente de arrasto correspondente à sustentação zero, e $K_{1}$ e $K_{2}$ coeficientes constantes que devem ser determinados a partir dos dados do aerofólio.

Na metodologia de projeto a abordagem (a) é utilizada e o comportamento hidrodinâmico de turbinas projetadas no LEA-UnB considera operação em regime nominal próximo à condição do ângulo de ataque assim definido. Portanto, a análise de transposição de escala entre modelo e protótipo, proposta no presente trabalho, utilizará estimativas de desempenho próximas à condições de $\alpha_{\text {opt }}$ (o que equivale também à condição nominal para $\lambda$ ).

O comportamento da camada limite e o estol sobre o perfil aerodinâmico é um ponto fundamental no desempenho de um aerofólio e está fortemente ligado ao número de Reynolds e portanto, à analise de escala hidrodinâmica. 
Quando existe movimento relativo entre um fluido e um corpo sólido, o escoamento fluido pode ser dividido em duas regiões. Uma onde os efeitos viscosos são desprezíveis e outra onde estes tornam-se significativos. Esta última região é conhecida como camada limite, e a influência da viscosidade é confinada em uma fina camada ao redor da parede do corpo. Na camada limite a velocidade varia de 0 a $99 \%$ da velocidade no escoamento livre, e existe em dois estados laminar e/ou turbulento dependendo da suavidade e semelhança com o escoamento livre ou à irregularidade e desorganização, respectivamente. Normalmente, o fluxo laminar desestabiliza e transiciona para turbulento devido a certas condições físicas, e esta transição é chamada de transição laminar-turbulenta.

As principais forças atuantes sobre a camada limite no aerofólio são a sustentação e o arrastro. A diminuição da força de sustentação e o aumento no arrastro levam à separação da camada limite, fenômeno conhecido como estol. As forças predominantes na camada limite quando acontece a separação da mesma são as forças de atrito, forças viscosas, e de pressão, intimamente relacionadas com o arrastro.

A seguir, define-se o número de Reynolds, número adimensional, que caracteriza o movimento do fluido. O número de Reynolds relaciona as forças de inercia e de atrito que atuam sobre o fluido. Portanto,

$$
R e=\frac{\text { Forças inercia }}{\text { Forças viscosas }}
$$

A magnitude das forças viscosas depende do carácter da camada limite e do número de Reynolds. Camadas limites laminares geram forças viscosas menores que as camadas limites turbulentas. Por outro lado, as forças viscosas variam inversamente com o número de Reynolds, isto é, quando o número de Reynolds diminui a força viscosa aumenta. Na Equação 2.71 pode ser observada a dependência do número de Reynolds com a viscosidade, $R e=f(\nu)$.

O gradiente do campo de pressões no fluxo na camada limite pode ser positivo ou negativo, aumentando ou diminuindo a pressão na direção do fluxo, e consequentemente, diminuindo ou aumentando a velocidade, respectivamente. No caso de gradiente positivo de pressão, por causa da força de atrito, chega um ponto em que no fluxo na camada limite carece da energia suficiente para movimentar-se na direção do escoamento ocorrendo uma reversão na direção do mesmo que passa a mover-se em direção à pressão decrescente. $\mathrm{Na}$ maioria das situações, uma vez que o fluxo de reversão é alcançado na camada limite, este começa a se separar do corpo criando uma grande esteira turbulenta. Esta separação chamada de estol, pode envolver parte ou toda a superfície do aerofólio e causa uma diminuição da sustentação e um aumento do arrastro no aerofólio. Na Figura 16 apresenta-se a separação no fluxo da camada limite e o estol na superfície do aerofólio. 


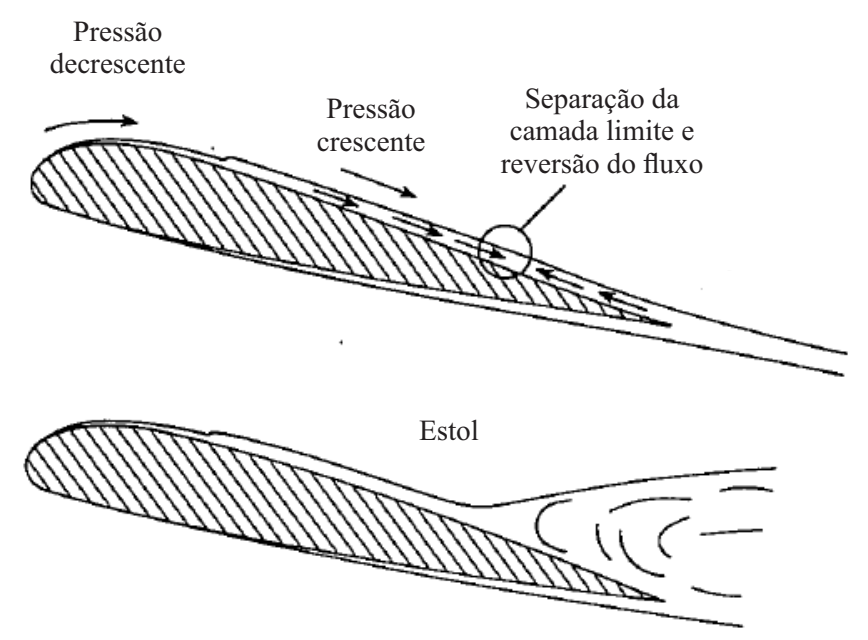

Figura 16 - Separação da camada limite, reversão do fluxo e estol em um perfil aerodinâmico.

O comportamento da camada limite e o estol em um aerofólio tem uma grande influência no projeto e desempenho de uma máquina. Na Figura 17 apresenta-se a curva $C_{L}$ vs $\alpha$ de um aerofólio. Nela podem ser observadas as regiões de pré (a) e pós-estol (b) em um aerofólio dependendo do ângulo de ataque para uma velocidade do escoamento fixa.

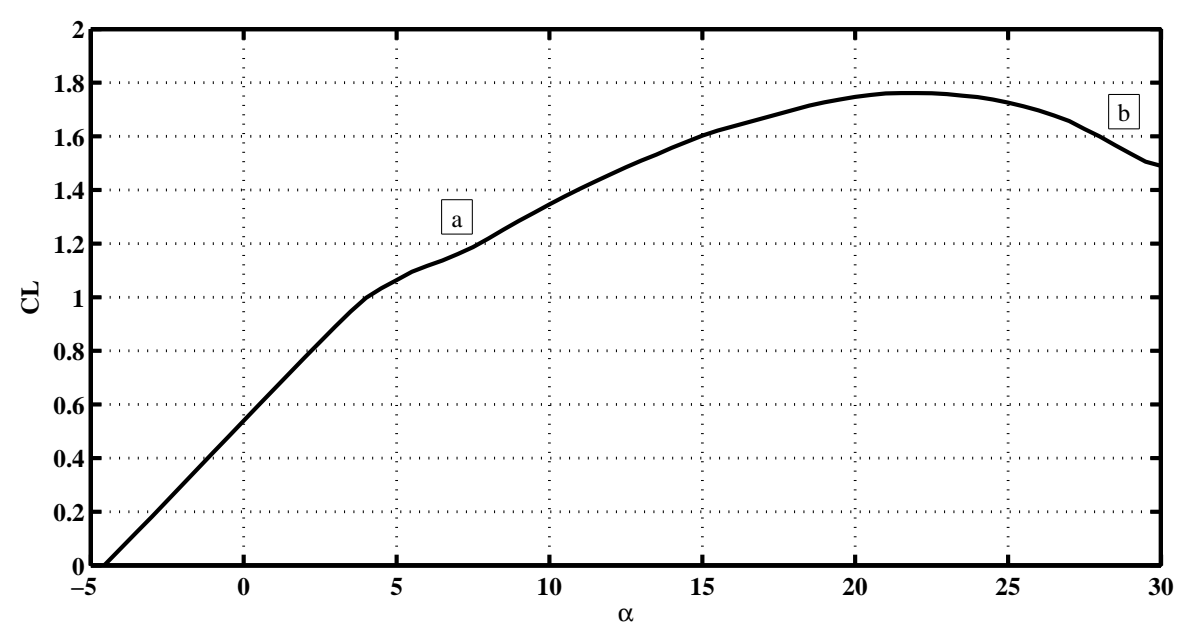

Figura 17 - Curva $C_{L}$ vs $\alpha$. Regiões pré (a) e pós-estol (b)

Quando o ângulo de ataque aumenta, a velocidade na superfície superior do aerofólio também aumenta, acelerando mais rapidamente na borda de ataque. Em termos de pressão, na superfície superior a pressão diminui e na superfície inferior aumenta causando um aumento da sustentação com ângulo de ataque. No entanto, chega um ponto em que a camada limite não pode mais suportar o gradiente de pressão e começa a descolar, o que origina uma diminuição da força de sustentação e um aumento do arrastro. 


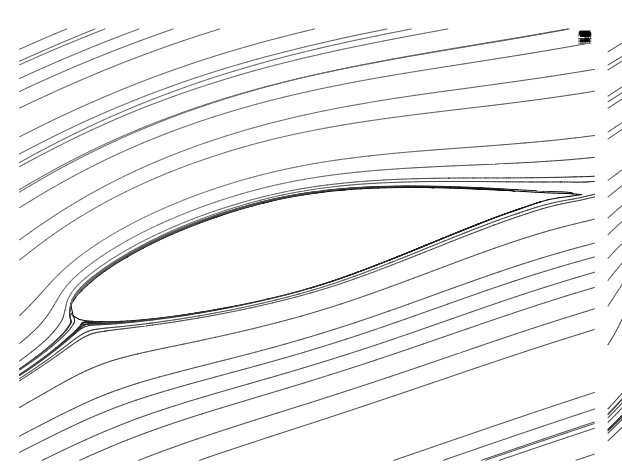

(a)

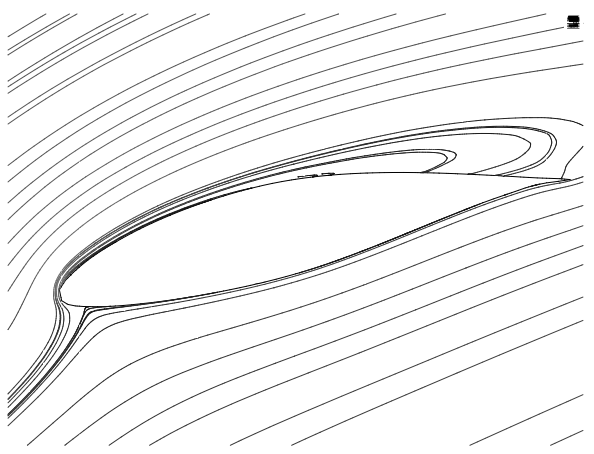

(b)

Figura 18 - Linhas de corrente em volta do perfil aerodinâmico: (a) Região pré-estol da curva $C_{L}$ vs $\alpha$. Camada limite colada ao corpo; (b) Região pós-estol da curva $C_{L}$ vs $\alpha$. Descolamento da camada limite e reversão do fluxo.

O foco deste trabalho centra-se tanto no estudo do protótipo como do seu modelo reduzido, com números de Reynolds da ordem de $10^{6}$ e $10^{4}$, respectivamente. Portanto, torna-se fundamental o estudo da dependência do número de Reynolds no comportamento do escoamento sobre aerofólios na posterior análise de dependência de escalas hidrodinâmicas, para a transposição de resultados modelo-protótipo.

Quando submetemos uma camada limite laminar a um gradiente de pressões positivo, segundo o número de Reynolds, esta reage de diferentes formas, como pode ser visto na Figura 19. Portanto, em termos gerais, para baixo número de Reynolds (condição do modelo) a camada limite laminar tenderá a separar-se, entretanto, para altos Reynolds, esta tenderá a desestabilizar-se e transicionar para o regime turbulento.

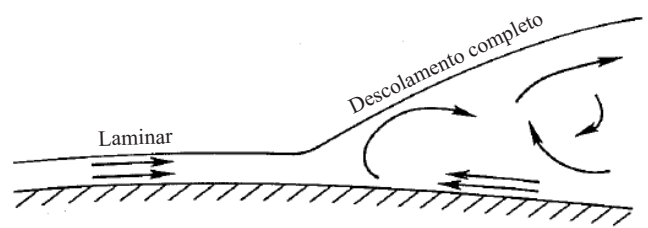

(a)

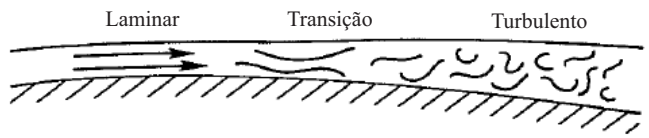

(b)

Figura 19 - Camada limite: (a) Baixo número de Reynolds. Separação completa da camada limite e estol. (b) Alto número de Reynolds. Transição laminar-turbulenta.

Para altos números de Reynolds (condição do protótipo), a camada limite laminar é menos estável e a transição para a camada turbulenta ocorre antes. A camada limite turbulenta é forte e capaz de suportar grandes gradientes de pressão antes da separação. Por outro lado, para baixo número de Reynolds, a camada limite laminar é mais estável e resistente à transição. A camada limite turbulenta é débil, e capaz de tolerar apenas ligeiros gradientes de pressão. Para um aerofólio gerar sustentação deve existir um gradiente de pressões entre as superfícies inferior e superior do mesmo, e para garantir que a sustentação seja adequada é necessário uma camada limite turbulenta, o que leva a um alto número de 
Reynolds.

Na Figura 20 e Figura 21 podem ser observadas as curvas de $C_{L}$ vs $\alpha$ e $C_{D}$ vs $\alpha$ para o perfil aerodinâmico NACA 65(3)618 para os números de Reynolds, $5 \cdot 10^{6}$ (alto), $5 \cdot 10^{5}$ (médio) e $5 \cdot 10^{4}$ (baixo).

Observa-se como para altos números de Reynolds os valores de sustentação são mais elevados e os de arrastro menores. Portanto, o estol acontece para ângulos de ataque maiores, isto é, a sustentação do aerofólio é prolongada por mais tempo. Por outro lado, observa-se como para baixos números de Reynolds o desempenho do aerofólio apresenta um pior desempenho, valores de sustentação baixos e de arrastro altos.

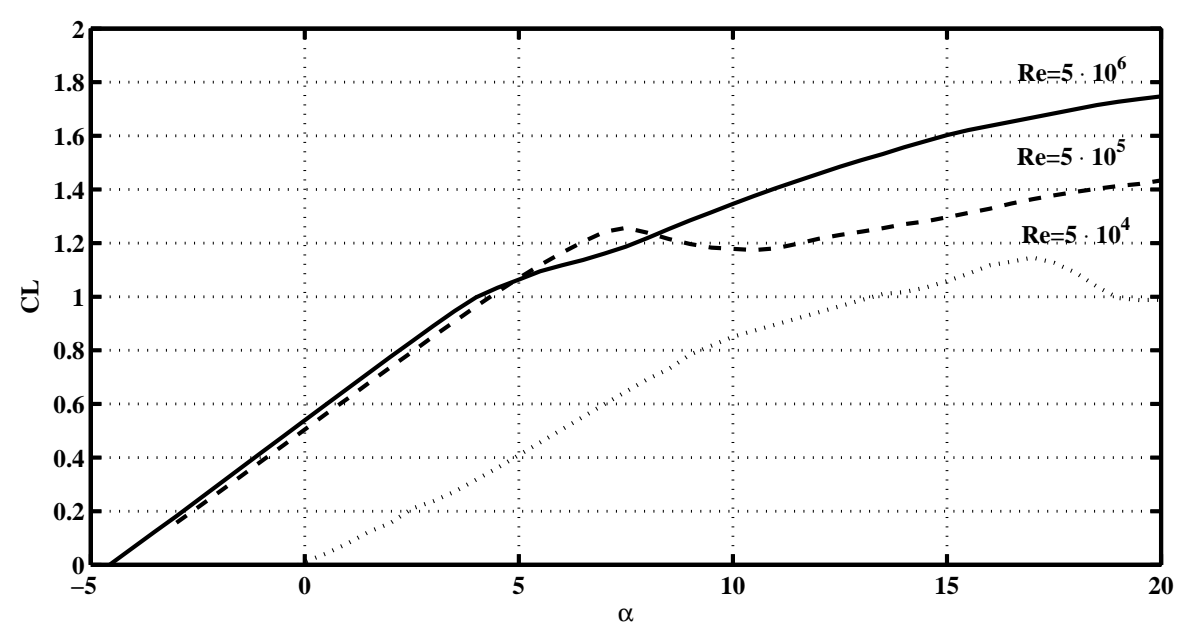

Figura 20 - Curvas $C_{L}$ vs $\alpha$ para vários números de Reynolds (NACA 65(3)618). Simulações XFOIL com $N_{\text {crit }}=9$, para os casos de $R e=5 \cdot 10^{6}$ e $R e=5 \cdot 10^{5}$, e $N_{\text {crit }}=5$ para $R e=5 \cdot 10^{4}$. 


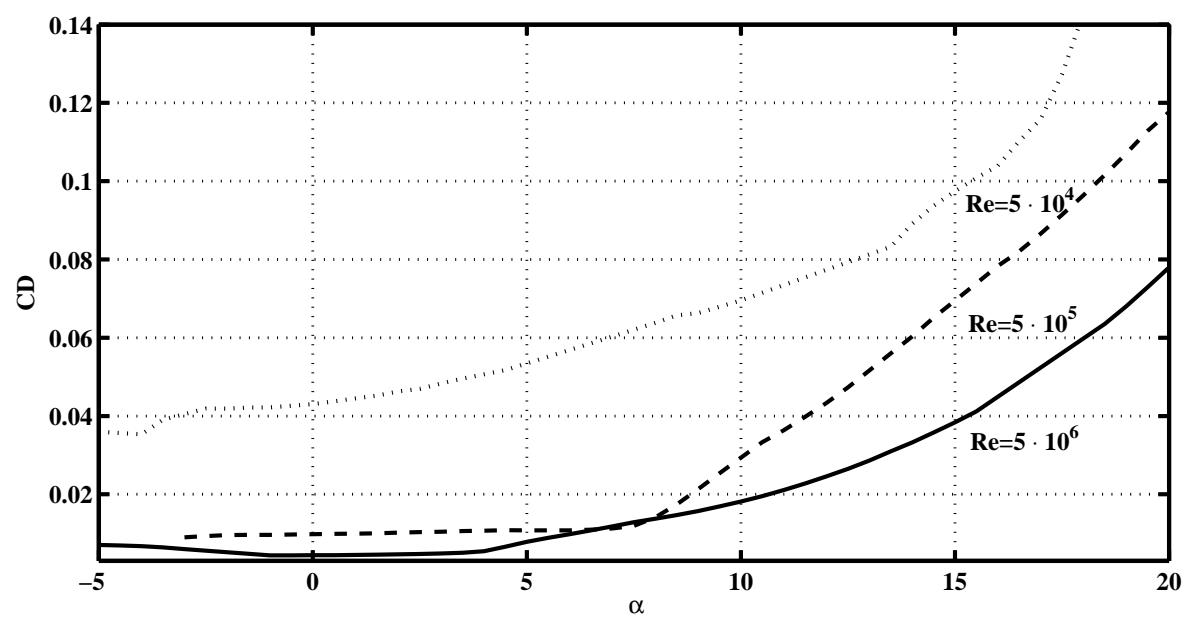

Figura 21 - Curvas $C_{D}$ vs $\alpha$ para vários números de Reynolds (NACA 65(3)618). Simulações XFOIL com $N_{\text {crit }}=9$, para os casos de $R e=5 \cdot 10^{6}$ e $R e=5 \cdot 10^{5}$, e $N_{\text {crit }}=5$ para $R e=5 \cdot 10^{4}$.

Neste trabalho, o aerofólio utilizado foi escolhido para o protótipo de turbina operando em água, isto é, com alto número de Reynolds. No caso do modelo reduzido, operando em ar, com baixo número de Reynolds, o aerofólio utilizado foi o mesmo porém, o desempenho aerodinâmico ficou comprometido. Isto devido a que aerofólios desenvolvidos para altos $R e$, porém, operando em baixo $R e$, levam a valores muito menores de sustentação e maiores arrastos em relação aos valores de projeto, com a consequente diminuição da eficiência aerodinâmica, que nas aplicações em turbinas, leva a uma diminuição de desempenho do rotor.

Perfis aerodinâmicos com números de Reynolds menores que $10^{5}$ tem sido objeto de vários estudos nos últimos anos. O desenvolvimento de aerofólios para baixos números de Reynolds e a introdução de 'turbulators' contribuíram para o aumento da eficiência aerodinâmica deste tipo de aerofólios e, consequentemente, na melhora do desempenho de modelos reduzidos de turbinas que operam com baixos Re. Os 'turbulators' são dispositivos colocados nas pás que induzem a transição do escoamento laminar para o turbulento na camada limite, e são usados para eliminar as bolhas originadas da separação laminar e retardar a separação do lado de sucção para altos ângulos de ataque (CAMPAGNOLO, 2013). Neste trabalho foram usados 'turbulators', na forma de 'transiton strip', para amenizar os efeitos do baixo número de Reynolds na eficiência aerodinâmica dos perfis das pás e, portanto do desempenho da turbina.

Na Figura 22 apresenta-se a variação do coeficiente de sustentação em baixo Reynolds, $5 \cdot 10^{4}$, para o perfil NACA $65(3) 618$ com e sem adição de 'transition strips'. Isto é, forçou-se a transição laminar-turbulenta no perfil aerodinâmico em $20 \%$ da corda para alcançar um melhor desempenho. 


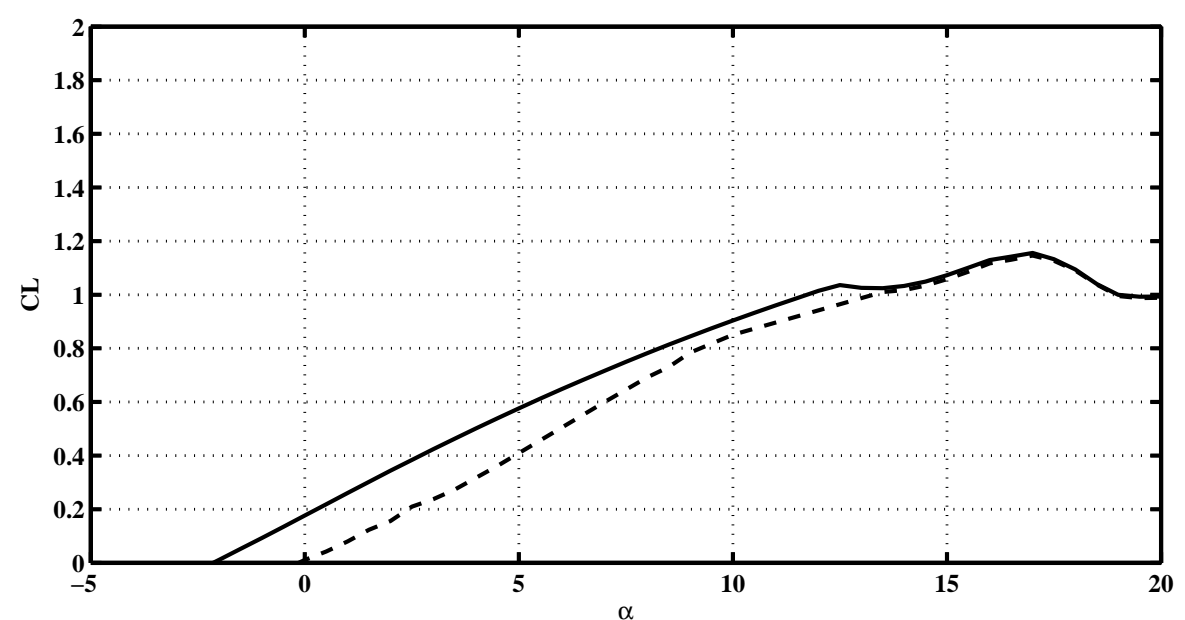

Figura 22 - Curva $C_{L}$ vs $\alpha$ (NACA 65(3)618). Simulações XFOIL com $N_{\text {crit }}=5$. - : 'transition strip' em $20 \%$ da corda; - - : Sem 'transition strip'

O desempenho de pás de turbinas hidrodinâmicas dependem do comportamento hidrodinâmico sobre cada seção das pás, portanto, os coeficientes de sustentação e arrastro no aerofólio determinarão a estimativa de $C_{p}$, tal e como foi visto na metodologia BEM.

Para o modelo e o protótipo a hidrodinâmica é bem diferente, no que concerne aos efeitos de transição laminar-turbulenta e a separação da camada limite. Isso torna muito difícil uma transposição universal entre modelo-protótipo, no entanto, este problema será discutido no próximo capítulo.

\subsection{Condições de similaridade}

As leis de escala tem a capacidade de converter as informações obtidas de um modelo em escala reduzida para seu protótipo em grande escala. As leis de escala tem validade sempre e quando exitam as condições de similaridade entre modelo e protótipo. As principais condições de similaridade que devem ser respeitadas para que uma máquina tenha comportamento similar ao seu modelo são as condições geométricas, cinemáticas e dinâmicas.

A similaridade geométrica é baseada no comprimento característico, $L_{0}$, e deve ser considerada em primeiro lugar. Um modelo e um protótipo são geometricamente similares se e somente se todas as dimensões do corpo conservam a razão de escala linear nas trés coordenadas (Equação 2.72). O principal problema na fabricação de um modelo que respeite a similaridade geométrica é replicar as características físicas do seu protótipo, tais 
como rugosidade específica, folgas e espessura.

$$
L_{0}=\frac{L_{M}}{L_{P}}=\text { constante, }
$$

A similaridade cinemática requer que modelo e protótipo tenham a mesma razão de escala de comprimentos(Equação 2.72) e tempos característicos (Equação 2.73).O resultado será que a razão de velocidade será a mesma para ambas as máquinas, em módulo e direção. Portanto, a razão de tempos característicos é expressada como

$$
t_{0}=\frac{t_{M}}{t_{P}}=\text { constante }
$$

e a razão de velocidades,

$$
v_{0}=\frac{v_{M}}{v_{P}}=\text { constante }
$$

Em máquinas de fluxo, a condição de similaridade cinemática será respeitada se os triângulos de velocidade foram semelhantes. Isto é, se as razões de velocidade de ponta de pá $(\lambda)$ mantem a semelhança. Portanto, $\lambda_{M}=\lambda_{P}$.

Por último, existe a semelhança dinâmica quando o modelo e o protótipo têm as mesmas razões de escala de comprimento, escala de tempo e escala de força. Sendo que a similaridade dinâmica existe simultaneamente com as similaridades geométricas e cinemáticas. Neste caso, as forças atuantes em modelo e protótipo terão a mesma razão de forças, em módulo e direção, entre modelo e protótipo.

$$
F_{0}=\frac{F_{M}}{F_{P}}=\text { constante, }
$$

A similaridade dinâmica pode ser também expressa como a razão entre os números de Reynolds dos dois escoamentos, já que o número de Reynolds relaciona as forças de inercia e viscosas atuantes em um fluido (Vide Equação 2.71). Normalmente, a discrepância entre os números de Reynolds das máquinas é grande e maior ainda se o fluido de trabalho é diferente para ambos os casos, como no caso deste trabalho, onde o protótipo trabalha em água e o modelo em ar. Portanto, a similaridade dinâmica entre um modelo e um protótipo é quase impossível de ser reproduzida. 


\section{Metodologia experimental}

Como dito anteriormente, o objetivo principal desta dissertação é a transposição de resultados de desempenhos hidrodinâmicos de rotores de turbinas com diferentes dimensões (modelo e protótipo). Pretende-se a partir das curvas de $C_{p}$ vs. $\lambda$ do modelo reduzido, obtidas mediante ensaios em túnel de vento, estimar a performance do protótipo operando em água realizando uma transposição de resultados. Os ensaios em túnel de vento também são usados para avaliar as simulações numéricas, apresentadas no Capítulo 4.

Neste capítulo apresenta-se a metodologia experimental empregada nos ensaios do modelo reduzido de turbina no túnel de vento, assim como uma descrição do modelo e dos instrumentos de medição usados para coleta de dados. Por último, é realizado uma análise sobre a transposição de resultados.

\subsection{Túnel de vento}

Os ensaios experimentais foram realizados no túnel de vento de circuito aberto do Laboratório de Energia e Ambiente da Faculdade de Tecnologia da Universidade de Brasília (UnB). A seção de testes tem dimensões de 1,2 m de altura, 1,2 m de largura e $2 \mathrm{~m}$ de comprimento. O ventilador está situado na saída do túnel e é acionado por um motor elétrico modelo WEG W22 de 10 HP, aspirando o ar desde a entrada do túnel até a saída, e a sua velocidade é controlada por meio do inversor CFW-09 Vectrue Inverter 10A 3CV. O fator de redução da área do bocal para a secção de testes é de 3,4:1,2. A velocidade do fluxo ar no interior do túnel pode variar entre 0 e $20 \mathrm{~m} / \mathrm{s}$. A intensidade de turbulência está em volta de $1 \%$ e camada limite no interior da seção de testes, onde a turbina é posicionada, é de $8 \cdot 10^{-3} \mathrm{~m}$. Nas Figura 23 e Figura 24 pode-se ver o túnel de vento utilizado neste trabalho, assim como suas dimensões (cotas em m). 

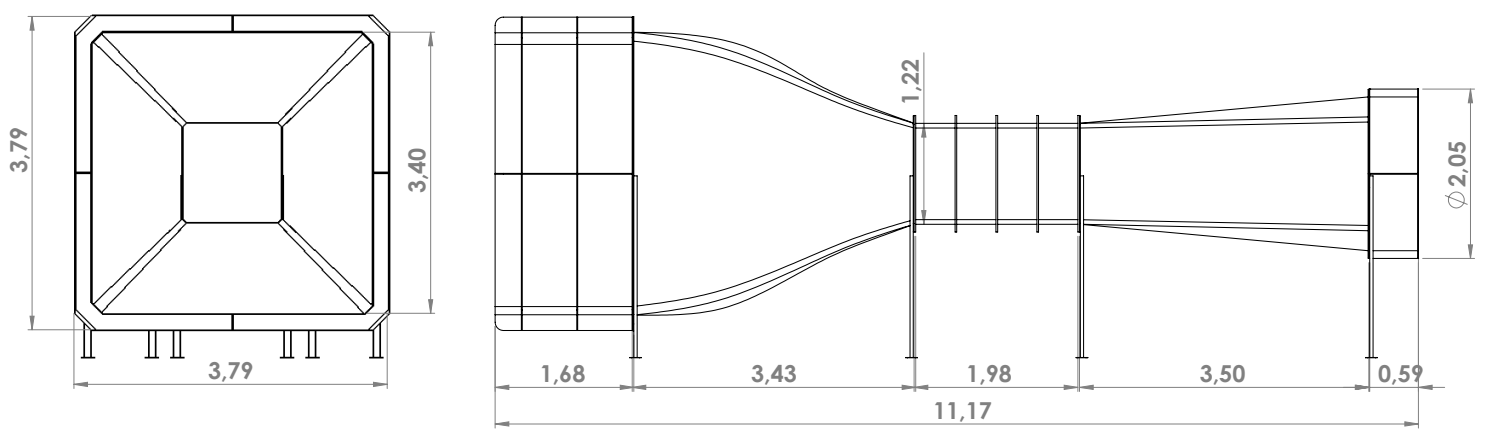

Figura 23 - Vistas acotadas (m) do túnel de vento do Laboratório de Energia e Ambiente da Faculdade de Tecnologia da UnB

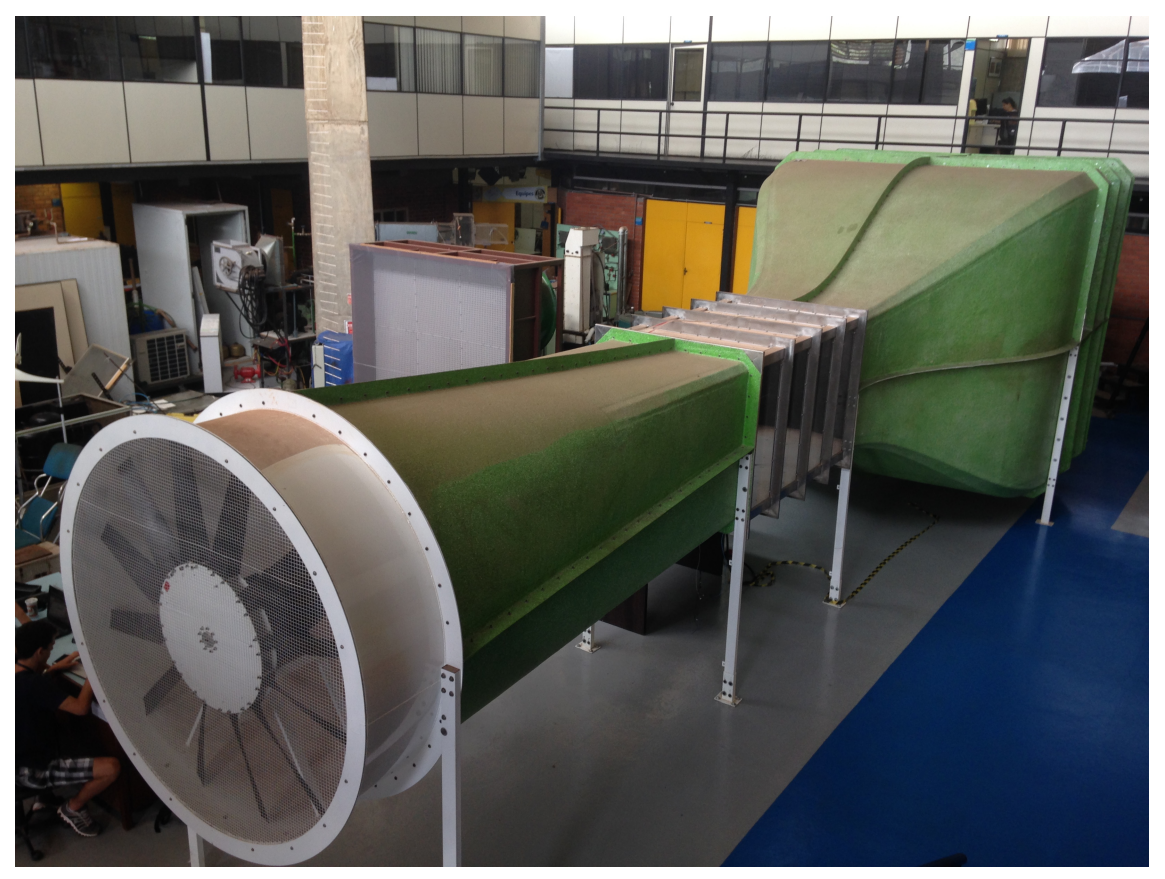

Figura 24 - Túnel de vento do Laboratório de Energia e Ambiente da Faculdade de Tecnologia da UnB 


\subsection{Modelo reduzido}

O modelo reduzido de turbina de eixo horizontal foi construído com um diâmetro de $500 \mathrm{~mm}$, buscando minimizar os efeitos de bloqueio no túnel de vento e de escala.

Os efeitos de bloqueio no interior do túnel de vento diminuem quanto menor é o tamanho do modelo. Por outro lado, os efeitos de escala correspondem às discrepâncias entre modelo e protótipo devido à falta de similaridade geométrica, cinemática e/ou dinâmica.

As similaridades geométricas e cinemáticas são facilmente obtidas. Porém, conseguir a similaridade dinâmica é um fator mais complexo já que é regida pelas forças dos dois escoamentos.

A similaridade dinâmica é baseada em números de Reynolds similares entre modelo e protótipo, e portanto, depende diretamente do tamanho do modelo. Neste sentido, procura-se que o modelo seja o maior possível para conseguir a similaridade dinâmica.

Portanto, como foi colocado anteriormente, o tamanho do modelo reduzido tem que ser otimizado de forma que se minimizem os efeitos de bloqueio e de escala, respectivamente. Sendo assim, o fator de escala escolhido para o modelo reduzido foi 1:20, e foi definido como

$$
\text { fator escala }=\frac{\text { Diâmetro protótipo }}{\text { Diâmetro do modelo }} \text {. }
$$

A construção do modelo foi feita respeitando os detalhes geométricos do protótipo na medida do possível, porém, conseguir a similaridade geométrica implica manter rugosidade, folgas, espessuras, o que torna a fabricação do modelo muito complexa.

A turbina, motivo de estudo neste trabalho, é uma turbina axial de eixo horizontal e três pás. Os perfis usados nas pás são do tipo NACA 65(3)618. As pás foram usinadas a partir de uma placa de resina de poliuretano e epoxi em uma máquina CNC de três eixos. Na Figura 25 pode ser observado o modelo reduzido no interior do túnel de vento. O modelo é localizado no interior da seção de testes a 1,2m da entrada da mesma, e seu eixo de rotação está situado aproximadamente no meio da seção de teste, a $583 \mathrm{~mm}$ da superfície inferior do túnel. 


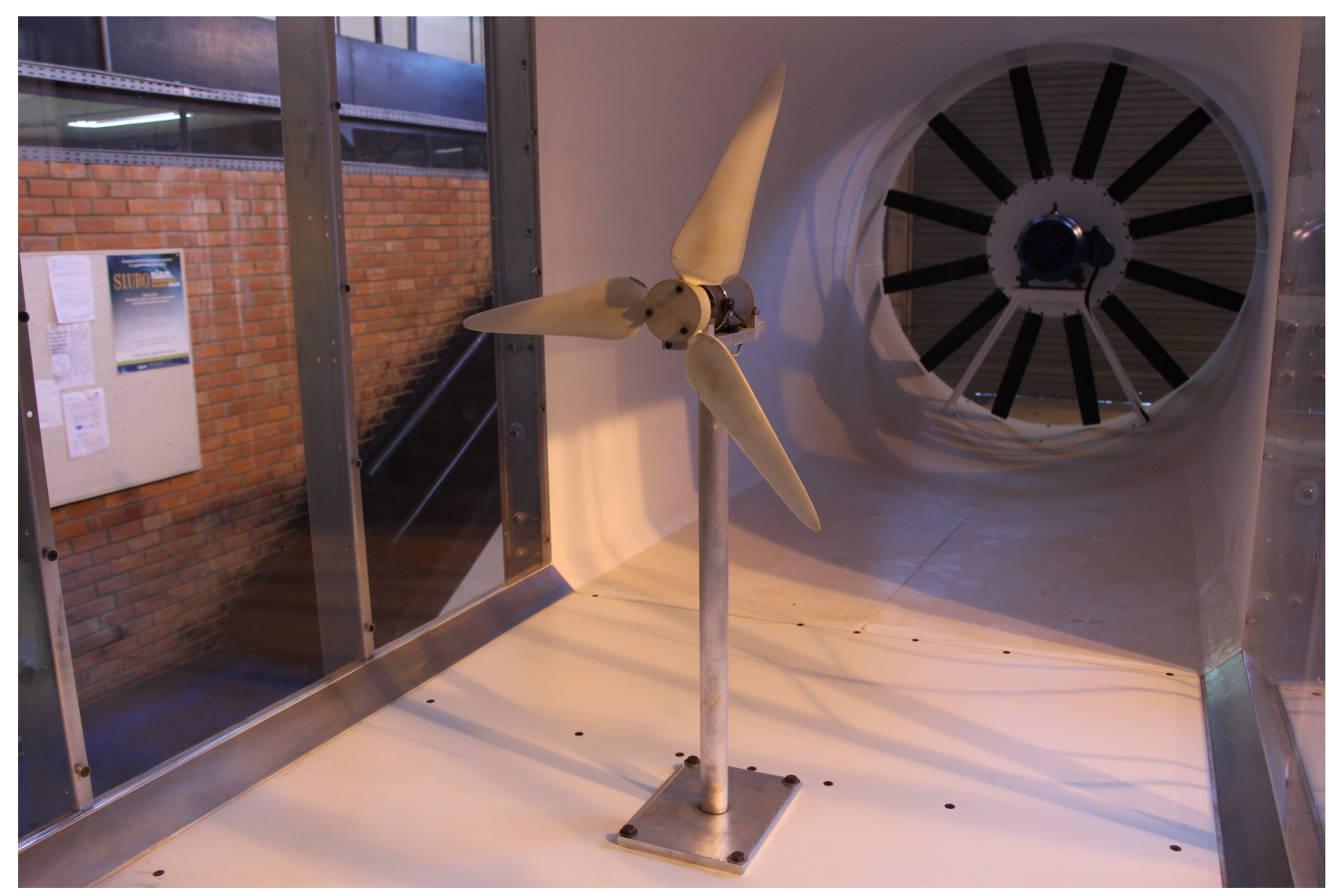

Figura 25 - Modelo reduzido no interior do túnel de vento.
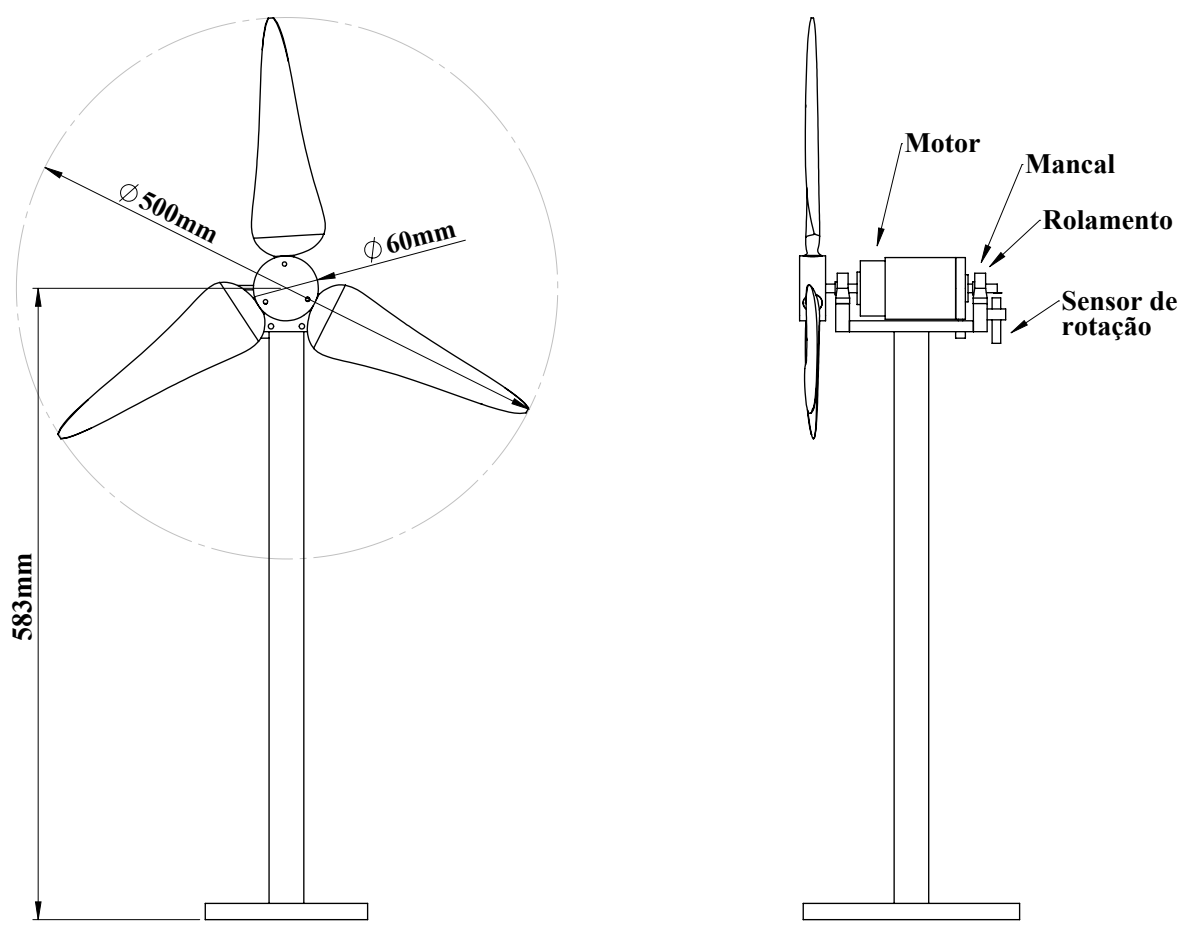

Figura 26 - Esquema do modelo reduzido 
O rotor da turbina é acoplado diretamente ao eixo de um motor elétrico DC de imã permanente (Electro-Craft 110W). O motor é usado como freio eletromagnético e permite controlar a velocidade de rotação da turbina mediante uma modulação de carga PWM e um sistema de controle PID. O motor é colocado em balanço para poder medir diretamente o torque a partir de uma célula de carga, e é apoiado sobre dois rolamentos esféricos posicionados no topo da estrutura que suporta o sistema da turbina. Nas Figura 26 e Figura 27 podem ser observados detalhes da montagem do motor em balanço.

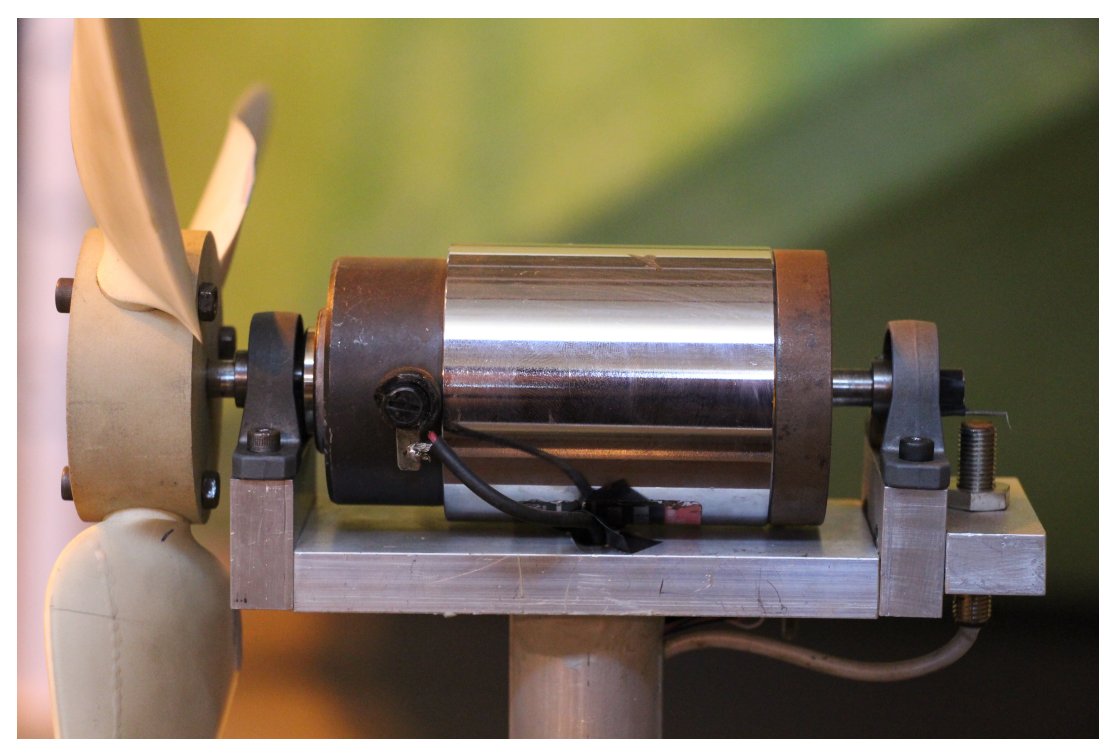

Figura 27 - Detalhe da montagem do motor em balanço sobre a estrutura

\subsection{Técnicas experimentais}

O objetivo específico dos ensaios foi o levantamento da curva de $C_{p}$ vs. $\lambda$ da turbina. No entanto, para caracterizar a uniformidade do escoamento no túnel foram tomadas medidas do perfil de velocidade em uma seção escolhida na frente da turbina e a intensidade de turbulência no ponto central desta seção. Estes resultados são apresentados nos APÊNDICES B e C.

Durante os ensaios no túnel de vento foram coletados dados de pressão, temperatura e velocidade do ar escoado, e de velocidade de rotação e torque da turbina. Para ajudar na visualização e compreensão das experiências, a Figura 28 apresenta um esquema da montagem da instrumentação e do modelo reduzido no interior do túnel de vento durante os testes experimentais. 


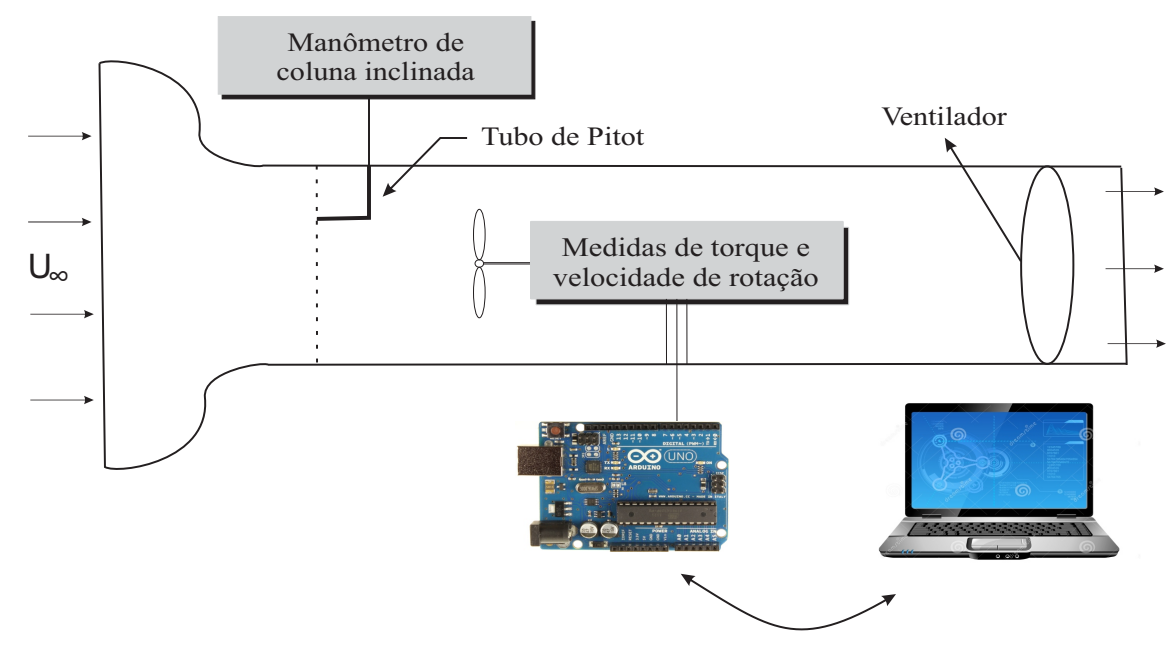

Figura 28 - Esquema do ensaio experimental do modelo reduzido

\subsubsection{Medidas de Pressão, Temperatura e Velocidade do escoamento livre}

A temperatura do fluxo de ar foi medida junto com a umidade relativa como o sensor digital DTH22 modelo AM2303 (range temperatura:-40 - $125{ }^{\circ} \mathrm{C}$ e precisão 0,1 ${ }^{\circ} \mathrm{C}$ ). A pressão estática foi medida com o sensor de pressão barométrica BMP180 (range pressão:300-1000hPA e precisão 0,01 Pa). Os sensores de pressão e temperatura foram embutidos na parede da seção de testes do túnel de vento e os dados foram coletados através de um computador conectado ao microcontrolador ARDUINO. A densidade $(\rho)$ foi calculada pela equação dos gases ideais como,

$$
\rho=\frac{P_{\infty}}{R_{a} T_{\infty}}
$$

onde $R_{a}$ é a constante dos gases ideais para o ar $8,314\left(\mathrm{~Pa} \mathrm{~m}^{3} / \mathrm{molk}\right)$ e $T_{\infty}(\mathrm{K})$ e $P_{\infty}(\mathrm{Pa})$ são temperatura e pressão do ar escoado no interior do túnel de vento. O erro na medida de densidade é menor que $0,05 \%$.

A velocidade do escoamento no interior do túnel é calculada a partir da medida de pressão usando um tubo de Pitot localizado na parte superior direita do túnel de vento a $20 \mathrm{~cm}$ da entrada da seção de testes, $14 \mathrm{~cm}$ da parede lateral e $10 \mathrm{~cm}$ da parede superior. A pressão dinâmica foi medida a partir da diferença entre a pressão estática e a pressão total com um manômetro de coluna inclinada de resolução $0,05 \mathrm{mmH}_{2} \mathrm{O}$ e fundo de escala 12,5 $\mathrm{mmH}_{2} \mathrm{O}$ conectado ao tubo de Pitot. O erro na medida da velocidade do escoamento livre é de $0,3 \%$. 

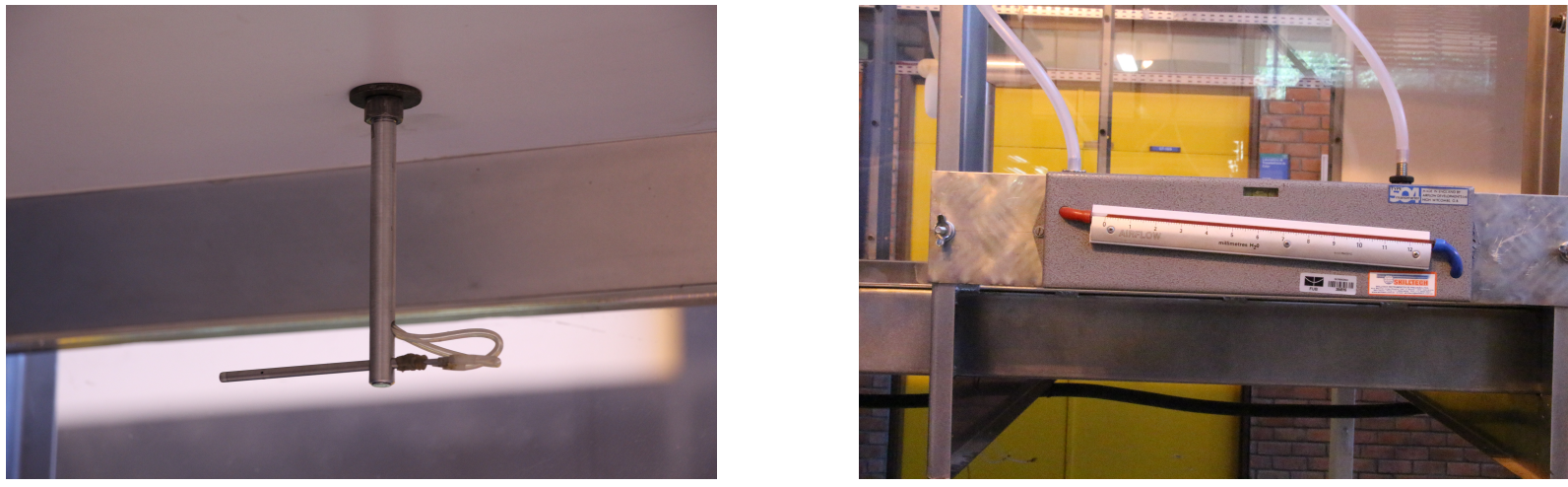

Figura 29 - Tubo de Pitot no interior do túnel de vento e manômetro de coluna inclinada

\subsubsection{Medida de Torque}

O torque do modelo é medido diretamente por meio de uma célula de carga tomada de uma balança digital de precisão $0.1 \mathrm{~g}$, e foi calibrada usando um sistemas de pesos conhecidos. A célula de carga registra a força vertical que um braço conectado ao gerador exerce sobre ela. A transmissão da força entre o freio e a balança é feita a través do braço metálico, como pode ser observado nas Figura 30 e Figura 31.

O torque é calculado pelo produto da força medida na célula de carga vezes a distância do ponto onde é aplicada a força. Esta distância, 54,3 mm, é apresentada na Figura 31. Os valores de força medidos pela célula de carga foram amplificados usando o amplificador HX711 e coletados através de um computador conectado ao microcontrolador ARDUINO. O erro obtido na medida de torque depende da faixa de velocidade de operação da turbina. Existe uma faixa de velocidade, correspondente ao estol e pós-estol aerodinâmico nas pás, em que a performance da turbina fica instável e apresenta vibrações estruturais. Nestes casos, o erro obtido na medida de torque está em volta de 7\%. Para as faixas de rotação de normal desempenho o erro é aproximadamente $2 \%$.
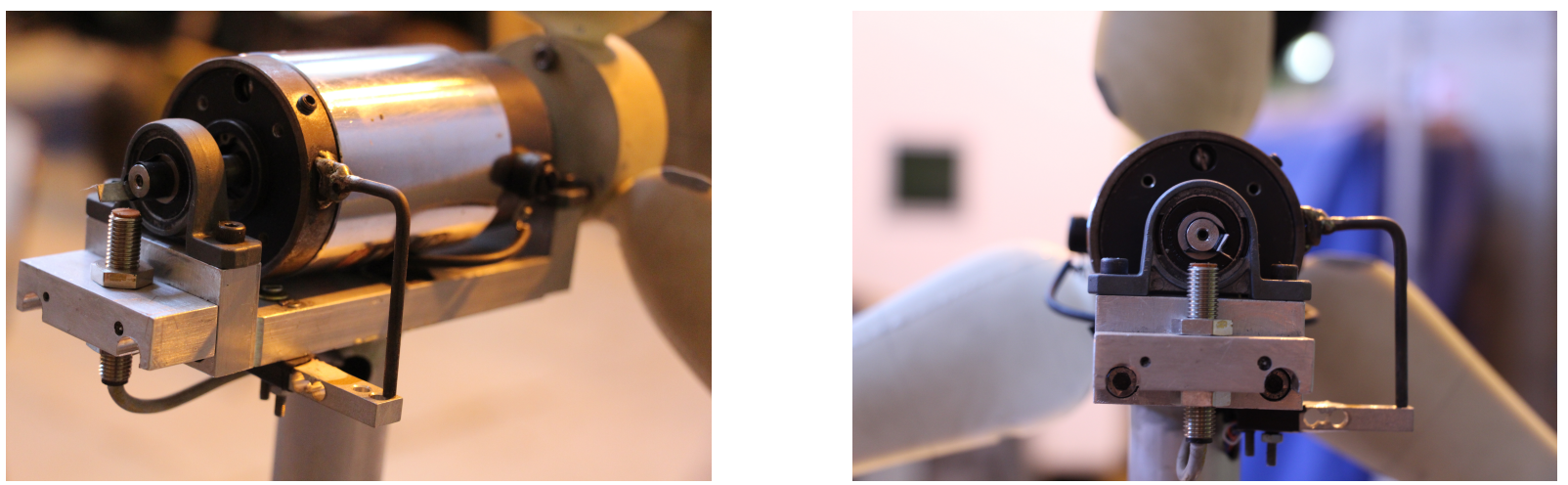

Figura 30 - Detalhe da célula de carga e o braço metálico e do sensor de proximidade indutivo 


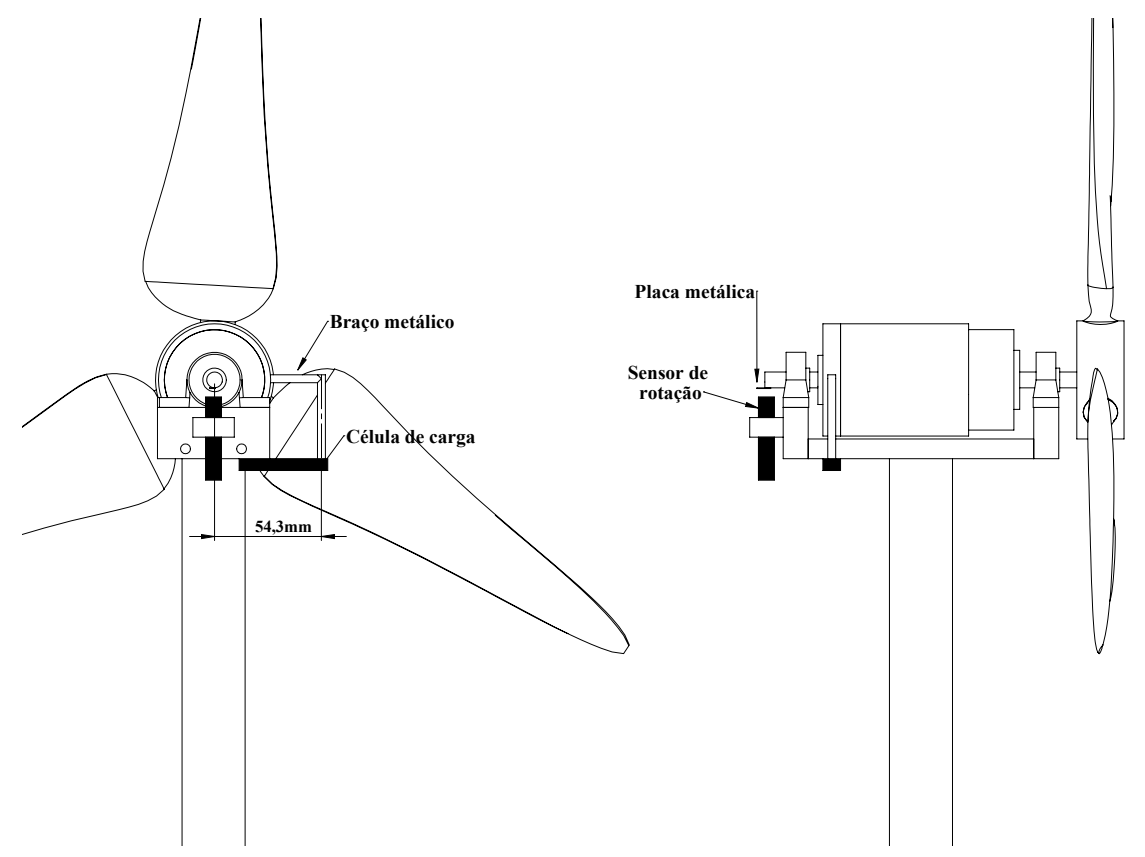

Figura 31 - Esquema dos sensores utilizados no modelo reduzido para medidas de velocidade e torque

\subsubsection{Controle de velocidade}

O intuito do controle da velocidade da turbina é conseguir uma performance estável em várias faixas de rotação. Tendo como fim o levantamento da curva de $C_{p}$ vs. $\lambda$, é preciso obter dados de velocidade de rotação e torque para vários pontos de funcionamento.

A velocidade de rotação da turbina foi medida a partir de um sensor indutivo de proximidade BHS LM8, fixado na parte traseira da estrutura que suporta a turbina. O sensor de proximidade detecta peças metálicas sem que o contato físico exista, sendo assim, uma pequena chapa metálica foi fixada ao eixo na sua parte traseira. Os pulsos por revolução detectados pelo sensor são contados usando o microcontrolador ARDUINO, obtendo assim o valor da velocidade de rotação em revoluções por minuto (rpm). O erro na medida de velocidade é aproximadamente $1 \%$. O sensor de rotação pode ser visto na Figura 30.

O circuito utilizado para controle da velocidade durante os ensaios da turbina é mostrado no esquema apresentado na Figura 32. O gerador do modelo reduzido é conectado a uma resistência externa e um transistor do tipo IRFZ48N encarregado de abrir e fechar o circuito. O transistor controla a conexão da resistência ao gerador e portanto, varia a quantidade de 'freio' sobre o sistema. O controle é feito a partir de um controlador do tipo proporcional integral derivativo (PID) que modula a carga aplicada ao sistema.

Foi preciso que a resistência externa fosse o menor possível, para que a carga aplicada fosse tão grande que o sistema freasse até velocidades de rotação em torno dos 


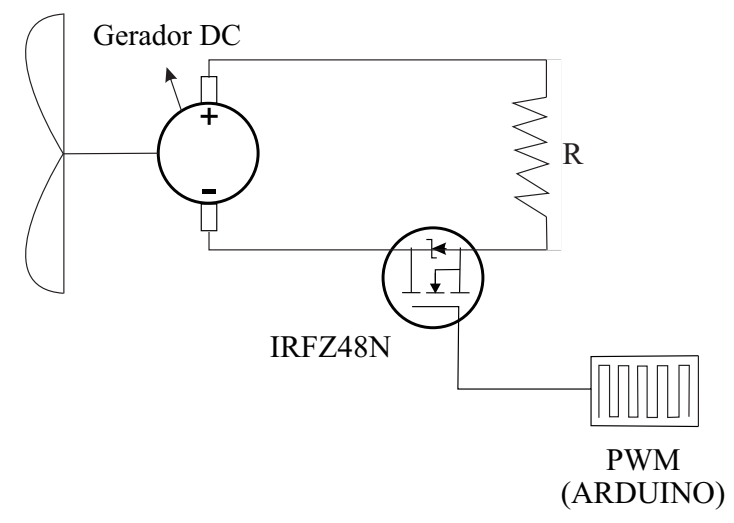

Figura 32 - Esquema do circuito elétrico para modulação da carga aplicada ao rotor

$300 \mathrm{rpm}$. Permitindo um amplo intervalo de velocidades para o levantamento de uma curva completa de $C p$ vs. $\lambda$. Sendo assim, após vários testes a resistência externa escolhida foi apenas a intrínseca do sistema, resistência dos fios e do motor. O qual implicou deixar o motor em curto circuito para frear tanto como possível.

A velocidade da turbina foi regulada através do controle do tempo de modulação da carga aplicada no motor. Para isto, foi usada a técnica de modulação PWM (Pulse Width Modulation), onde o período de um sinal periódico é modificado. O PWM é uma modulação digital cíclica que controla o tempo que a onda permanece em sua amplitude máxima pela porcentagem do tempo de trabalho (Duty Cycle). O PWM é criado pelo microcontrolador ARDUINO.

O tempo de modulação do PWM é regulado por um sistema de controle automático PID da velocidade. O sistema calcula a diferença entre a velocidade de rotação real da turbina e uma velocidade predeterminada (setpoint), esta diferença é chamada de erro. A partir do erro da velocidade o valor do controlador PID é calculado e usado para regular o tempo de modulação do PWM, aumentando ou diminuindo a carga para atingir a velocidade requerida. Segundo o valor do PID, o PWM tomará um valor ou outro regulando a carga conectada ao gerador e assim a velocidade de rotação da turbina. Fisicamente, o transistor é o componente encarregado de abrir e fechar o circuito no tempo de modulação estabelecido. 

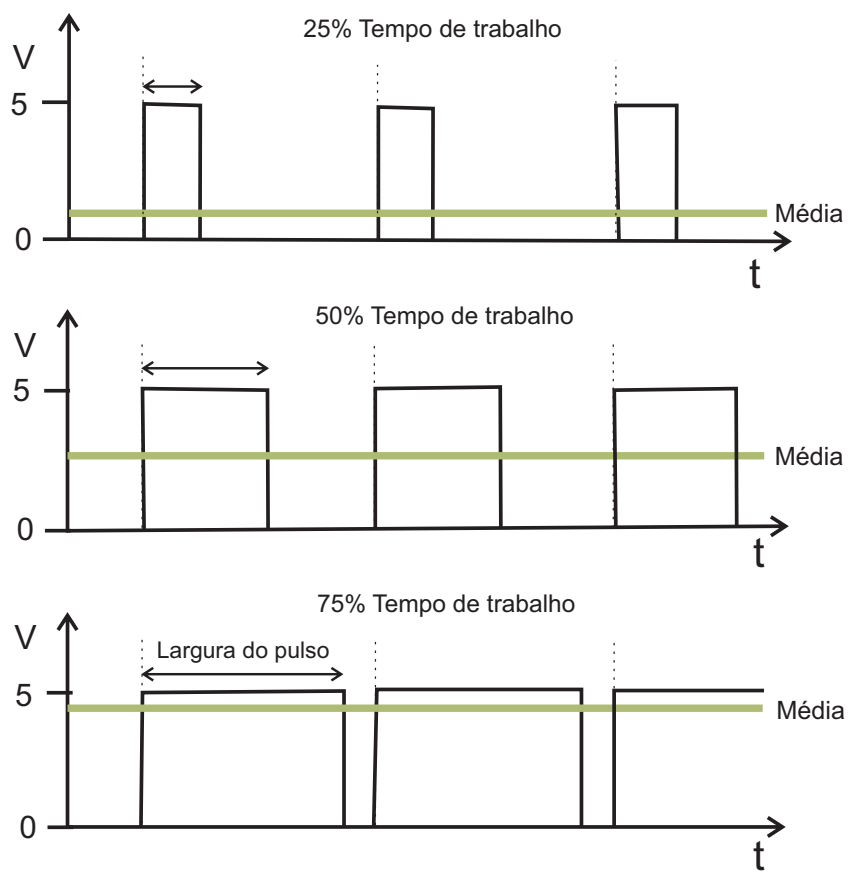

Figura 33 - Modulação por largura de pulso (PWM)

Na Figura 33 apresenta-se a modulação PWM para diferentes tempos de trabalho. As linhas pontilhadas representam o período de tempo, inverso à frequência do PWM, que no caso de ARDUINO é 500hz. Quando o PWM trabalha com 50\% da carga, a onda fica $50 \%$ do tempo em sua amplitude máxima e 50\% em sua amplitude mínima, portanto, o transistor ficará metade do tempo aberto e metade fechado, resultando a carga aplicada ao gerador a carga média.

Nos casos extremos, temos que quando a onda do PWM permanece em sua amplitude máxima (100\% do tempo de trabalho) o transistor se encontra fechado fazendo com que o gerador fique em curto circuito. Por outro lado, quando a modulação do PWM é $0 \%$ do tempo de trabalho o transistor estará aberto deixando o gerador sem carga.

No esquema apresentado na Figura 34 apresenta-se o diagrama de blocos que representa o controle automático PID para a velocidade de rotação da turbina. O código foi implementado usando o microcontrolador ARDUINO conectado ao circuito da Figura 32.

Os parâmetros do PID foram calculados usando o método de sintonização de Ziegler-Nichols de malha fechada. Em primeiro lugar, aplicando o degrau na planta foi determinada a ganancia crítica, $K_{\text {crítico }}=2$, considerando apenas o ganho proporcional, isto é, fazendo $T_{d}$ igual a zero e $T_{i}$ igual a infinito. A ganancia crítica é o valor da ganancia proporcional que faz com que o sistema oscile de forma mantida ante qualquer perturbação. 


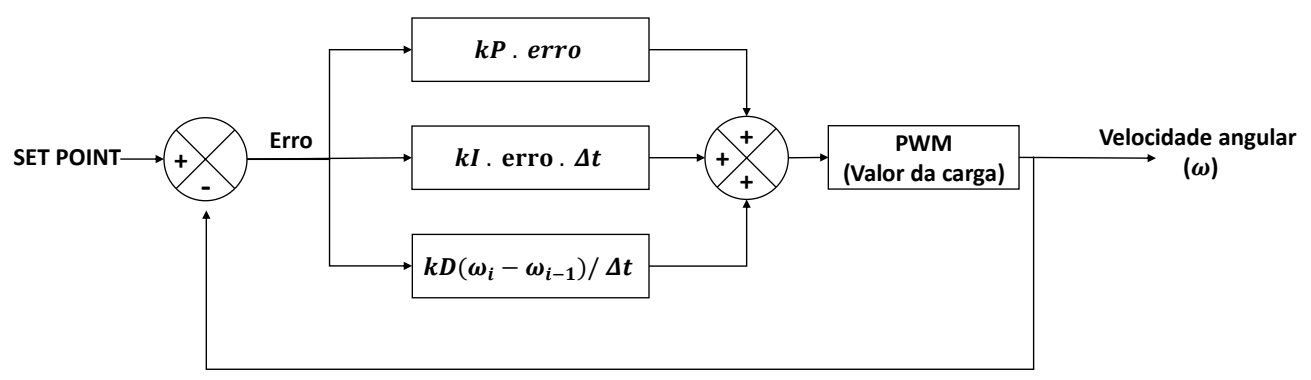

Figura 34 - Diagrama de blocos do sistema de controle da velocidade PID Fonte: (MENDES, 2015)

Posteriormente, foram determinadas a frequência de oscilação e o período crítico, $T_{c}$, com os quais foram calculados os parâmetros do controlador.

No ensaio do modelo em malha fechada para $K_{\text {crítico }}=2$ foi obtido o valor do período crítico $T_{\text {crítico }}=0,5$. Com esses dados foram de terminados $K_{p}, T_{i}$ e $T_{d}$ a partir da tabela de sintonização de Ziegler-Nichols.

Tabela 1 - Tabela de sintonização de Ziegler-Nichols para o cálculo dos parâmetros do PID

\begin{tabular}{lll}
\hline \multicolumn{3}{c}{ Parâmetros PID } \\
\hline$K_{p}$ & $0,60 K_{\text {crítico }}$ & 1,20 \\
$T_{i}$ & $0,50 T_{\text {crítico }}$ & 0,25 \\
$T_{d}$ & $0,13 T_{\text {crítico }}$ & 0,06 \\
\hline
\end{tabular}

\subsection{Ensaio do modelo reduzido no túnel de vento}

O objetivo dos ensaios do modelo reduzido no túnel de vento é o levantamento da curva adimensional $C_{p}$ vs. $\lambda$. Os ensaios foram realizados para diferentes velocidades do escoamento livre 8, 10 e $12 \mathrm{~m} / \mathrm{s}$. O procedimento experimental empregado consistiu em manter a velocidade do escoamento constante e variar a velocidade de rotação da turbina mediante um controlador PID, como já foi explicada anteriormente.

O ponto de partida em cada ensaio foi o sistema 'totalmente freado', isto é, 100 $\%$ da carga aplicada. Desse ponto em adiante, a velocidade de rotação foi controlada a cada 200 rpm até atingir a velocidade máxima do sistema que corresponde a $0 \%$ da carga, 'sistema em aberto'.

Em alguns casos, os ensaios foram realizados de forma inversa à descrita acima. Isto é, o ensaio começou com o modelo girando sem nenhum tipo de 'freio', sem carga aplicada no sistema,e gradualmente, fomos aplicando carga no motor até chegar no estado 
de carga máxima. Isto foi feito para conhecer a histerese do sistema. Foi concluído que a histerese é pequena já que as curvas obtidas pelos dois métodos são próximas.

Para analisar a performance da turbina as curvas de $C_{p}$ vs. $\lambda$ são construídas, sendo $C_{p}$ coeficiente de potência e $\lambda$ ou $T S R$ a razão de velocidade de ponta pá. Estes são determinados pelas equações

$$
\begin{gathered}
C p=\frac{P}{\frac{1}{2} \rho A U_{\infty}^{3}}, \\
\lambda=\frac{\omega r}{U_{\infty}},
\end{gathered}
$$

sendo $U_{\infty}$ a velocidade do escoamento, $r$ o raio do rotor, $\omega$ a velocidade de rotação do rotor, $A$ a área do rotor calculada como $A=\pi r^{2}$ e $P$ a potência mecânica no eixo calculada como

$$
P=\tau \omega
$$

onde $\tau$ é o torque no eixo determinado pelo produto da força medida pela célula de carga vezes a componente horizontal da distância do eixo ao ponto de apoio do braço na célula de carga. O erro no coeficiente de velocidade de ponta de pá, TSR, é 1\%. Os erros na potência mecânica e no coeficiente de potência são $7 \%$ na faixa de velocidades correspondentes ao pós-estol nas pás e $2 \%$ no resto de pontos de funcionamento da turbina. Tal e como foi apresentado para as medidas de torque.

\subsection{Correções de Bloqueio}

Um elemento fundamental na análise de resultados experimentais obtidos em túnel de vento é remover os efeitos de bloqueio nos dados medidos. Os efeitos de bloqueio sólido são normalmente desconsiderados, no entanto, os efeitos de parede afetam à expansão do fluxo a jusante e são conhecidos como efeitos de bloqueio na esteira. É sabido que as medidas de empuxo e potência tomadas durante o ensaio em túnel de vento são maiores que se o modelo for testado sem confinamento do escoamento, a dizer, com fluxo livre de ar. A razão de bloqueio (BR) vem definida como o cociente entre a área do disco que representa o rotor e a área da seção de testes do túnel. Neste caso,

$$
B R=\frac{(0,25)^{2} \pi}{(1,2)^{2}}=13,6 \%
$$


Segundo Ryi et al. (2015), Chen e Liou (2011) se a razão do bloqueio é maior que $10 \%$, os efeitos de parede não devem ser ignorados. Sendo assim, será necessário aplicar correção de bloqueio nos dados obtidos dos ensaios no túnel de vento.

Na bibliografia são encontrados vários métodos de correção de bloqueio para ensaios experimentais de turbinas em túnel de vento. Todos eles são baseados no cálculo da velocidade do fluxo livre de ar equivalente $\left(u^{*}\right)$, que corresponde à velocidade medida no túnel $\left(u_{\infty}\right)$ para a turbina nas mesmas condições de funcionamento, velocidade angular, velocidade do disco atuador e empuxo. Isto leva a corrigir os parâmetros que definem a performance do rotor, tal que

$$
\begin{aligned}
T S R^{*} & =T S R\left(\frac{u_{\infty}}{u^{*}}\right), \\
C_{T}^{*} & =C_{T}\left(\frac{u_{\infty}}{u^{*}}\right)^{2}, \\
C_{p}^{*} & =C_{p}\left(\frac{u_{\infty}}{u^{*}}\right)^{3} .
\end{aligned}
$$

A primeira correção de bloqueio foi desenvolvida por Glauert (1933) para hélices em túneis de vento usando as equações de conservação da massa e de momentos considerando o modelo do disco atuador. Para corrigir o efeito de bloqueio na expansão da esteira no caso de turbina Barnsley e Wellicome (1990) fizeram algumas modificações nas equações propostas por Glauert.

Outros métodos são propostos na literatura como é o caso de (MIKKELSEN; SøRENSEN, 2002), (BAHAJ et al., 2007) e (RYI et al., 2015). Todos estes métodos são baseados nas equações de conservação do momento axial usando o modelo do disco atuador, tal como Glauert o fez.

Neste trabalho usaremos as equações propostas por (BAHAJ et al., 2007) para corrigir o efeito de parede na expansão da esteira, devido à simplicidade de resolução do sistema de equações e a similaridade dos resultados obtidos com os aportados na simulação numérica como apresentaram Mikkelsen e Sørensen (2002). Após aplicar os princípios de continuidade e momentos, nas seções A e B, são obtidas as seguintes relações para as velocidades do escoamento no tubo de velocidade (Vide Figura 35). 


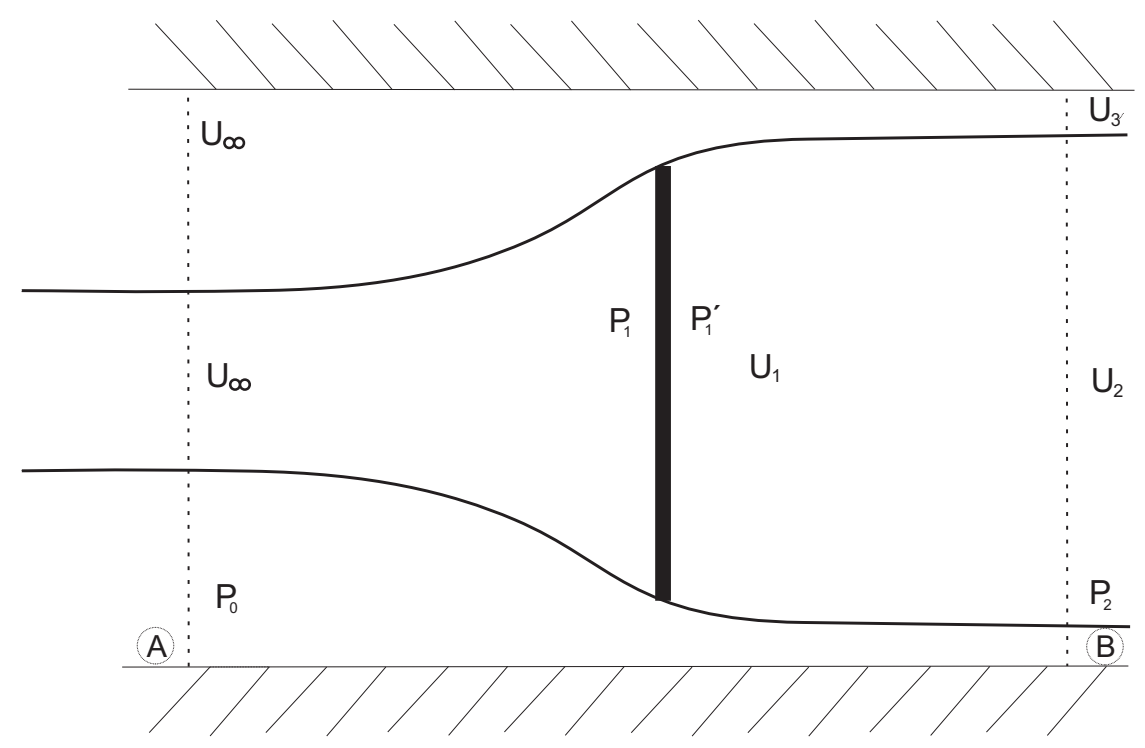

Figura 35 - Esquema do modelo do disco atuador com as velocidades do escoamento em várias seções

$$
\begin{gathered}
\frac{u_{1}}{u_{2}}=\frac{-1+\sqrt{1+B R\left(\left(u_{3} / u_{2}\right)^{2}-1\right)}}{B R\left(\left(u_{3} / u_{2}\right)-1\right)}, \\
\frac{u_{\infty}}{u_{2}}=\frac{u_{3}}{u_{2}}-B R\left[\frac{u_{1}}{u_{2}}\left(\frac{u_{3}}{u_{2}}-1\right)\right], \\
C_{T}=\left(\frac{u_{2}}{u_{\infty}}\right)\left[\left(\frac{u_{3}}{u_{2}}\right)^{2}-1\right],
\end{gathered}
$$

que resulta em

$$
\frac{u_{2}}{u_{\infty}}=\sqrt{\frac{C_{T}}{\left(\left(u_{3} / u_{2}\right)-1\right)}} .
$$

As equações acima são resolvidas mediante um processo iterativo onde se assume um valor para $u_{3} / u_{2}$ e as equações 3.8, 3.9 e 3.11 são resolvidas. O processo continua até obter o mesmo valor de $u_{\infty} / u_{2}$ das equações 3.9 e 3.11. Uma vez conhecidas as relações entre as velocidades em diferentes seções do escoamento é possível obter o valor equivalente da velocidade do fluxo livre de ar $\left(u^{*}\right)$ dada por

$$
\frac{u_{\infty}}{u^{*}}=\frac{u_{1} / u_{\infty}}{\left(u_{1} / u_{\infty}\right)^{2}+C_{t} / 4}
$$


Para resolver as equações temos que estimar um valor para o coeficiente de empuxo $C_{T}$. Este valor é obtido pelas equações BEM através do software Qblade. O valor escolhido para o $C_{T}$ é o correspondente ao $\lambda$ onde o $C_{p m a x}$. Portanto, o $C_{T}$ escolhido é igual a 0,6.

Após resolver o sistema de equações de forma iterativa usando o software Matlab, uma vez conhecido o valor de $C_{T}$, obteve-se o fator de correção de bloqueio, $B F$, tal que,

$$
\frac{u_{\infty}}{u^{*}}=0,97
$$

As curvas experimentais obtidas dos ensaios em túnel de vento serão corrigidas usando o fator de correção de bloqueio. No Capítulo 5 são apresentadas as curvas $C p$ vs. $\lambda$ com e sem correção de bloqueio, que são comparadas com os resultados obtidos na simulação numérica.

Campagnolo (2013)realizou um estudo numérico para validar os diferentes métodos de correção de bloqueio. Apresentou as curvas $C p$ vs. $\lambda$ após análise CFD, considerando o caso da turbina com e sem restrições de parede. Aplicou os métodos de correção de bloqueio para o caso da turbina no interior de um túnel de vento concluindo que os métodos de Bahaj (2013) e de Mikkelsen (2002) são os que fornecem melhores correções. 


\subsection{Análise de transposição modelo-protótipo}

Nesta seção é apresentada a análise de transposição de resultados hidrodinâmicos entre modelo e protótipo realizada. O objetivo é propor uma equação semi-empírica que permita realizar a transposição de escalas entre duas turbinas de diferentes dimensões operando em diferentes fluidos. Pretende-se a partir dos resultados de coeficiente de potencia, $C_{p}$, obtidos durante os ensaios em túnel de vento para o modelo reduzido estimar os valores de $C_{p}$ para o protótipo operando em água.

Como foi colocado anteriormente, a teoria da similaridade diz que uma máquina somente terá o comportamento similar ao seu modelo se forem respeitados os três tipos possíveis de homogeneidades: dimensional, cinemática e dinâmica. É possível conseguir, facilmente, as similaridades geométricas e cinemáticas, porém a similaridade dinâmica, baseada na equivalência entre os números de Reynolds entre modelo e protótipo, é quase impossível de ser reproduzida. No caso de turbinas hidrodinâmicas, fatores inerentes à hidrodinâmica do escoamento sobre pás girantes tais como transição laminar-turbulenta, descolamento da camada limite, entre outros, fazem com que os estudos de transposição de escalas, dependentes do número de Reynolds, não possam ser generalizados devido à complexidade dos fenômenos. No entanto, neste trabalho será proposta uma lei semiempírica para a transposição de escalas entre modelo-protótipo.

Em primeiro lugar, é apresentada uma análise adimensional para conhecer a relação entre as variáveis do problema. A potência obtida para uma turbina de diâmetro característico $D$, velocidade de rotação $\omega$, inserida em um fluido de densidade $\rho$, viscosidade dinâmica $\mu$ e velocidade do escoamento característica $u$ será função destas variáveis, e portanto,

$$
P=f(D, \omega, \rho, \mu, u) .
$$

Pelo teorema $\Pi$ de Buckingham a relação entre a potência e as restantes variáveis pode ser expressada através de três grupos adimensionais tais que,

$$
\frac{P}{\rho D^{2} u^{3}}=f\left(\frac{\rho u D}{\mu}, \frac{\omega D}{u}\right) .
$$

Sendo estos grupos adimensionais comummente expressados como coeficiente de potência (3.16), número de Reynolds (3.17) e TSR (3.18),

$$
\begin{gathered}
C_{p}=\frac{P}{\frac{1}{2} \rho A u^{3}}, \\
R e=\frac{\rho u D}{\mu},
\end{gathered}
$$




$$
T S R=\frac{\omega R}{u}
$$

e portanto, a relação entre a potência da turbina com o resto de variáveis fica como

$$
C_{p}=f(R e, T S R)
$$

O coeficiente de potência, $C_{p}$, é função do número de Reynolds e do TSR, tanto para o modelo como para o protótipo.

A análise de transposição é realizada no ponto de projeto da turbina protótipo correspondente a $\alpha_{\text {opt }}$. Sendo este, o ponto de funcionamento de ambas máquinas, tem-se que $T S R_{\text {mod }}=T S R_{\text {prot }}$. Logo,

$$
\frac{C_{p_{\text {prot }}}}{C_{p_{\text {mod }}}}=f\left(\frac{R e_{\text {prot }}}{R e_{\text {mod }}}\right)
$$

Baseados nas equações da metodologia BEM, uma relação entre entre $C_{p}$ e $R_{e}$ é deduzida. Partindo da equação diferencial da potência, Equação 2.22, e dividindo esta por $0,5 \rho u_{\infty}^{3}\left(\pi R^{2}\right)$, tem-se o coeficiente de potência diferencial, $d C_{p}$, de forma que

$$
d C_{p}=8 \lambda^{2} a^{\prime}(1-a) r^{*} d r^{*}
$$

sendo $r^{*}$ o raio adimensional tal que, $r^{*}=r / R$. Como pode ser observado a Equação 3.21 está escrita em termos do fator de indutor axial, a, e do fator de indução tangencial, $a^{\prime}$. Observa-se pela Equação 2.32 como estas duas variáveis são correlacionadas através do triângulo de velocidades na pá, dado pelo $\lambda_{r}$, de forma que

$$
a^{\prime}=\frac{1}{2}\left[\sqrt{1+\frac{4 a(1-a)}{\lambda_{r}^{2}}}-1\right] .
$$

Por outro lado, se relacionarmos os coeficientes de potência para modelo e protótipo através da Equação 3.21 para o mesmo ponto de funcionamento, o ponto de projeto do protótipo, tem-se que

$$
\frac{d C_{p_{\text {prot }}}}{d C_{p_{\text {mod }}}}=\frac{\left.a^{\prime}(1-a) r^{*} d r^{*}\right|_{\text {prot }}}{\left.a^{\prime}(1-a) r^{*} d r^{*}\right|_{\text {mod }}} .
$$

Os coeficientes de indução axial e radial podem ser calculados a partir da metodologia BEM. O método BEM calcula valores de a e a' para cada partição feita na pá e para cada TSR. Neste caso, a análise realizada foi feita considerando apenas para o raio meio da pá desconsiderando a dependência dos fatores de indução com a posição radial. 
Portanto, a relação entre os coeficientes de potência apresentada na Equação 3.23 fica como

$$
\frac{C_{p_{\text {prot }}}}{C_{p_{\text {mod }}}}=\frac{\left.a^{\prime}(1-a)\right|_{\text {prot }}}{\left.a^{\prime}(1-a)\right|_{\text {mod }}} .
$$

Na Figura 36 é representada a Equação 3.24 para cada TSR. Os valores de coeficiente de potência foram calculados a partir dos valores obtidos da metologia BEM para a e a', para modelo e protótipo, no raio médio da pá para os vários valores de TSR.

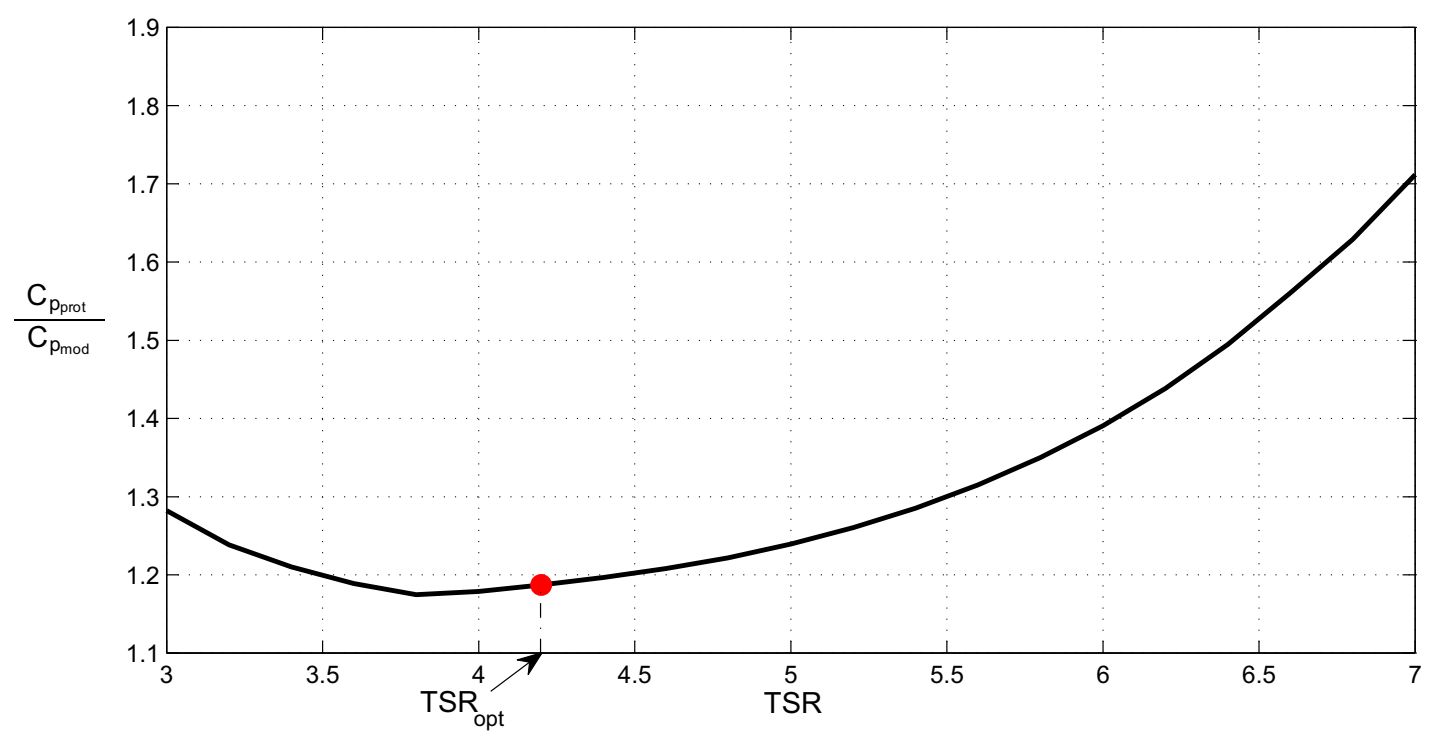

Figura 36 - Relação entre os coeficientes de potência, para protótipo e modelo, $C_{p_{\text {prot }}} / C_{p_{\text {mod }}}$, com TSR para o raio médio da pá.

Na Figura 36 é representado o valor entre os coeficientes de potência no raio médio das pás para o valor de $T S R$ de projeto que corresponde com o $\alpha_{\text {opt }}$. O valor de $C_{p_{\text {prot }}} / C_{p_{\text {mod }}}=1,18$ para $T S R=4,19$.

Baseado no valor obtido para a relação de coeficientes de potência entre modelo e protótipo no ponto ótimo, propõe-se uma lei semi-empírica, dependente do número de Reynolds para qualquer $T S R$, para a transposição de resultados modelo-protótipo, de forma que

$$
\frac{C_{p_{\text {prot }}}}{C_{p_{\text {mod }}}}=\left(\frac{R e_{\text {prot }}}{R e_{\text {mod }}}\right)^{m},
$$


sendo $m$ um fator de escala calculado como,

$$
m=\frac{\log \left[\frac{C_{p_{\text {prot }}}}{C_{p_{\text {mod }}}}\right]}{\log \left[\frac{R e_{\text {prot }}}{R e_{\text {mod }}}\right]}
$$

onde,

$$
\log \left[\frac{C_{p_{\text {prot }}}}{C_{p_{\text {mod }}}}\right]=1,18,
$$

segundo a Equação 3.24. Os números de Reynolds usados são $R e_{\text {prot }}=5,2 \cdot 10^{6} \mathrm{e}$ $R e_{\text {prot }}=8,3 \cdot 10^{4}$, e portanto, o valor de $m$ calculado é $m=0,04$.

Portanto, os valores de $C_{p}$ obtidos para o modelo reduzido durante os ensaios experimentais são transpostos mediante a Equação 3.25, e assim é obtida uma curva de $C_{p}$ vs $\lambda$ que representa o desempenho da turbina protótipo.

O resultado obtido é válido apenas para este caso, não podendo o extrapolar para outros problemas. Já que, como foi colocado anteriormente, não é possível generalizar este resultado devido à complexidade dos fenômenos que ocorrem nas turbinas hidrodinâmicas. Portanto, para a transposição de resultados em outras turbinas o fator de escala, m, deverá ser novamente calculado mediante as equações da metodologia BEM.

Porém, a curva de desempenho obtida para o protótipo em água a partir dos resultados experimentais do modelo reduzido é robusta devido a que os resultados obtidas foram validados usando simulações numéricas CFD e BEM. 


\section{Metodologia numérica}

Nesto capítulo apresenta-se a metodologia empregada no estudo numérico do modelo reduzido de turbina hidrocinética de eixo horizontal e do seu protótipo. A validação dos resultados experimentais e a obtenção da curva de $C_{p}$ vs $\lambda$ do protótipo foram os principais motivos pelos quais foi realizada a simulação numérica, assim como a avaliação detalhada do comportamento hidrodinâmico da turbina.

A dinâmica de fluidos computacional, CFD (Computational fluid dynamics), consiste na resolução das equações diferenciais governantes do escoamento usando aproximação numérica. Em princípio, com uma malha suficientemente refinada a solução obtida representará razoavelmente à realidade do escoamento turbulento tridimensional (SANDERSE; KOREN, 2011).

Neste trabalho as simulações numéricas da turbina de eixo horizontal (modelo e protótipo) foram realizadas pelo software ANSYS CFX R16.1 usando as equações médias de Navier Stokes, RANS (Reynolds-Averaged Navier-Stokes), que proporcionam uma descrição estatística do escoamento. Na metodologia RANS as variáveis das equações de Navier Stokes são divididas em uma parte média e outra flutuante, e modelos de fechamento de correlações estatísticas para o campo flutuante são empregadas. A descrição do escoamento médio portanto, pode ser utilizada.

Nas equações médias de Navier Stokes correlações de flutuações aparecem como $\overline{u_{i}^{\prime} u_{j}^{\prime}}$, conhecidas como tensor de Reynolds. Existem vários modelos para o tensor Reynolds. Os mais usados na literatura são os modelos de duas equações, $k-\epsilon, k-\omega$ e $k-\omega S S T$ (Shear-Stress Transport). O modelo $k-\epsilon$ é usualmente encontrado em aplicações de esteira de turbinas eólicas. Este modelo funciona bem para regiões do escoamento livre fora da camada limite. Por outro lado, o modelo $k-\omega$ é baseado na frequência de dissipação turbulenta $(\omega)$ e apresenta bons resultados em regiões próximas a parede. O modelo $k-\omega$ SST (Shear-Stress Transport), foi descrito por MENTER (1993) e MENTER (1994), e combina os modelos $k-\epsilon$ e $k-\omega$, dependendo da região calculada. Isto é, para regiões próximas a paredes se usará o modelo $k-\omega$ e para regiões de escoamento livre o modelo $k-\epsilon$. Na literatura (SORENSEN; MICHELSEN; SCHRECK, 2002; MO; LEE, 2012), observa-se que este modelo é o mais usado no caso de simulações de turbinas de eixo horizontal. Portanto, tal modelo foi adotado nas simulações aqui realizadas.

Foram realizadas as simulações do modelo reduzido em ar e do protótipo em água, o que servirá de base para uma avaliação da mesma máquina, em condições de números de Reynolds diferentes. A metodologia utilizada em ambos casos foi a mesma, simplesmente foi mudado o fluido e a escala geométrica da turbina. Neste capítulo é apresentada de forma 
detalhada a simulação realizada para o modelo reduzido. Em primeiro lugar apresenta-se o modelo geométrico escolhido para simulação e posteriormente a malha utilizada e as condições de contorno empregadas para resolução do problema. Foram simulados vários pontos de funcionamento da turbina, calculando em cada caso o $C_{p}$ como o objetivo de levantar a curva $C_{p}$ vs $\lambda$ para realizar a validação dos resultados experimentais. O $C_{p}$ foi calculado como a integração das esforços atuantes nas pás.

\subsection{Modelo geométrico}

O modelo geométrico 3D do rotor foi realizado pelo software SolidWorks e posteriormente importado para o ANSYS CFX R16.1 para simulação. As pás foram geradas a partir dos dados de aerofólio, corda, torção e raio, fornecidos no Apêndice A do Anexo, para modelo e protótipo. Nas simulações utilizou-se um modelo simplificado, para o rotor de três pás, usando como hub uma composição de semiesfera e cilindro. No caso do protótipo, o diâmetro do rotor é igual a $\mathrm{D}=10 \mathrm{~m}$, e para a construção do rotor do modelo reduzido foi aplicada uma escala 1:20. A Figura 37 apresenta o rotor simplificado usado nas simulações do protótipo.

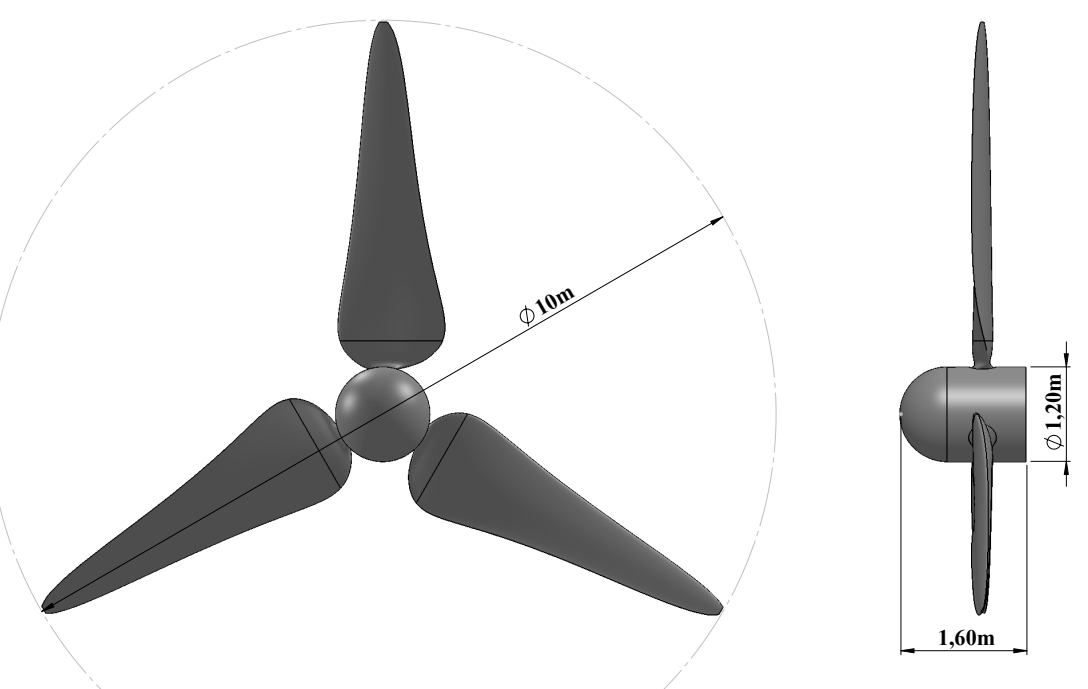

Figura 37 - Rotor simplificado usado nas simulações do protótipo

\subsection{Geração de malha}

Para geração da malha foi empregado o software Ansys Meshing CFD. Na Figura 38 observa-se o domínio computacional utilizado para simulação. Pode-se ver como o domínio está dividido em duas partes: um domínio rotativo, de forma cilíndrica, de 1,04D de diâmetro 
e 0,2D de comprimento, com alta densidade de elementos e um domínio estacionário com forma de prisma retangular de dimensões 8D de largura, 8D de altura e 16D de comprimento, que contém o domínio cilíndrico e tem concentrado uma baixa densidade de elementos. Todas as dimensões foram expressas em função do diâmetro do rotor.

O domínio estacionário foi construído o suficientemente grande para permitir o desenvolvimento completo da esteira. Porém, um domínio grande significa um grande custo computacional. Foram refinadas as zonas do domínio onde a aerodinâmica do rotor ainda é predominante para obter uma boa predição do escoamento.
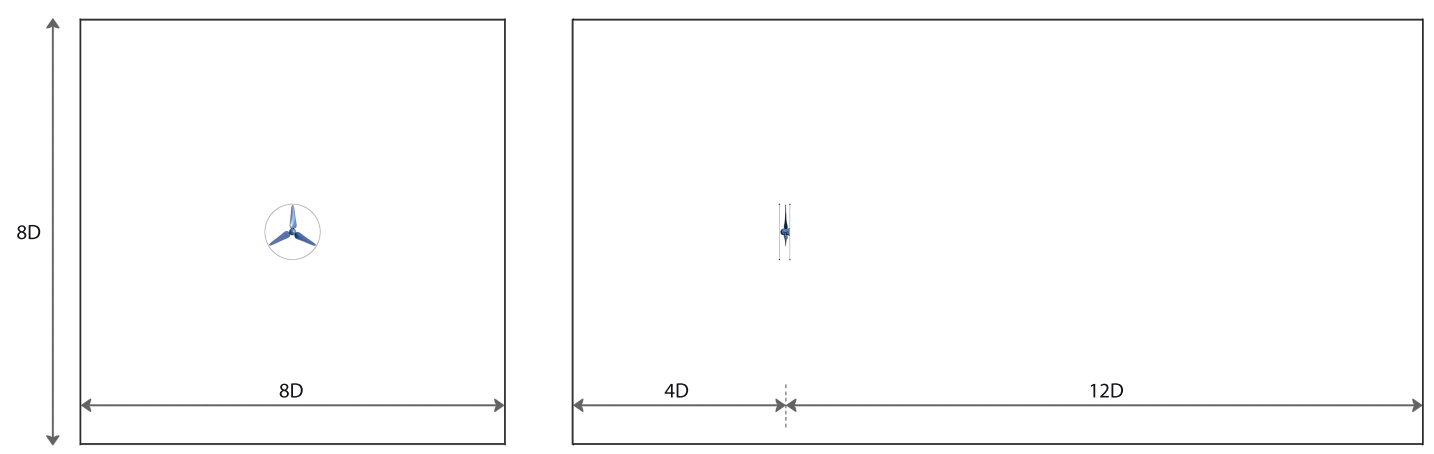

Figura 38 - Domínio computacional usado na simulação do modelo reduzido

Segundo a literatura é importante a localização entre os domínios para não ter interferências nas condições de contornos impostas na entrada e saída do fluxo. No caso da entrada, temos que garantir que a distância entre os domínios seja o suficientemente grande para que a condição de contorno de velocidade à entrada não interfira no escoamento do rotor já que pode existir um aumento artificial do fator de indução axial (MO; LEE, 2012; MOSHFEGHI; SONG; XIE, 2012). Na literatura encontramos que a partir de uma distância maior que 1,5D as simulações são realizadas de forma satisfatória (MO; LEE, 2012; OGGIANO, 2014). Neste caso, essa distância é igual a quatro vezes o diâmetro (4D), portanto, garantimos uma boa condição de velocidade de escoamento não perturbado. Por outro lado, como nessa região não são observados gradientes de pressão ou velocidades muito significativos não é preciso um refinamento da malha excessivo.

No caso da saída, a literatura recomenda uma distância para desenvolvimento da esteira completa maior que 10D. Porém, a esteira próxima $(<3 \mathrm{D})$ é a que mais influencia na predição de desempenho do rotor. Neste caso, a distância entre o rotor e a saída do escoamento foi de 12D. Porém, a malha na esteira foi refinada 3D, o sugerido na literatura.

Na Figura 39 observa-se a malha no domínio total do modelo reduzido. Os elementos escolhidos na construção da malha foram elementos tetraédricos e prismáticos. Os elementos tetraédricos se adaptam melhor à geometrias complexas, como é o caso da superfície da 
pá. Por outro lado, os elementos prismáticos foram aplicados nas regiões próximas à parede para representar a camada limite (SILVA, 2014). Na Figura 40 observa-se com mais detalhe as regiões onde o refinamento da malha foi maior. Pode-se ver como uma pequena parte da região a montante do rotor e a região da esteira próxima a jusante do rotor tem uma concentração maior de elementos já que são locais onde a aerodinâmica tem efeitos importantes no desempenho do rotor, e portanto, na predição de bons resultados.

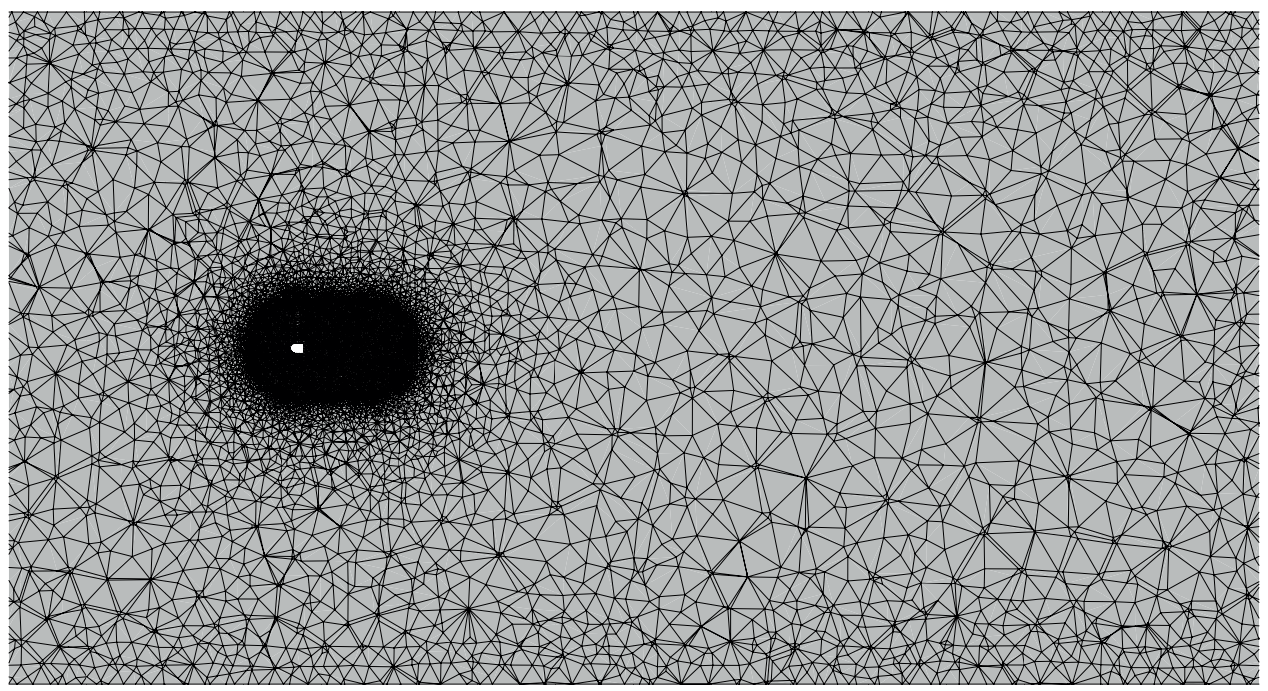

Figura 39 - Malha no domínio computacional com 7,5·10 nós
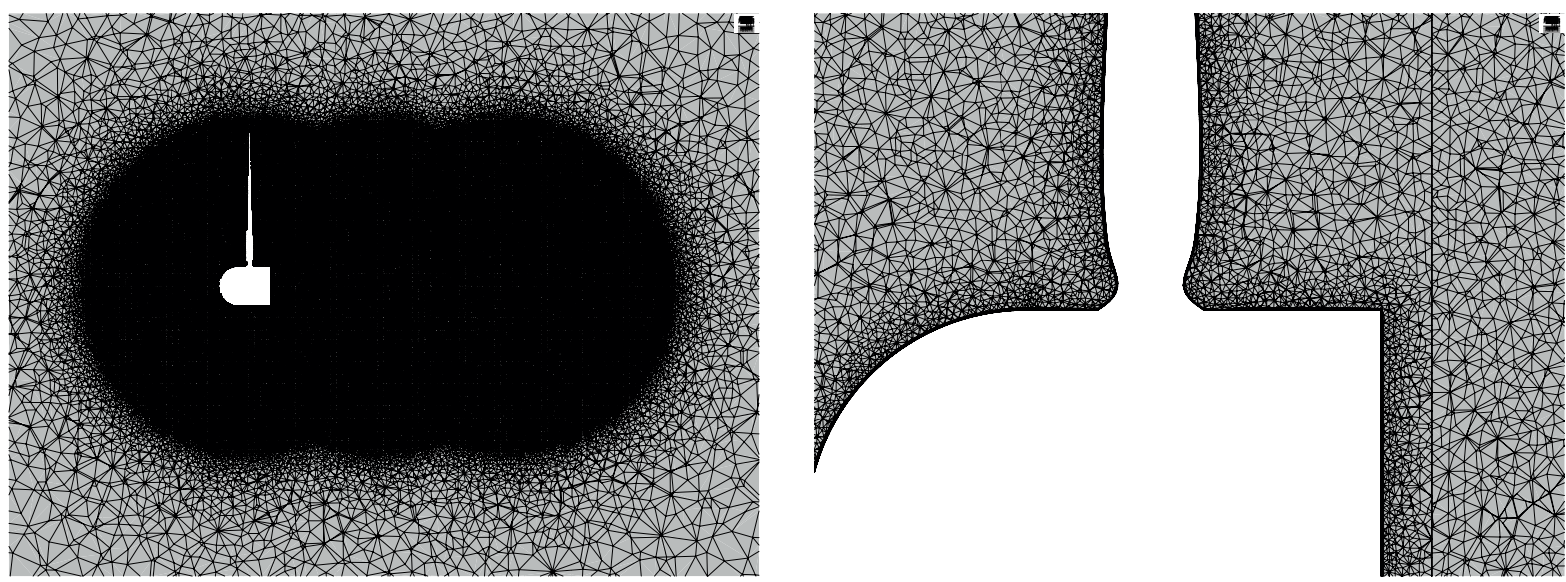

Figura 40 - Detalhe do refinamento da malha a montante e a jusante no rotor

Na Figura 41 apresenta-se a malha na superfície do rotor e com mais detalhe a malha na superfície de uma das pás.

A malha na superfície do rotor também foi fortemente refinada, além de incluir várias camadas de elementos prismáticos simulando a camada limite para captar a produção 
e dissipação da turbulência. Para obter bons resultados na simulação é importante definir a quantidade de camadas prismáticas e a taxa de crescimento. Neste caso foram usadas 15 camadas com taxa de crescimento igual a 1,2 .
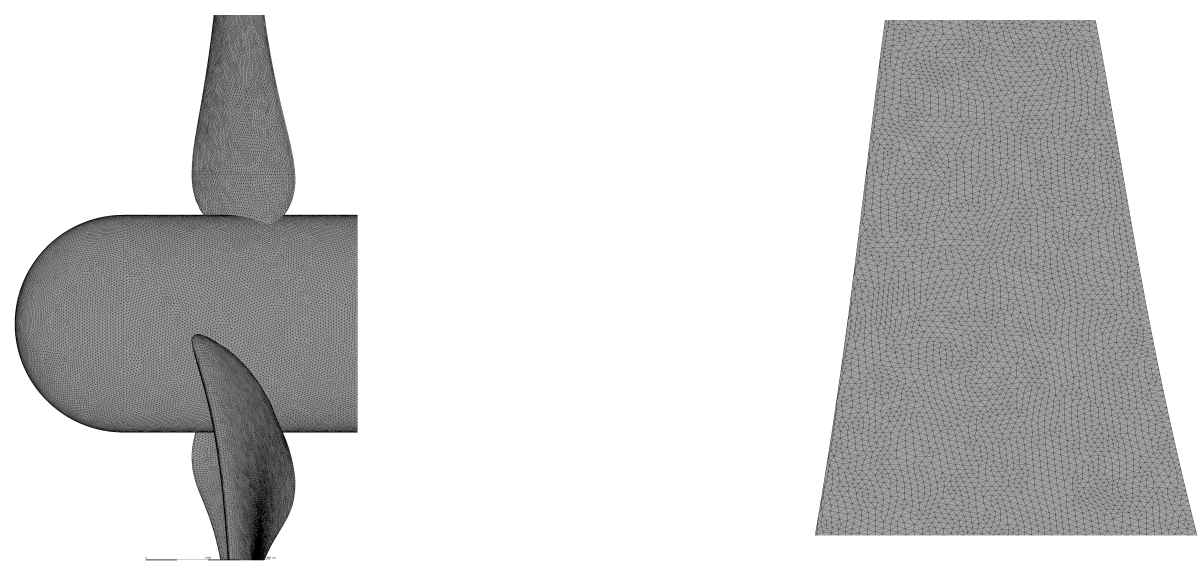

Figura 41 - Detalhe do refinamento da malha no rotor e na pá

Para obter uma completa resolução da camada limite é necessário que a malha seja capaz de conter nós com valores de $y^{+}$menores que 2 , sendo $y^{+}$um parâmetro adimensional que avalia distância entre a parede e o elemento.Por meio do cálculo de y+, o modelo SST seleciona qual abordagem será dada à turbulência: $k-\omega$ ou $k-\epsilon$ (SILVA, 2014).

A malha apresentada nas Figuras 39, 40 e 41 corresponde à Malha 4 da Tabela 2, isto é, uma malha de aproximadamente 7,5 milhões de nós. Na Tabela 2, apresenta-se o estudo de convergência de malha realizada. Neste podem ser observados os valores de $y^{+}$, máximos e médios, obtidos em cada caso, assim como a potência produzida [W] e o coeficiente de potência.

Tabela 2 - Estudo de convergência de malha.

\begin{tabular}{lcccccc}
\hline & N de nós & Refinamento na & \multicolumn{2}{c}{$y^{+}$} & Potência & \\
& {$\left[10^{6}\right]$} & esteira[m] & Máximo & Médio & {$[\mathrm{W}]$} & Cp \\
\hline Malha 1 & 1,84 & 0,5 & 42,761 & 1,5737 & 58,4492 & 0,290748 \\
Malha 2 & 3,96 & 0,9 & 36,0161 & 1,41664 & 78,9361 & 0,392635 \\
Malha 3 & 5,69 & 0,9 & 40,3347 & 1,43862 & 81,1373 & 0,403607 \\
Malha 4 & 7,48 & 1,4 & 42,6638 & 1,55724 & 68,2900 & 0,339699 \\
Malha 5 & 9,51 & 1,4 & 31,6976 & 0,415731 & 66,3701 & 0,330149 \\
\hline
\end{tabular}

O estudo de convergência foi realizado para o ponto de funcionamento correspondente a uma velocidade do escoamento igual a $12 \mathrm{~m} / \mathrm{s}$ e uma velocidade de rotação de $2000 \mathrm{rpm}(\lambda=4,36)$. A malha parou de ser refinadas quando se obtiveram valores de $C_{p}$ e potência com um erro menor que $3 \%$. 
No caso do protótipo, foi também utilizada uma malha com elementos prismáticos e tetraédricos, da mesma forma que nas simulações do modelo. A malha usada nas simulações teve aproximadamente $8 \cdot 10^{6}$ nós. Utilizou-se o mesmo critério que no caso do modelo reduzido para o estudo de convergência de malha.

\subsection{Condições de contorno}

As condições de contorno aplicadas ao domínio computacional são apresentadas a seguir. Com estas condições procurou-se representar da forma mais fiel possível um ensaio em túnel de vento, sem restrição de parede. Por outro lado, estas condições são iguais as encontradas em trabalhos com simulações de turbinas similares (MO; LEE, 2012; MOSHFEGHI; SONG; XIE, 2012; SILVA, 2014). Na Figura 42 apresentam-se as condições de contorno aplicadas ao domínio simulado.

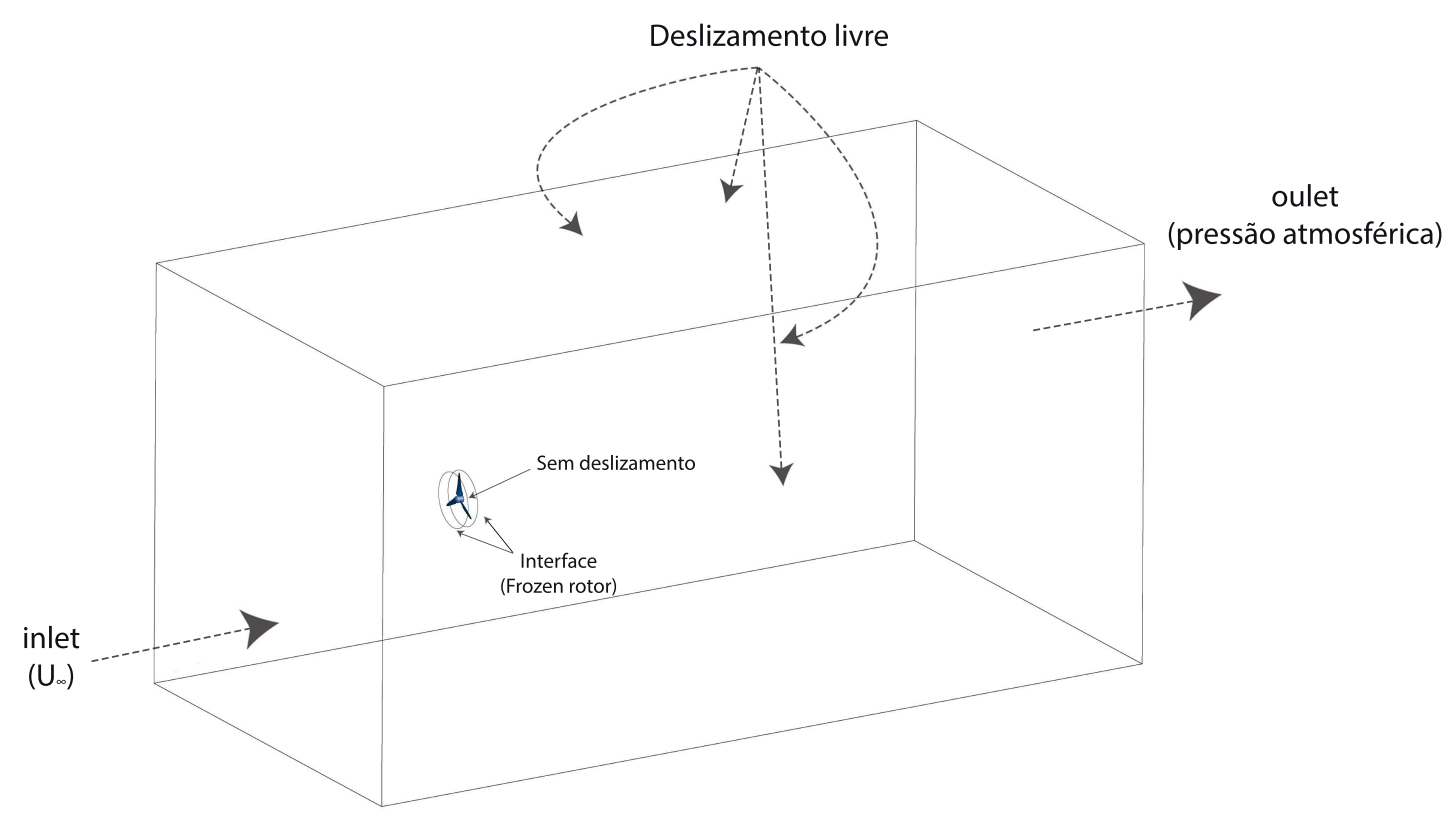

Figura 42 - Condições de contorno usadas na simulação

- Seção de entrada: A condição de contorno imposta ao escoamento na seção de entrada ao domínio estacionário é uma condição de perfil uniforme de velocidade com intensidade de turbulência 10\%. A pressão é dada pelas equações de movimento.

- Seção de saída: A condição de pressão atmosférica é imposta ao escoamento na seção de saída ao domínio estacionário.

- Paredes laterais: Nas paredes laterais do domínio estacionário é imposta a condição de deslizamento livre para evitar a interferência do túnel no escoamento. Já que a tensão de cisalhamento entre as paredes e o fluido é nula. 
- Superfície do rotor: Condição de não deslizamento na superfície do rotor sendo a velocidade nula na dita superfície.

- Interfaces: Foram vinculadas as faces comuns entre os domínios estacionário e rotativo. A propriedade de rotor congelado ("Frozen Rotor") foi adicionada com o fim de transformar os componentes do domínio estacionário para um sistema de referência móvel. Passando a considerar as forças centrífugas e de Coriolis.

O objetivo da simulação foi o levantamento da curva de $C_{p}$ para conhecer a performance da turbina e poder validar os resultados experimentais. Para obter dita curva, foram simulados vários pontos de operação da máquina. No caso, a velocidade do escoamento permaneceu constante e igual a $12 \mathrm{~m} / \mathrm{s}$ e a velocidade de rotação foi variada para obter informações do coeficiente de potência em todo o intervalo de funcionamento. As velocidades de rotação [rpm] usadas na simulação foram 500, 700, 1000, 1200, 1400, 1600, 1800, 2000, 2200, 2400, 2600, 3000 e 3200.

A convergência das simulações foi dada pelo monitoramento da variável $C_{p}$. Cada simulação teve no mínimo 200 iterações e se chegados nesse ponto flutuações eram observadas o processo iterativo era continuado.

Para o protótipo, as condições de contorno aplicadas foram as mesmas, com a única diferencia que o fluido escoado nesse caso era água. Vários pontos de operação foram simulados para o levantamento da curva de $C_{p}$ vs $\lambda$, tendo como constante a velocidade do escoamento do fluido igual a $2,5 \mathrm{~m} / \mathrm{s}$ e variando a velocidade de rotação, da mesma forma que no caso do modelo. 


\section{Resultados e discussões}

Neste capítulo são apresentados os resultados obtidos, experimentais e numéricos, para modelo e protótipo. Assim como a transposição de resultados modelo-protótipo. A consistência dos resultados será discutida, bem como a descrição das diferenças hidrodinâmicas do escoamento em duas escalas geométricas.

\subsection{Estudo de curvas de desempenho (modelo e protótipo)}

Nesta seção são apresentados os resultados obtidos no túnel de vento para o modelo reduzido para as velocidades de $8 \mathrm{~m} / \mathrm{s}, 10 \mathrm{~m} / \mathrm{s}$ e $12 \mathrm{~m} / \mathrm{s}$, assim como os resultados obtidos a partir do estudo numérico realizado para modelo e protótipo utilizando os softwares ANSYS CFX R16.1 e Qblade (PECHLIVANOGLOU, 2010). As curvas numéricas são validadas através dos resultados experimentais obtidos no túnel de vento.

No decorrer deste trabalho, algumas modificações foram feitas sobre o modelo reduzido aperfeiçoando assim a metodologia experimental.

Foi identificado que o sombreamento que a estrutura exercia nas pás podia estar prejudicando o desempenho da turbina. Após modificações construtivas o sombreamento sobre as pás diminuiu melhorando o desempenho do modelo (Vide Figura 45). Na Figura 43 observa-se como a parte superior da estrutura onde o motor é apoiado foi diminuída, deixando o sistema sem interferências nas pás.

Por outro lado, foram colocados nas pás 'turbulators' na forma de 'transition strips' (CAMPAGNOLO, 2013). Localizados no lado de sução da pá a $20 \%$ da corda tomando como referencia a borda de ataque. Na Figura 44 podem ser observados com maior detalhe os 'transition strips'.

A utilização de 'transition strips' em ensaios de modelos reduzidos de turbinas eólicas é uma prática relatada em vários trabalhos similares (BOTTASSO; CAMPAGNOLO; PETROVIC, 2014; CAMPAGNOLO, 2013). Tais dispositivos proporcionam uma transição de regime do escoamento laminar para turbulento na camada limite sobre a superfície da pá. Desta maneira, para condições de baixo número de Reynolds, o comportamento do escoamento é modificado para um comportamento mais similar a altos números de Reynolds. 


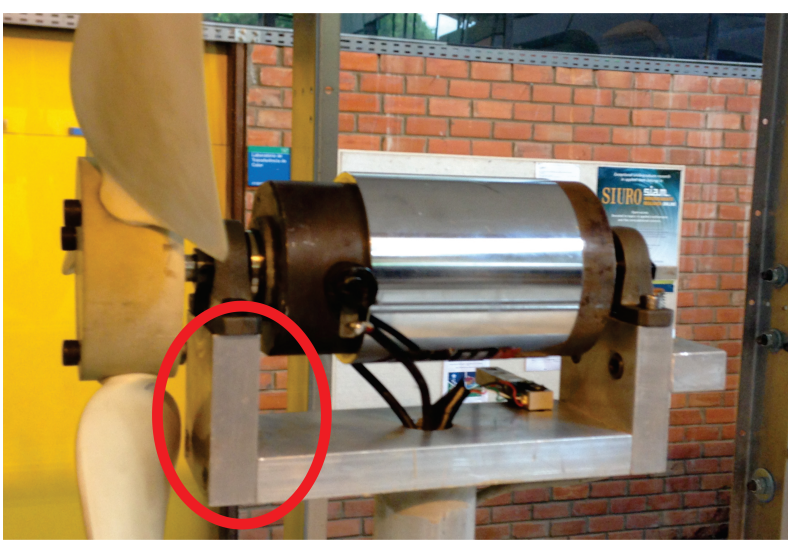

(a)

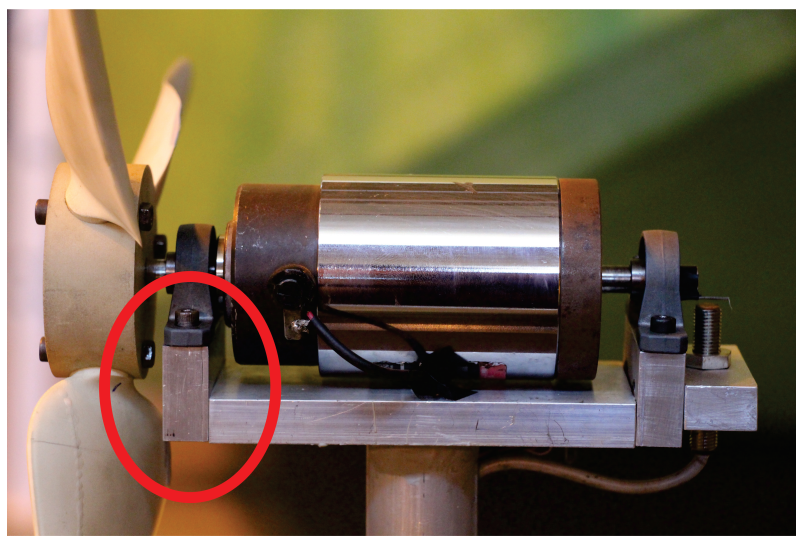

(b)

Figura 43 - (a) Montagem inicial do modelo; (b) Montagem melhorada para reduzir o sombreamento nas pás

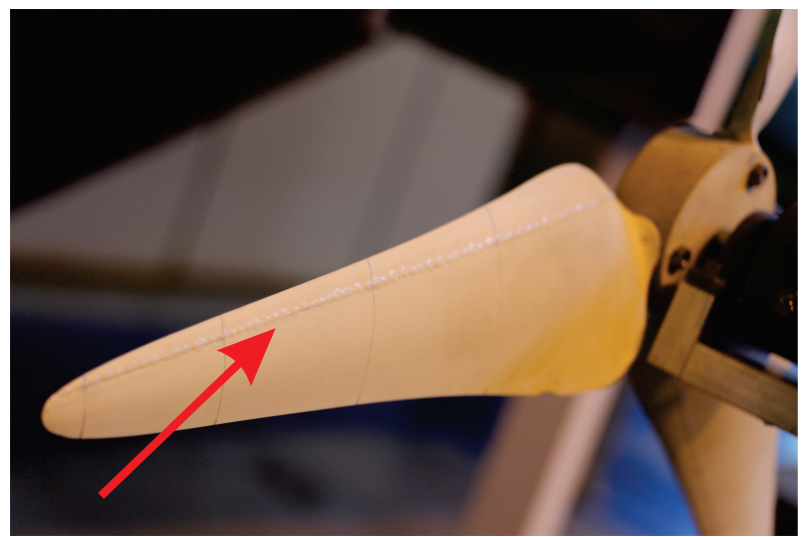

Figura 44 - Detalhe do 'transition strips' em uma pá

Na Figura 45 apresentam-se os resultados experimentais do modelo reduzido no interior do túnel de vento obtidos para as velocidades de 8, 10 e $12 \mathrm{~m} / \mathrm{s}$. Para cada caso, podem ser observadas três curvas que representam à montagem inicial, montagem melhorada e a incorporação de 'transition strips', respectivamente.

As curvas obtidas após eliminar o sombreamento sobre as pás apresentam maiores valores de $C_{p}$ para aproximadamente os mesmos valore de $\lambda$. No entanto, após adição dos 'transition strips' nas pás as curvas apresentaram valores ainda maiores de $C_{p}$ e de $\lambda$. Neste caso, foram atingidos maiores valores de $\lambda$ e as curvas apresentaram uma maior abertura. Portanto, a partir da Figura 45, percebe-se que para as três velocidades estudadas foi observada a mesma tendência no desempenho da turbina após as modificações físicas realizadas sobre o modelo.

Observa-se também como a parte da curva correspondente ao pós-estol fica muito próxima em todos os casos. Portanto, as alterações físicas realizadas sobre o modelo tiveram 
pouca influencia no comportamento da turbina para esse regime de funcionamento devido à redução da sustentação nas pás pelas condições do escoamento.

Por outro lado, os valores de $C_{p}$ encontrados foram similares nos três casos, sendo $C_{p}=0,35, C_{p}=0,37$ e $C_{p}=0,39$ para 8,10 e $12 \mathrm{~m} / \mathrm{s}$, respectivamente. Para as velocidades de fluxo livre de 10 e $12 \mathrm{~m} / \mathrm{s}$ o valor máximo de coeficiente de potência foi encontrado para $\lambda=5,2$, no entanto, para $8 \mathrm{~m} / \mathrm{s}$ o máximo valor de $C_{p}$ foi para $\lambda=4,6$.

Considerando todos os ensaios realizado no túnel de vento para o modelo reduzido o maior valor de $C_{p}$ encontrado foi 0,39 para $\lambda=5,2$, para a velocidade de $12 \mathrm{~m} / \mathrm{s}$ com 'transition strips'. O valor máximo de $C_{p}$ obtido inicialmente para esta velocidade foi $C_{p}=0,29$ para $\lambda=4,5$. Portanto, pode-se ver como após algumas ações (diminuição do efeito do sombreamento e indução da transição do regime do escoamento laminar para turbulento) os resultados de desempenho do modelo reduzido apresentaram melhorias significativas.

Cada ensaio foi realizado três vezes e foi observado como os resultados obtidos eram consistentes e confiáveis. A máxima velocidade de rotação medida no túnel de vento foi 3500 rpm, devido a limitações do motor e do sistema de adquisição.

No Anexo é apresentada a análise de propagação de incertezas realizada para obter os erros de $C_{p}$ e $\lambda$. Na Figura 45 estes erros são apresentados em forma de barra de erro, horizontal e vertical, em cada ponto. Os erros horizontais, nas medidas de TSR, devidos às incertezas trazidas pelas medidas de velocidade de escoamento e velocidade de rotação foram muito pequenos, da ordem de 0,01, e portanto, quase não saõ percebidos nos gráficos.

Por outro lado, os erros obtidos na medida de coeficiente de potência estão diretamente relacionados às medidas de torque realizadas pela célula de carga. Estes erros variam segundo a faixa de rotação, podendo-se observar como os maiores erros se produzem para valores de $\lambda$ entre 3 e 4 . Este intervalo corresponde ao começo de perda de sustentação nas pás, o estol. Em todos os ensaios o sistema apresentou vibrações consideráveis para as faixas de velocidades em torno aos 800-1200 rpm, correspondentes aos valores de $\lambda$ entre 3 e 4, e é por isso o aumento considerável do erro nas medidas de torque para ditos pontos de operação. 


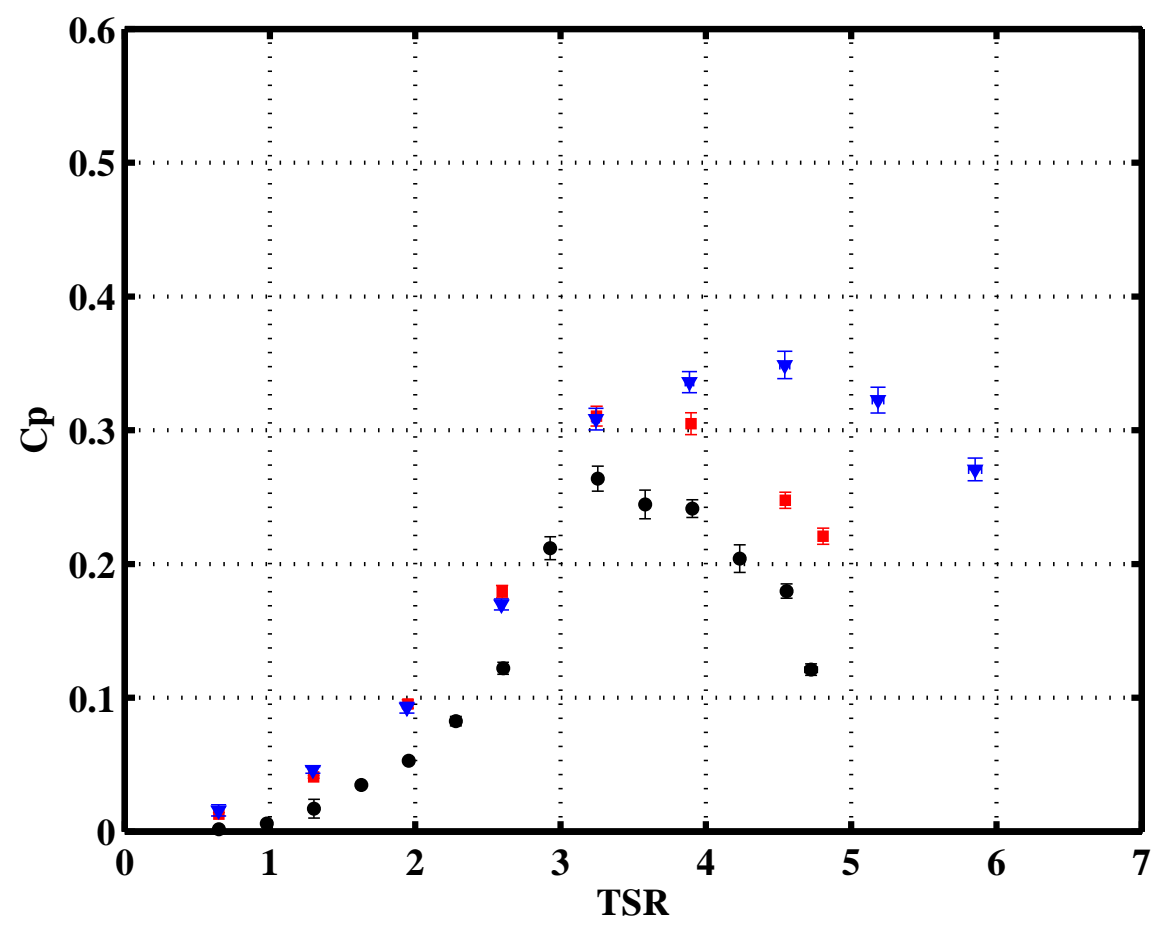

(a)

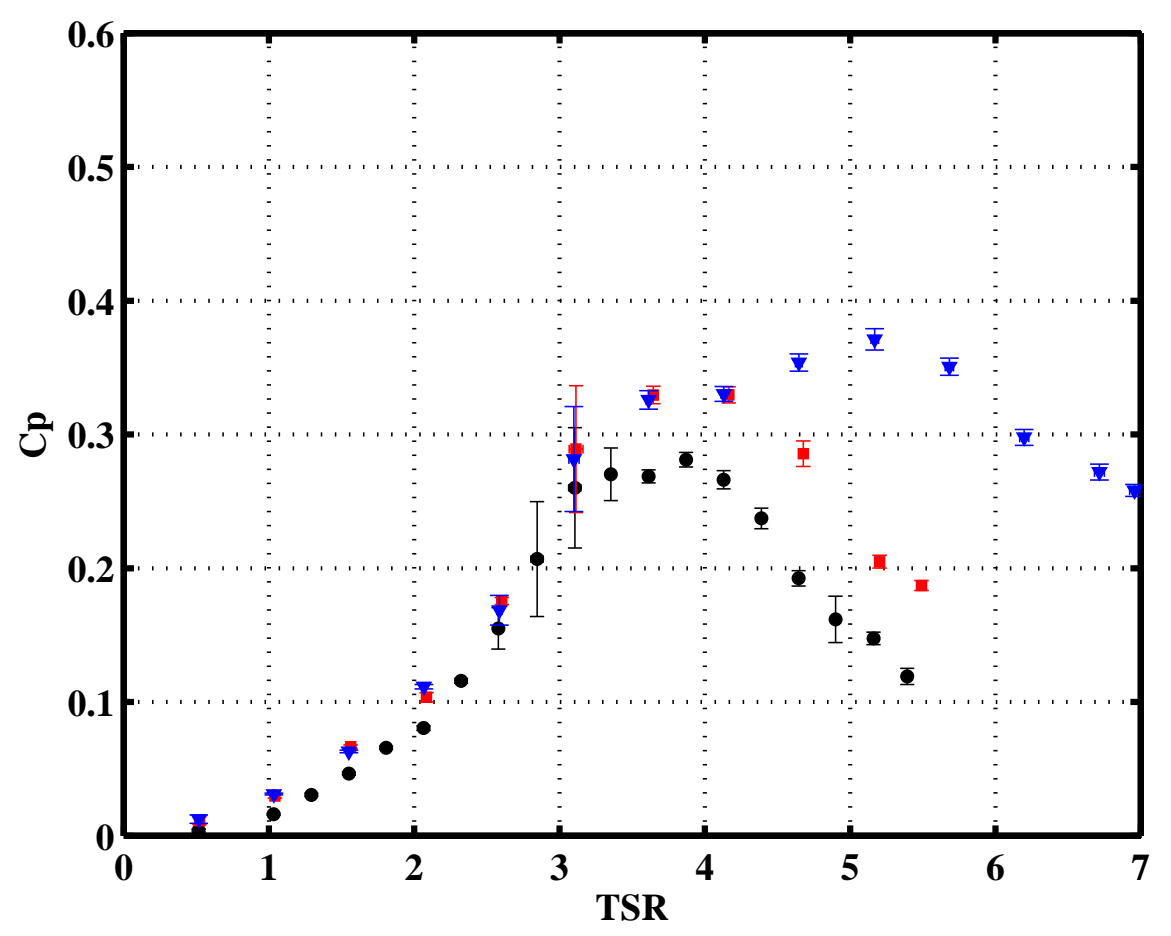

(b) 


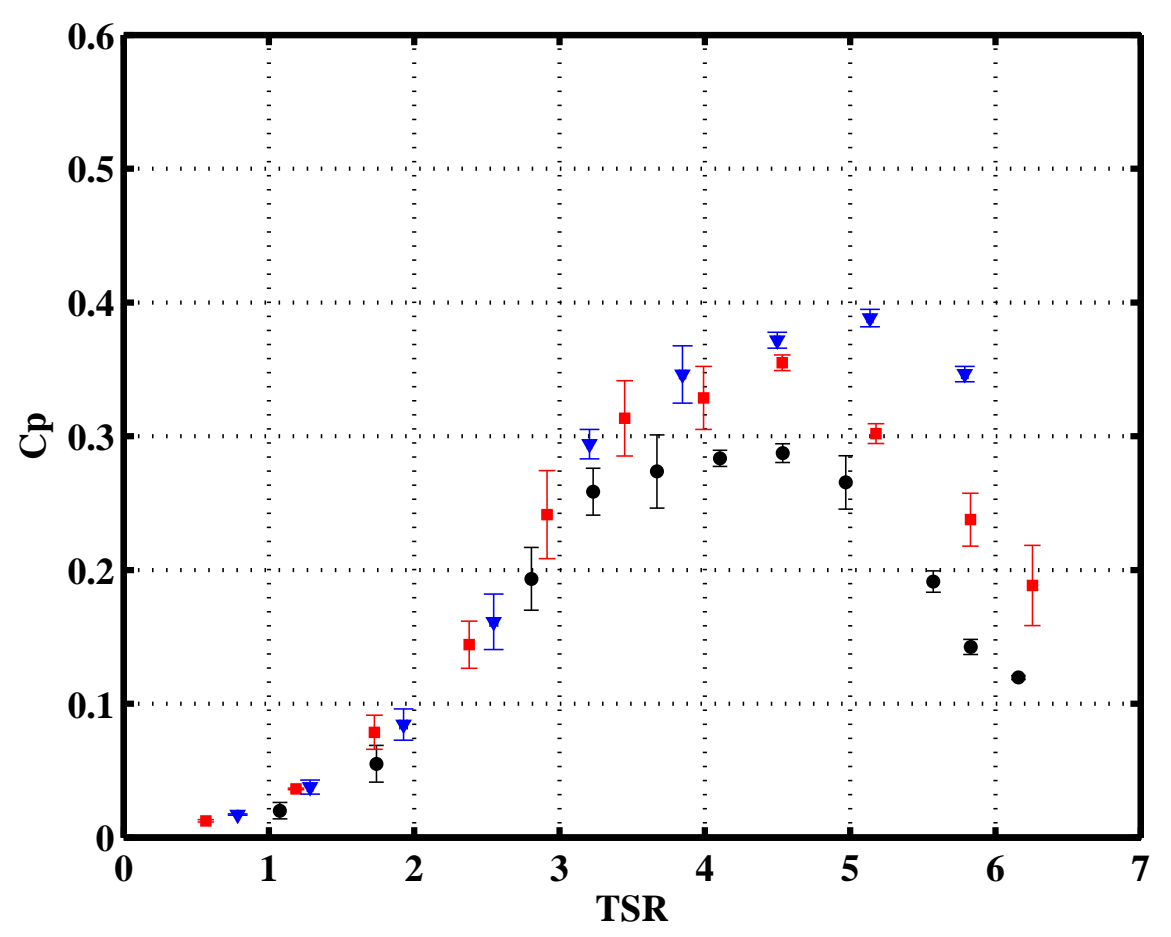

(c)

Figura 45 - Curvas experimentais de $C_{p}$ vs. $\lambda . \bullet$ : Montagem inicial; $\boldsymbol{~}:$ Montagem melhorada; $\mathbf{\nabla}$ : Transition Strips. (a) $8 \mathrm{~m} / \mathrm{s}$; (b) $10 \mathrm{~m} / \mathrm{s}$; (c) $12 \mathrm{~m} / \mathrm{s}$

$\mathrm{Na}$ análise de resultados de modelos reduzidos em túnel de vento, um fator importante a ser considerado é o efeito de bloqueio sobre os resultados medidos devido às paredes do túnel de vento (RYI et al., 2015). Segundo Ryi et al. (2015), Bottasso, Campagnolo e Petrovic (2014), Chen e Liou (2011) quando o fator de bloqueio, BR, é maior que 10\% é necessário aplicar correção de bloqueio. Neste caso, $B R=13,6 \%$ e portanto, os resultados experimentais obtidos foram corrigidos utilizando o fator de bloqueio. Para o cálculo do fator de bloqueio, $B F$, foi aplicado o método de Bahaj (BAHAJ et al., 2007). No Capítulo 3 na Seção 3.5 foi apresentado o método de forma detalhada.

Na Figura 46 apresenta-se a curva de desempenho do modelo reduzido em túnel de vento após aplicar a correção de bloqueio sobre os resultados experimentais obtidos. Pode-se observar, da mesma forma que no trabalho de Bahaj et al. (2007) para ensaios em túnel de água, que a parte da curva correspondente ao pós-estol apenas apresenta mudanças após a correção de bloqueio. Por outro lado, para $\lambda$ maiores que 4 são observadas mudanças significativas após a correção dos dados experimentais, tais como uma pequena diminuição nos valores de $C_{p}$ e $\lambda$ para esses pontos. A diminuição nos valores de $C_{p}$ é devido ao confinamento do modelo no interior do túnel de vento que faz com que os dados medidos sejam maiores que os realmente esperados. 


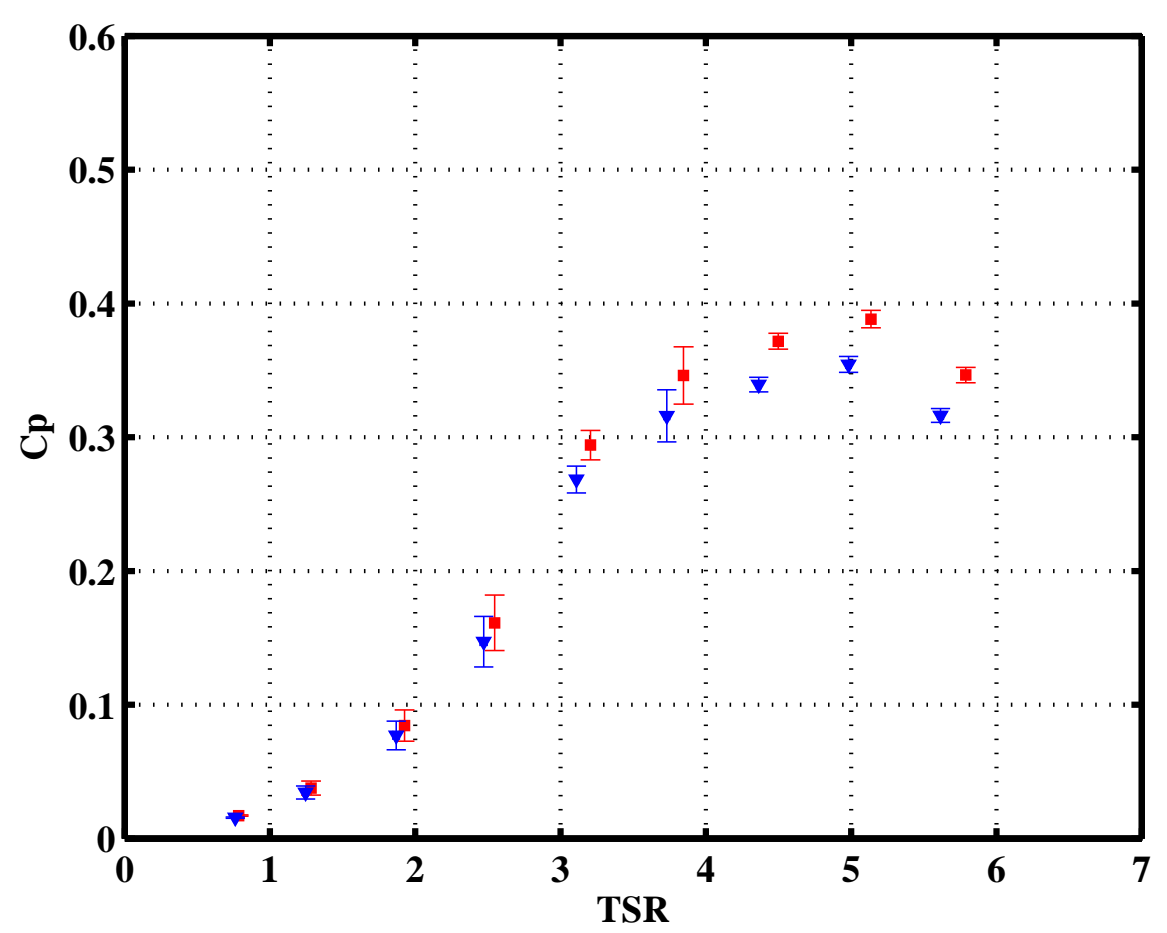

Figura 46 - Curvas experimentais de $C_{p}$ vs. $\lambda$ para $12 \mathrm{~m} / \mathrm{s}$. $\square$ : Curva experimental Transition Strips; $\mathbf{\nabla}$ : Curva experimental - Correção de bloqueio

No que segue, os resultados obtidos a partir das simulações numéricas serão apresentados para modelo e protótipo. Com isto pretende-se fazer a comparação das curvas de desempenho das duas turbinas estudadas, protótipo operando em água e modelo em ar, para assim analisar a viabilidade de uma transposição de resultados entre elas.

As simulações BEM foram realizadas usando tanto o software livre Qblade como um código próprio desenvolvido utilizando o software MATLAB para garantir a confiabilidade dos resultados. A metodologia BEM usa como parâmetros geométricos de entrada informações das pás, corda, ângulo de torção e raios, e o perfil aerodinâmico, neste caso o NACA 65(3)618. Nas simulações BEM o primeiro passo foi gerar as informações sobre o perfil aerodinâmico, as curvas polares, a partir do código XFOIL, para um intervalo de ângulos de ataque de -5 a $30^{\circ}$. Posteriormente, as curvas foram extrapoladas para um intervalo de -180 a $180^{\circ}$, devido a que o código BEM precisa desses dados.

Um fator fundamental na obtenção de predições válidas de desempenho em turbinas hidrodinâmicas pelo método BEM é o uso de curvas polares correspondentes a números de Reynolds locais no ponto de projeto da turbina (MONTEIRO et al., 2013). O número de Reynolds local calculado para o modelo reduzido com 0,5 m de diâmetro, utilizando ar como fluido escoando e condições de operação de $12 \mathrm{~m} / \mathrm{s}$ e $2000 \mathrm{rpm}$ foi $8,3 \cdot 10^{4}$. No caso do protótipo em água, com $10 \mathrm{~m}$ de diâmetro, operando a 2,5 m/s e $20 \mathrm{rpm}$ o número de Reynolds local calculado foi $5,2 \cdot 10^{6}$. O número de Reynolds local para o modelo 
reduzido é considerado um baixo número de Reynolds e portanto, como foi comentado anteriormente, e da mesma forma que nos ensaios experimentais, a transição do regime laminar para o turbulento foi induzida. Dita transição foi localizada em $20 \%$ da corda no lado de sução das pás (BOTTASSO; CAMPAGNOLO; PETROVIC, 2014). O fator Ncrit, que proporciona um critério de transição segundo o estado do túnel de vento, foi escolhido como Ncrit=5 para o modelo reduzido devido às interferências do túnel de vento sobre o modelo e Ncrit=9 para o protótipo, valor estândar.

Os resultados obtidos das simulações BEM são apresentados na Figura 48 e Figura 49 para modelo e protótipo. As curvas BEM, em ambos os casos, foram comparadas com as simulações CFD.

As simulações CFD foram realizadas no Laboratório de Energia e Ambiente (LEA) da Universidade de Brasília (UnB) usando a versão R16.1 do ANSYS. As simulações foram realizadas em uma maquina com dois processadores Intel Xeon E5-2643 3.5 GHz, 24 núcleos e uma memória RAM de 32 GB. Para cada simulação foram gastas aproximadamente 15 horas, e foram realizadas 13 simulações para o modelo reduzido e 7 para o protótipo.

Para o modelo reduzido, a simulação CFD foi realizada considerando um escoamento de ar a uma velocidade constante de $12 \mathrm{~m} / \mathrm{s}$, por outro lado, para o protótipo o fluido escoado foi água e a velocidade do fluxo livre considerada foi a velocidade de projeto 2,5 m/s. Em ambos os casos, as turbinas foram simuladas para várias pontos de operação, variando a velocidade de rotação e mantendo constante a velocidade do escoamento, conseguindo assim o levantamento da curva de $C p$ vs. $\lambda$.

As simulações para modelo e protótipo foram realizadas de forma análoga, apenas mudando o fluido escoado e a escala geométrica da turbina. Os domínios computacionais e as malhas usadas foram as mesmas, apenas foi aplicado o fator de escala 1/20 protótipomodelo. Por outro lado, os modelos de turbulência empregados e as condições de contorno impostas sobre o domínio foram iguais para ambos os casos. No Capítulo 4 foi apresentado o estudo numérico CFD de forma mais detalhada.

Nas Figuras 48 e 49 são ilustradas as curvas de desempenho, para modelo e protótipo, obtidas a partir das simulações BEM e CFD. Em ambos os casos, as curvas numéricas, BEM e CFD, apresentam valores de $C_{p}$ similares. 


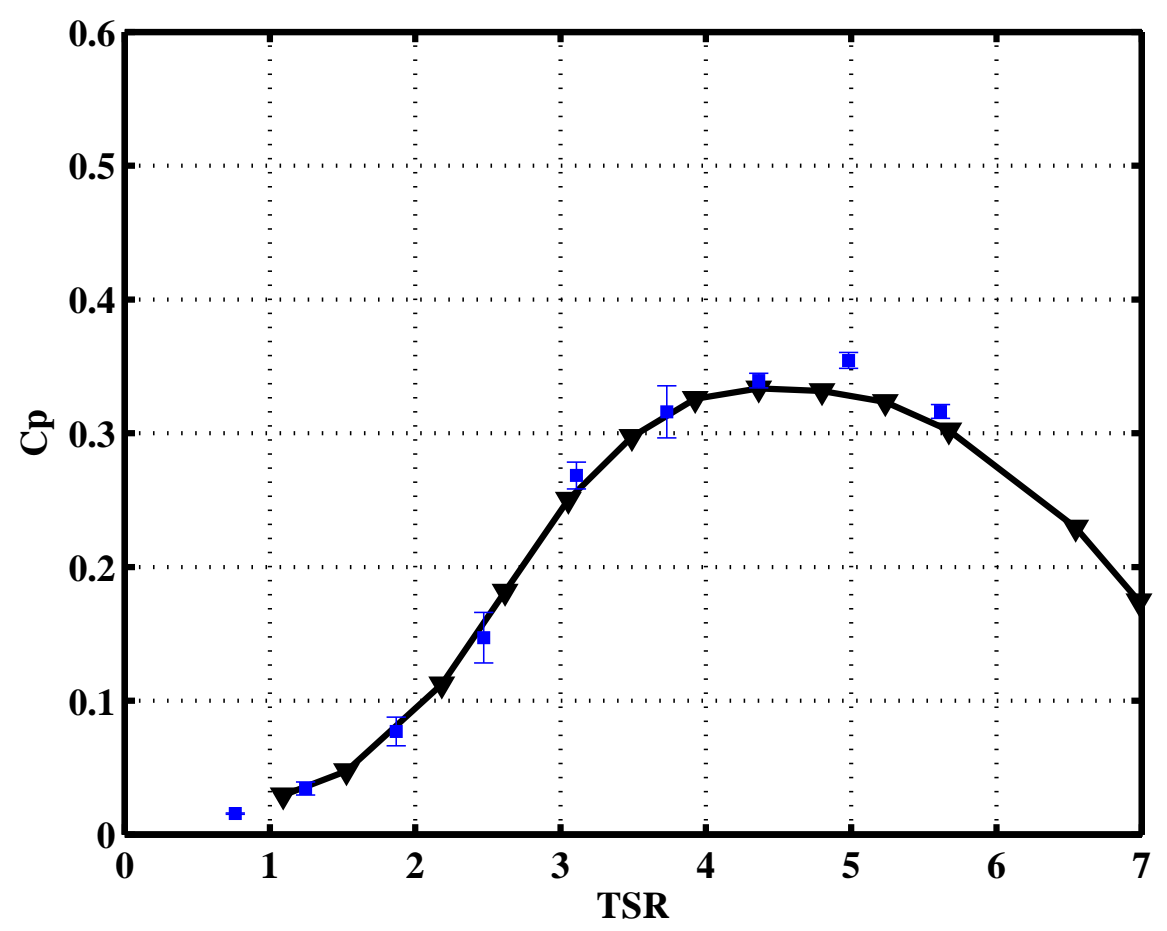

Figura 47 - Curva de desempenho $C p$ vs. $\lambda$ do modelo reduzido. $\mathbf{\nabla}$ : CFD; $\mathbf{\square}$ : ExperimentalCorreção bloqueio.

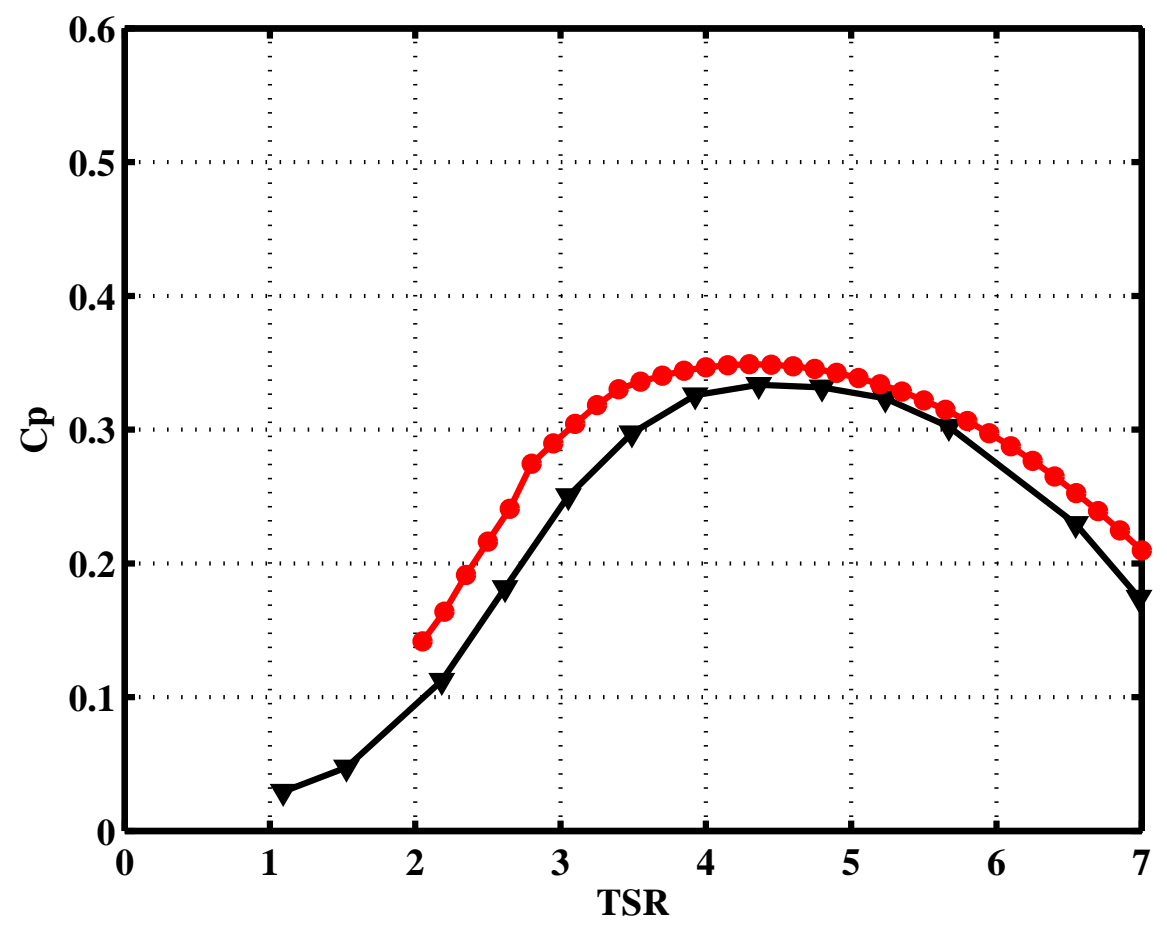

Figura 48 - Curva de desempenho $C p$ vs. $\lambda$ do modelo reduzido. $\bullet$ : BEM; $\boldsymbol{\nabla}$ : CFD. 


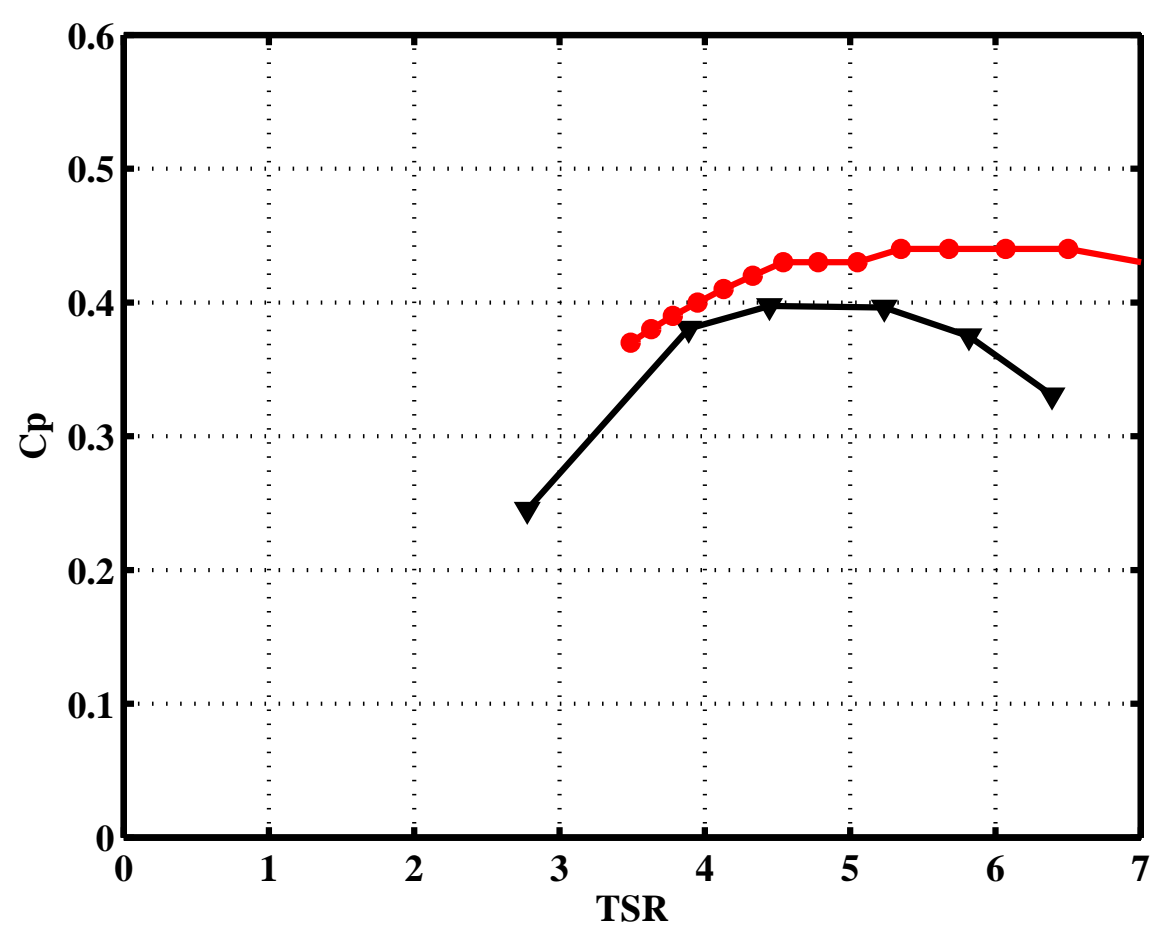

Figura 49 - Curva de desempenho $C p$ vs. $\lambda$ do protótipo. •: BEM; $\mathbf{\nabla}$ : CFD.

Na Figura 48 são apresentadas as curvas numéricas, CFD e BEM, e na Figura 47 são comparadas as curvas numérica CFD e experimental corrigida para o modelo reduzido. Percebe-se como as curvas numéricas e experimental-corrigida são muito próximas, e ambas coincidentes no ponto de máximo $C_{p}$. Este ponto vem dado por $C_{p}=0,33$ e $\lambda=4,36$. A região pré-estol em todas as curvas apresenta a mesma tendência. Já a região pós-estol, apresentou algumas diferenças na simulação BEM, mas nada significativo. Nesta região, os dados obtidos da simulação CFD e dos ensaios experimentais foram muito próximos, de forma que as curvas traçadas para a faixa de valores de $\lambda$ menores foram coincidentes.

Devido à similaridade das curvas de desempenho, para o modelo reduzido, obtidas das diferentes formas, cabe ressaltar como os resultados obtidos são consistentes e confiáveis. E portanto, ficam validadas as metodologias numéricas e experimental empregadas durante este trabalho.

No caso das simulações realizadas para o protótipo, observa-se como as curvas numéricas, BEM e CFD, apresentam valores similares para o ponto de projeto, como pode ser visto na Figura 49. Isto é uma características dos códigos BEM, que oferecem resultados confiáveis apenas para este ponto. O ponto de desenho da máquina definido durante o projeto da mesma corresponde ao valor de $\lambda=4,18$, para umas condições de $u_{\infty}=2,5 \mathrm{~m} / \mathrm{s}$ e $\omega=20 \mathrm{rpm}$. Em torno a esse valor de $\lambda$, pode-se ver como as curvas apresentam comportamentos análogos. As restantes regiões da curva não apresentaram 
comportamentos tão similares quanto os observados no caso do modelo reduzido. Os resultados obtidos mediante a simulação CFD, se apresentam mais confiáveis devido à robustez deste tipo de simulações. Portanto, o problema na discrepância dos resultados pode ser devido a alguns problemas apresentados pelo código BEM. Foi observado, para o caso do protótipo, que a previsão de $C_{L}$ e $C_{D}$ dadas pelo software XFOIL integrado ao código BEM foi ligeiramente diferente dos dados experimentais para o mesmo perfil aerodinâmico e número de Reynolds, obtidos pelo Abbott, Doenhoff e Stivers (1945).

A partir das Figuras 48 e 49, observa-se como o comportamento das curvas de desempenho para modelo e protótipo são similares. Ambas as curvas tem seu máximo de $C_{p}$ para valores de $\lambda$ muito próximos, em torno a $\lambda=4,5$. Os valores máximo de coeficiente de potência para modelo e protótipo, obtidos a partir das simulações $\mathrm{CFD}$, são $C_{p}=0,33$ e $C_{p}=0,39$, respectivamente. A partir dos resultados apresentados nas figuras acima será realizada a transposição de resultados entre modelo e protótipo. 


\subsection{Características hidrodinâmicas do escoamento (modelo e pro- tótipo)}

A seguir serão apresentadas as características hidrodinâmicas do escoamento, para modelo e protótipo, obtidas a partir da simulação numérica CFD. Os estudos hidrodinâmicos foram realizados para diferentes pontos de funcionamento, isto é, diferentes valores de $\lambda$, para poder conhecer que ocorre nos diferentes regimes de operação da turbina. Foram estudadas as condições do escoamento para $\lambda=2,8$, região pós-estol, $\lambda=3,9$, começo do estol nas pás e $\lambda=6,4$, regime pré-estol com altas rotações.

Nas Figuras 50 e 51 é são apresentadas as linhas de corrente sobre o extradorso das pás, para modelo e protótipo, respectivamente. Também, podem ser observadas as linhas de correntes em volta dos perfis aerodinâmicos médios das pás e o campo de pressão nos mesmos. Tudo isto para diferentes rotações da turbina, mantendo-se a velocidade média do escoamento não perturbado constante e igual a $12 \mathrm{~m} / \mathrm{s}$ e $2,5 \mathrm{~m} / \mathrm{s}$, para modelo e protótipo respectivamente.

Como foi comentado no Seção 2.4, a camada limite é gerada devido à influencia dos efeitos viscosos em regiões próximas à parede, os quais provocam uma diminuição da energia cinética das partículas fluidas e portanto, em determinadas condições estas não conseguem superar o gradiente de pressões adverso. Em ocasiões, este gradiente é tão grande que muda a direção do fluido na região da camada limite, produzindo o colapso da mesma, e portanto o fenômeno conhecido como estol, devido à falta de sustentação.

É fundamental definir em um projeto de rotor de turbina para quais pontos a mesma opera em condições de estol, devido a que a perda de sustentação ocasionada nestes casos reflete em uma redução drástica do rendimento da turbina e em ocasiões, vibrações indesejadas no rotor que podem trazer falhas estruturais.

No que segue, serão analisados os fenômenos hidrodinâmicos que acontecem para cada caso objeto de estudo, devido as diferentes topologias que apresenta o escoamento em condições de pré e pós-estol. O comportamento das linhas de corrente e o campo de pressão em torno à seção de pá selecionada é quase idêntica para modelo e protótipo, já as linhas de corrente sobre as pás apresentam algumas pequenas diferenças, sempre comparando ambas as turbinas para os mesmos valores de $\lambda$.

Na representação do escoamento médio em forma de linhas de correntes, para modelo e protótipo, pode-se visualizar o colapso da camada limite ao longo da pá caracterizado pela estagnação e deflexão das linhas de correntes (Figura 50 e Figura 51). Percebe-se como o escoamento na camada limite na superfície das pás apresenta comportamentos diferentes em condições de pré e pós estol, observando-se que o colapso da camada limite ocorre inicialmente na raiz da pá propagando-se até a ponta da mesma. 
O ângulo de ataque possui uma relação direta com a intensidade do escoamento não perturbado e com a velocidade de rotação da turbina. Por isso, baseado no triângulo de velocidades apresentado na Figura 11, observa-se como um aumento da rotação tende a alinhar o escoamento com a linha central do aerofólio, diminuindo o ângulo de ataque. Este fenômeno, pode ser visto nas Figuras 50c e 51c, para modelo e protótipo, respectivamente, onde as linhas de corrente se apresentam paralelas à corda do perfil aerodinâmico. Isto acontece para altas velocidades de rotação, neste caso, correspondentes a um alto valor de $\lambda=6,4$.

Esta região é conhecida como região pré-estol, e nela as linhas de corrente percorrem a pá de forma suave e paralela à corda e em direção ao bordo de fuga. Na Figura 51c observase como o escoamento está totalmente aderido à pa, já na Figura 50c correspondente ao modelo reduzido, observa-se como, o escoamento está também aderido à pá porém, apresenta uma pequena faixa de descolamento na região próxima ao bordo de fuga.

Nas Figuras 50a e 51a, correspondente a $\lambda=2,8$, observa-se como o escoamento começa a descolar da parede do perfil na região próxima ao bordo de fuga, devido à reversão do fluxo que leva à recirculação do fluxo nessa região. Isto ocorre pela diminuição da velocidade de rotação que leva a um aumento do ângulo de ataque, acarretando o descolamento da camada limite. Este fenômeno de estol é observado para as duas turbinas.

Nesta região, conhecida como região pós-estol, observa-se como as linhas de corrente tendem a percorrer a pá na direção radial. Breton (2008) atribui este fenômeno à influencia da força centrífuga que propaga o colapso da camada limite em direção à ponta da pá. No caso do modelo percebe-se como a camada limite está totalmente colapsada, devido a que as linhas de corrente estão percorrendo a pá toda desde a base até a ponta. Já no caso do protótipo, observa-se como na região próxima ao bordo de ataque ainda tem uma pequena porção de escoamento aderida a pá.

O último caso a analisar, apresenta uma situação intermédia ás estudadas até agora e corresponde a um valor de $\lambda=3,9$. No caso do protótipo, observa-se como as linhas de corrente começam a descolar aparecendo o colapso da camada limite. As linhas de corrente ainda se apresentam como paralelas mas aparecem os primeiros sinais de descolamento próximos ao borde de fuga. Já no caso do modelo, pode-se ver como aproximadamente a metade da pá apresenta descolamento da camada limite e a outra adesão do escoamento. Portanto, para esse mesmo valor de $\lambda$ o modelo apresenta um comportamento, no que se refere ao estol, mais avançado que o protótipo.

De forma geral, os comportamentos hidrodinâmicos para modelo e protótipo são próximos para os mesmos valores de $\lambda$, nas regiões pré e pós estol. As diferenças encontradas na evolução do descolamento da camada limite são devidas aos diferentes números de Reynolds para cada caso. Já que para altos número de Reynolds os valores de sustentação são maiores acontecem o descolando da camada limite mais tarde. 


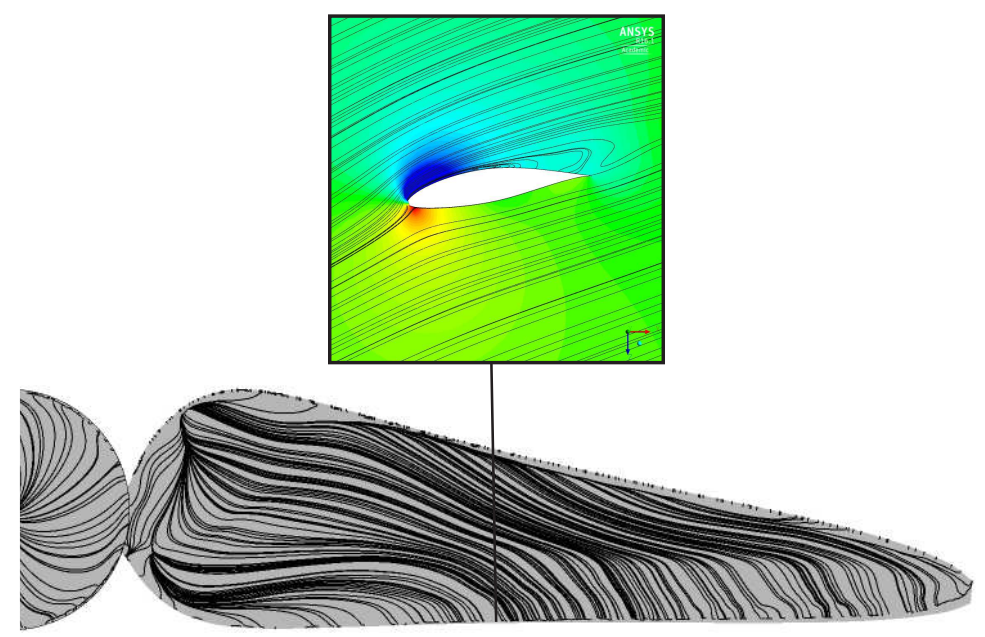

(a)

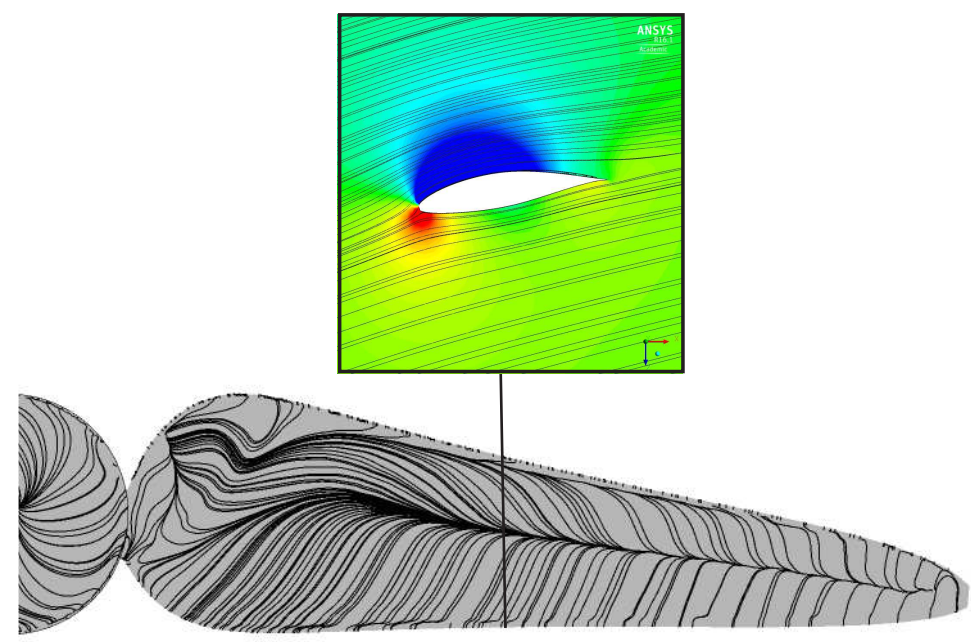

(b)

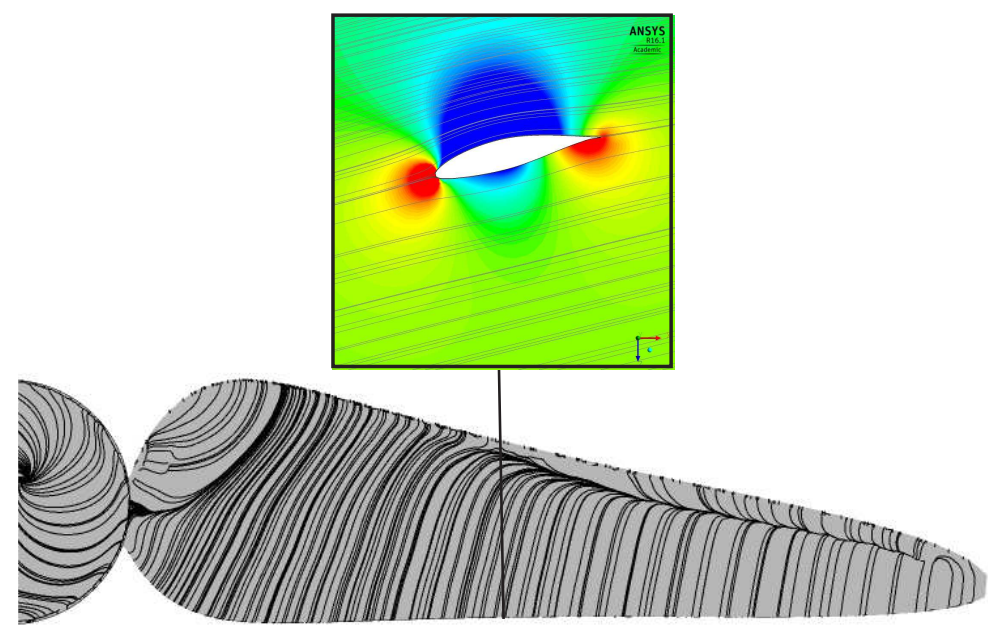

(c)

Figura 50 - Linhas de correntes sobre as pás e em volta do perfil aerodinâmico médio das mesmas para o modelo reduzido (a) $\lambda=2$, 8; (b) $\lambda=3,9$; (c) $\lambda=6,4$ 


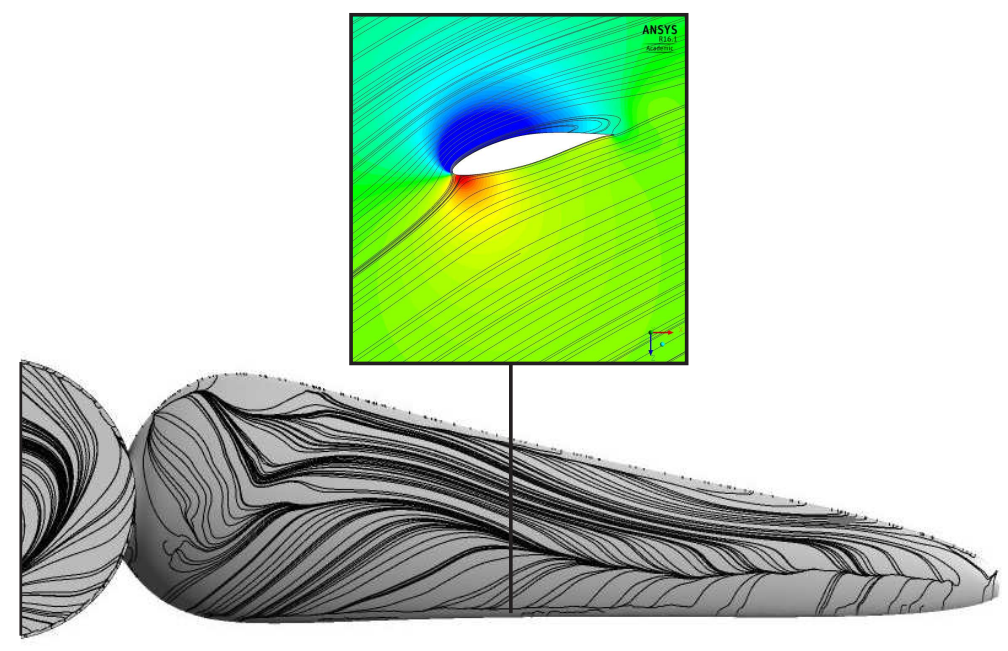

(a)

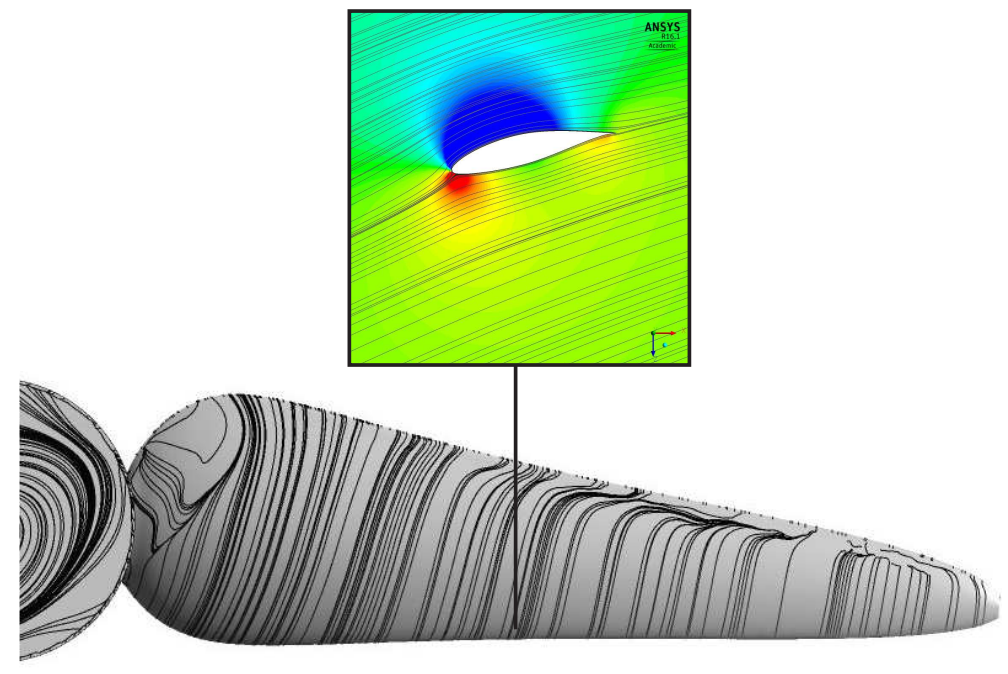

(b)

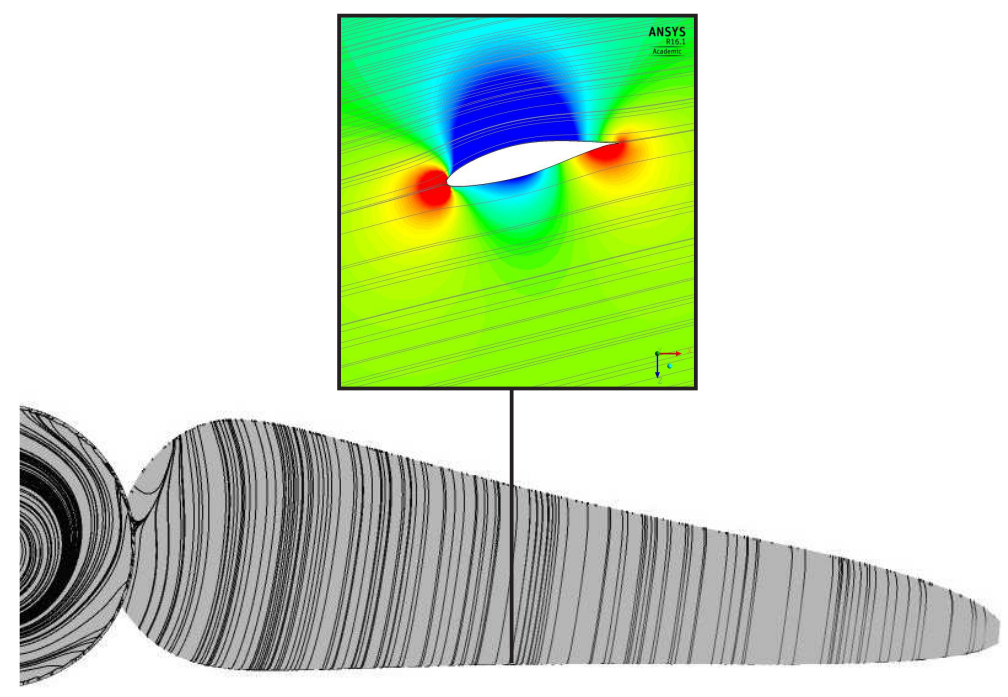

(c)

Figura 51 - Linhas de correntes sobre as pás e em volta do perfil aerodinâmico médio das mesmas para o protótipo (a) $\lambda=2,8$; (b) $\lambda=3,9$; (c) $\lambda=6,4$ 
Com o intuito de analisar o comportamento da esteira para os diferentes valores de $\lambda$ objeto de estudo, para modelo e protótipo, são apresentadas as Figuras 52 e 53 que ilustram o comportamento de velocidade axial normalizada e a energia cinética de turbulência normalizada ao longo da direção axial do rotor.

Em primeiro lugar, a Figura 52 apresenta o campo de velocidades axial normalizado em volta das turbinas para os três valores de $\lambda$ estudados. Em todos os casos, observa-se como a velocidade cai no encontro com o rotor e aos poucos vai se recuperando na região da esteira. Em todos os casos do modelo reduzido, após uma distância correspondente a 5D (cinco diâmetros) a velocidade é recuperada totalmente. Para o protótipo é necessária uma distância de 8D para a recuperação total da esteira.

Após os rotores, na linha central correspondente à posição radial ( $\mathrm{r}=0)$ percebe-se uma queda acentuada da velocidade axial normalizada ocasionada pela presença da nacele. Esta queda de velocidade é muito mais acentuada no caso do protótipo devido ao tamanho da máquina. No caso do modelo reduzido, esse efeito é dissipado a uma distancia de aproximadamente $0,5 \mathrm{D}$ do rotor apresentando a velocidade axial nessa posição o mesmo padrão de outras posições radiais. Sem embargo, para o protótipo esta recuperação leva em torno de 2D até conseguir apresentar o padrão de velocidades radiais.

Em geral, a turbina exerce uma grande influência no escoamento, fundamentalmente a jusante da mesma. O escoamento após passar pela turbina desacelera de forma abrupta devido à energia absorvida pelo rotor e à energia utilizada na mudança de direção do escoamento. Percebe-se nas imagens como a interferência do rotor no escoamento vai decrescendo com a posição radial.

Observa-se também, para ambos os casos, como o campo de pressões gerado pelo rotor é perceptível a uma distância entre $0,5 \mathrm{D}$ e $1 \mathrm{D}$ a montante do rotor devido à diminuição de velocidades apresentada. Isto é um indicativo de que o fator de indução axial nessa região tende a ser diferente de zero a partir desses pontos afetados pela presença do rotor.

$\mathrm{Na} 52 \mathrm{a}$, correspondente a $\lambda=2,8$, região pós-estol das turbinas, observa-se como a velocidade após as pás é maior que no resto dos casos. Isto devido ao aumento de velocidade devido ao estol acontecido nas pás.

$\mathrm{Na}$ situação correspondente a $\lambda=3,9$, região do estol, as velocidades radiais apresentam um padrão de velocidade mais desordenado que nos outros casos. Também, pode ser visto como a queda de velocidade após o rotor é menor que nos restantes estudos.

No entanto, como foi observado o comportamento da velocidade axial não se apresenta muito diferente se compararmos modelo e protótipo. 


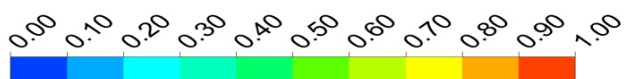
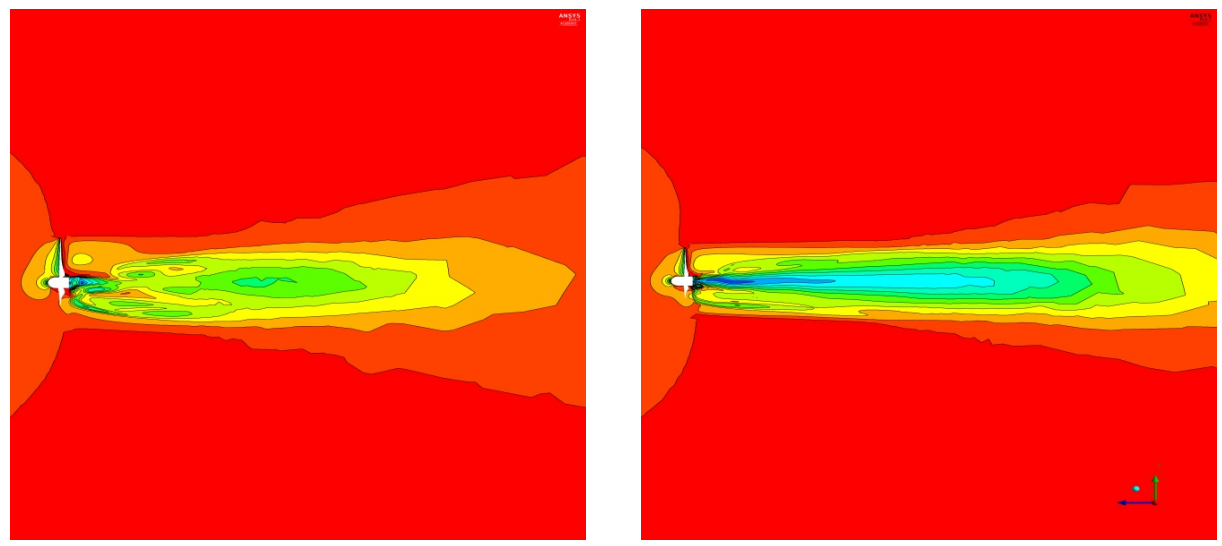

(a)
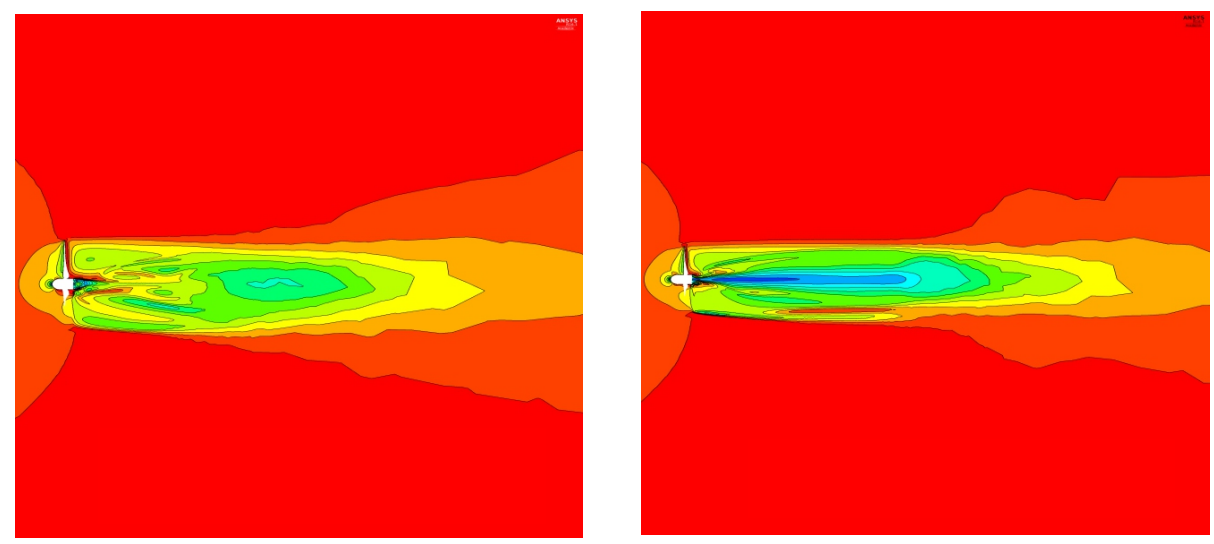

(b)
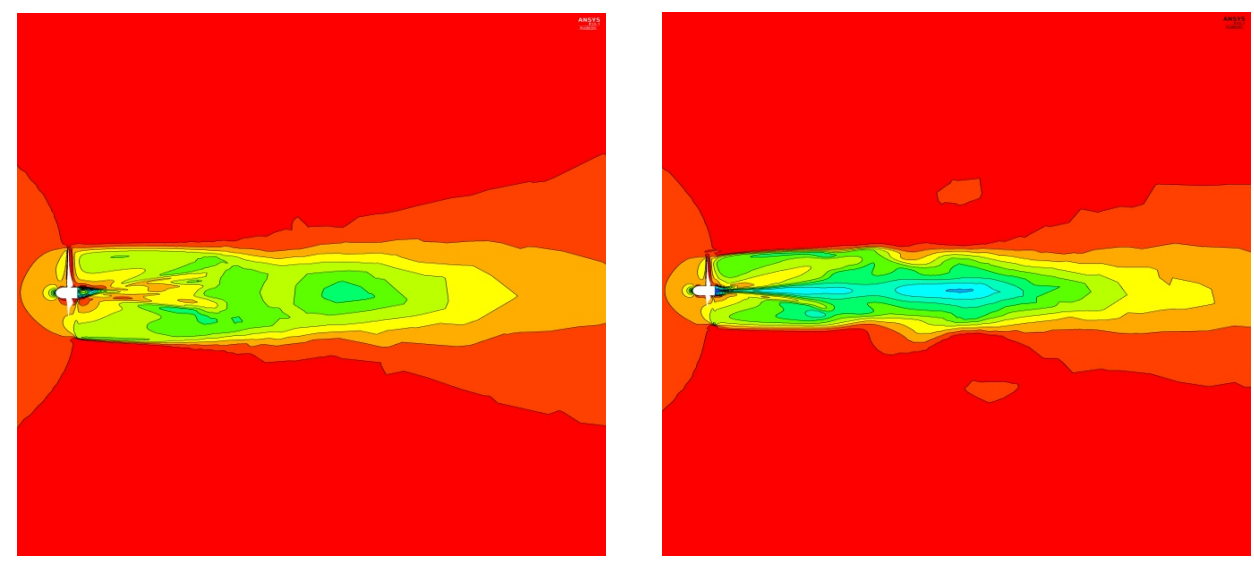

(c)

Figura 52 - Velocidade axial do escoamento em volta da turbina para modelo reduzido (esquerda) e protótipo (direita) para varios valores de $\lambda$ (a) $\lambda=2,8$; (b) $\lambda=3,9$; (c) $\lambda=6,4$ 
A energia cinética turbulenta mostrada na Figura 53, aumenta subitamente após a turbina devido à formação e desprendimento dos vórtices. Após este aumento, a energia cinética de turbulência apresenta uma queda que va se estendendo ao longo da esteira.

Em todos os casos, pode ser observado como a energia cinética de turbulência é maior nas situações correspondentes ao funcionamento da turbina em regime pós-estol, $\lambda=2,8$. Nestes casos, a energia cinética turbulenta após o rotor é grande sendo dissipada ao longo da esteira de forma rápida.

Por outro lado, a energia cinética turbulenta para $\lambda=6,4$, operação das turbinas em regime pré-estol, é muito menor que nos casos anteriores. Isto é devido a que nesta situação o fluxo é suave e ordenado, como foi comentado anteriormente.

Observado as esteiras, percebe-se como as esteiras nos casos do modelo reduzido são muito menores que as esteiras nos casos do protótipo, dissipando a energia de turbulência muito mais rapidamente. O qual pode ser devido à grande diferença nos números de Reynolds em ambos os casos. Porém, na esteira próxima parece que o padrão de energia cinética de turbulência é similar para as duas turbinas estudadas.

Algumas diferenças foram encontradas nas analises realizadas anteriormente. Como os tamanhos das esteiras de velocidade axial e energia cinética turbulenta ou o grau de evolução do descolamento da camada limite nos pontos de operação estudados. Estas diferenças são associadas aos diferentes tamanhos das máquinas e aos diferentes números de Reynolds que caracterizam a dinâmica dos escoamentos.

No entanto, os comportamentos hidrodinâmicos para modelo e protótipo explorados por meio da simulação CFD podem ser considerados próximos. Devido à falta de similaridade dinâmica poderia ser esperado que as características hidrodinâmicas fossem mais diferente, porém, apenas foram analisados alguns fenômenos hidrodinâmicos. 

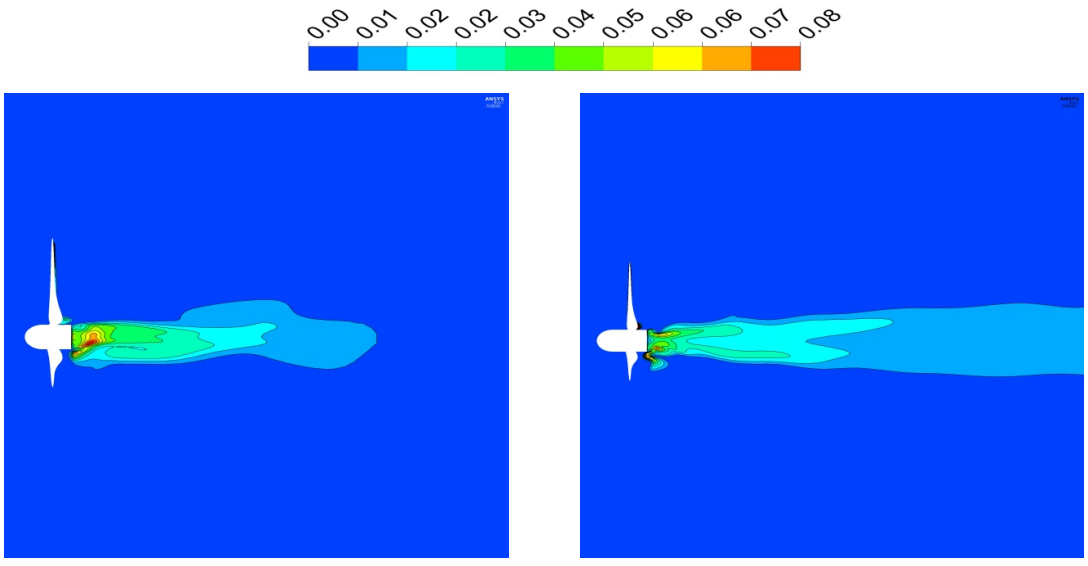

(a)
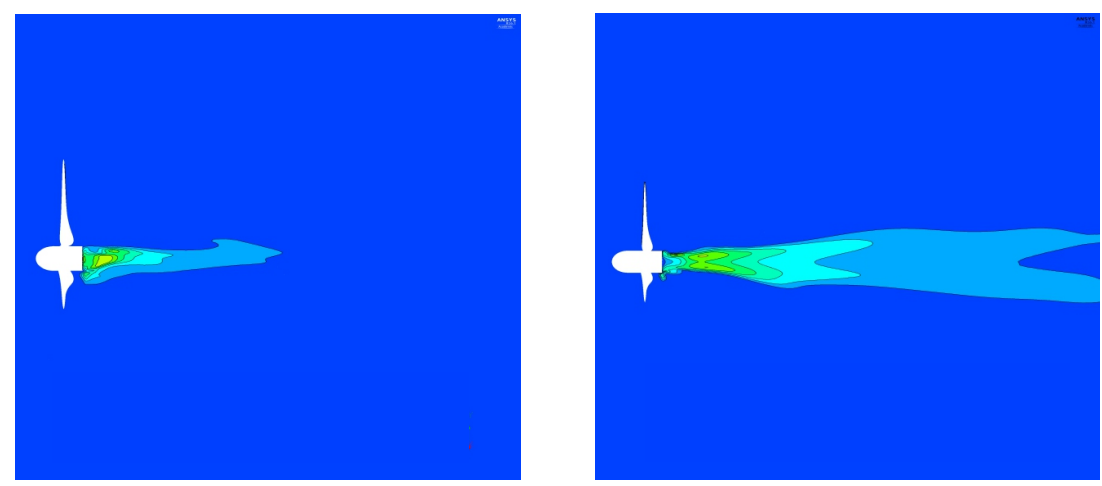

(b)
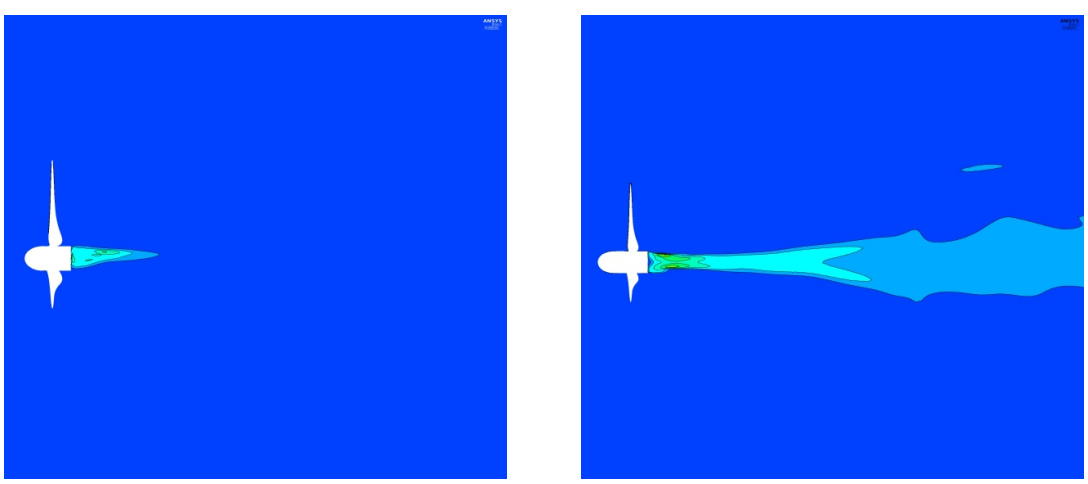

(c)

Figura 53 - Energia cinética de turbulência do escoamento em volta da turbina para modelo reduzido (esquerda) e protótipo (direita) para varios valores de $\lambda$ (a) $\lambda=2,8$; (b) $\lambda=3,9$; (c) $\lambda=6,4$ 


\subsection{Transposição Modelo-Protótipo}

Nesta secção são apresentados os resultados obtidos da transposição modeloprotótipo baseados na equação empírica

$$
\frac{C_{p, p r o t}}{C_{p, \text { mod }}}=\left(\frac{R e_{\text {prot }}}{R e_{\text {mod }}}\right)^{m}
$$

onde os subíndices 'prot' e 'mod' correspondem a protótipo e modelo, respectivamente, $R e$ é o número de Reynolds local, no caso do modelo $R e=8,3 \cdot 10^{4}$ e do protótipo $R e=5,2 \cdot 10^{4}$, e $m$ é um fator de escala calculado a partir das equações da metodologia BEM.

Por meio da análise adimensional foi demonstrado, na secção 3.6, que o coeficiente de potência depende exclusivamente do número de Reynolds e da razão de ponta de pá.

Por outro lado, pelas equações do BEM, foram relacionados os coeficientes de potência para modelo e protótipo através da Equação 5.2 para a mesma posição radial e o mesmo ponto de funcionamento, sendo este o ponto de projeto do protótipo, correspondente a $\alpha_{\text {opt }}$ e portanto, tem-se que $T S R_{\text {mod }}=T S R_{\text {prot }}$.

$$
\frac{C_{p_{\text {prot }}}}{C_{p_{\text {mod }}}}=\frac{\left.a^{\prime}(1-a)\right|_{\text {prot }}}{\left.a^{\prime}(1-a)\right|_{\text {mod }}}
$$

Os valores dos fatores de indução axial e radial, a e a', dependem exclusivamente do ponto de operação, $\lambda$ e do número de Reynolds.

A lei semi-empírica proposta apresentada na Equação 5.1 é dependente do número de Reynolds e de um fator de escala, calculado após igualar as relações de coeficiente de potência para modelo e protótipo obtidas das Equações 5.2 e 5.1.

Com este trabalho, procurou-se uma maneira de obter resultados de desempenho para um protótipo de turbina a partir dos dados do seu modelo reduzido obtidos experimentalmente em um túnel de vento, motivado pelos altos custos e complexidade nos ensaios experimentais de grandes turbinas.

Cabe ressaltar, que o protótipo da turbina opera com água e o modelo reduzido com ar. Isto é outro fator chave na transposição de resultados devido aos diferentes números de Reynolds. Os túneis de água, mesmo para modelos reduzidos, apresenta uma operação de maior complexidade assim como a construção de um modelo para água.

Por meio da análise de transposição de resultados uma curva de desempenho de $C_{p}$ vs $\lambda$ para o protótipo foi obtida a partir dos dados experimentais obtidos durante os ensaios de túnel de vento para o modelo reduzido e da equação semi-empírica proposta (Equação 5.1). 
Na Figura 54 apresenta-se a curva de desempenho $C_{p}$ vs $\lambda$ resultado da transposição modelo-protótipo. Assim como as curvas de desempenho experimental e numéricas CFD para modelo e protótipo.

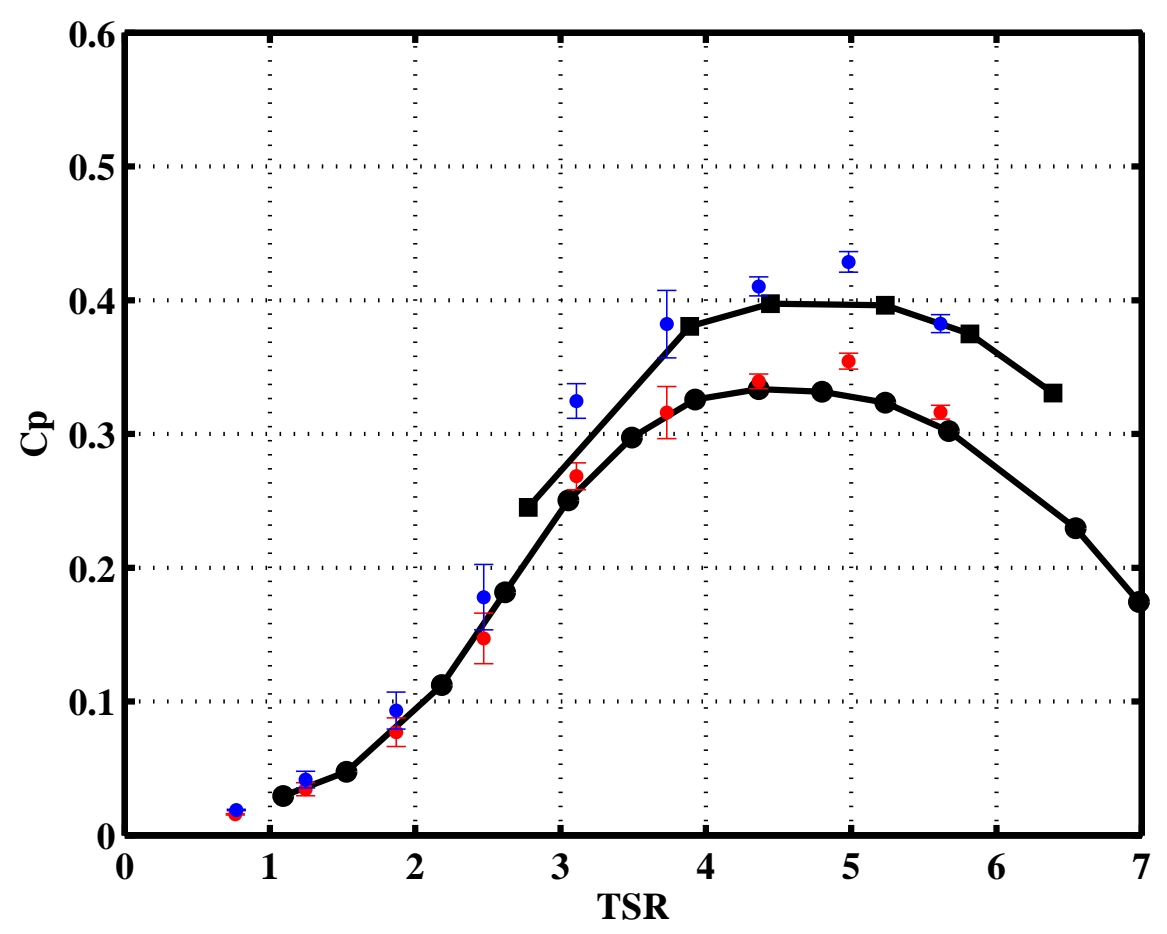

Figura 54 - Comparação das curvas de $C p$ vs. $\lambda$ numérica e experimental após aplicar a correção de bloqueio. •: Transposição modelo-protótipo; •: Experimental Correção bloqueio; •: CFD-modelo; a: CFD-protótipo

Observa-se como a curva obtida é similar à curva $C_{p}$ vs $\lambda$ obtida da simulação CFD para o protótipo, o qual valida a metodologia proposta para este caso de estudo especificamente. Percebe-se que na região de menores valores de $\lambda$ todas as curvas apresentam um comportamento similar, sendo que os valores experimentais apenas apresentam variações após aplicar a equação de transposição.

\subsection{Análise dos resultados}

Foram realizadas simulações RANS no ANSYS CFX R.16 para o protótipo, em àgua, e para seu modelo em escala 1:20, em ar. O domínio computacional utilizado foi o mesmo em ambos os casos, apenas foi aplicada a escala de um para o outro. Nas malhas utilizadas nas simulações $\left(7,5 \cdot 10^{6}\right.$ nós) foram empregados elementos tetraédricos, devido à complexidade geométrica, e prismáticos, para simular a camada limite. Em ambos casos, foram realizadas simulações para os diferentes pontos de operação. No caso do protótipo, foi fixada a velocidade da água escoada em $2,5 \mathrm{~m} / \mathrm{s}$ e variada a velocidade de rotação, 
chegando a resultados de $C_{p}$ máximo de 0,4 para $\lambda=4,44$. Para o modelo reduzido, a velocidade do ar escoado foi de $12 \mathrm{~m} / \mathrm{s}$ e o $C_{p}$ máximo obtido foi igual a 0,33 para $\lambda=4,36$. Cabe ressaltar como os valores máximos de $C_{p}$ foram obtidos para aproximadamente o mesmo valor de $\lambda$.

Por outro lado, foram realizadas simulações empregando a metodologia BEM por meio do software Qblade e de um código próprio implementado no software MATLAB. Para conseguir os resultados desejados, e tal como foi observado na literatura, no caso do modelo foi forçada a transição do escoamento do regime laminar para turbulento nas pás do rotor a $20 \%$ da corda no lado de sução. Isto devido ao baixo número de Reynolds local, no caso do modelo $\left(8,3 \cdot 10^{4}\right)$ frente ao do protótipo $\left(5,2 \cdot 10^{6}\right)$. Na literatura, nos casos de estudo de modelos reduzidos de turbinas de eixo horizontal em túnel de vento apresentam um problema da queda de eficiência aerodinâmica, devido a que normalmente os perfis utilizados foram desenhados para trabalhar em alto $R e$, e terminam trabalhando para baixos Re. O fator Ncrit escolhido para estas simulações foi Ncrit=5, tal e como reporta a literatura para esses casos. Nas simulações BEM do protótipo foi escolhido o parâmetro Ncrit como Ncrit=9, e não foi induzida a transição do escoamento de laminar para turbulento. Os dois métodos BEM empregados usaram o software XFOIL para o cálculo dos coeficientes de sustentação e arrastro.

Os resultados obtidos, no Qblade e no código BEM, foram similares. Para o caso do modelo o $C_{p}$ máximo encontrado foi igual a 0,35 para um valor de $\lambda=4,3$, resultado muito próximo ao obtido pela simulação numérica $\mathrm{CFD}, C_{p}=0,33$ para $\lambda=4,36$. Os resultados de $C_{p}$, do protótipo, obtidos em torno ao ponto de projeto, $\lambda=4,19$, são similares. $\mathrm{Na}$ simulação CFD o $C_{p}=0,4$ e na simulação BEM $C_{p}=0,41$. Os resultados obtidos, neste caso, mediante as simulações BEM e CFD não são tão próximos quanto os obtidos para o modelo. Isto pode ser devido a que a predição das curvas polares realizada no software XFOIL se apresenta ligeiramente diferente aos resultados experimentais obtidos para o mesmo perfil com o mesmo número de Reynolds por Abbott, Doenhoff e Stivers (1945).

A validação dos resultados numéricos obtidos para o modelo reduzido foi feita mediante ensaios experimentais realizados em um túnel de vento fechado de seção $1,2 \mathrm{~m}$ $\mathrm{x} 1,2 \mathrm{~m}$. As curvas de desempenho do modelo reduzido foram levantadas a partir das medidas de velocidade de rotação e torque do modelo reduzido. Após os primeiros ensaios realizados não foram encontrados os resultados esperados. Algumas melhorias construtivas e de montagem foram realizadas sobre o modelo para melhorar o desempenho da turbina.

Em primeiro lugar foi reduzido o sombreamento que a estrutura suporte exercia sobre as pás, e observou-se uma melhoria significativa no desempenho da turbina. No ensaio realizado com velocidade de escoamento $12 \mathrm{~m} / \mathrm{s}$ o valor máximo do $C_{p}$ passou de 0,29 a 0,35 , para $\lambda=4,53 \mathrm{em}$ ambos casos. Nos ensaios com velocidades 8 e $10 \mathrm{~m} / \mathrm{s}$ também foram obtidos valores de $C_{p}$ mais elevados após as melhorias mantendo o valor de $\lambda$. 
Posteriormente, foram colocados 'transitions strips' no extradorso das pás, localizados a $20 \%$ da corda desde a borda de ataque, no lado de sução da pá, para conseguir o mesmo efeito usado na simulação BEM. Procurou-se induzir a transição do escoamento do regime laminar para o turbulento procurando um aumento de sustentação nas pás, com seu conseguinte aumento de eficiência. Após a adição dos 'transitions strips' foram observadas melhorias significativas no desempenho do rotor. O valor máximo do coeficiente de potência aumentou e foi deslocado para direta. Isto aconteceu para as trés velocidades do escoamento ensaiadas. No caso da velocidade igual a $12 \mathrm{~m} / \mathrm{s}$ o máximo da curva foi $C_{p}=0,39$ para $\lambda=5,13$. Em todas as curvas de $C_{p}$ vs $\lambda$ levantadas, a zona da curva que representa o pós-estol no rotor não apresentou variações de uma curva para outra. Devido à falta de sustentação das pás na faixa de baixa rotações não foram percebidos os efeitos após as melhorias físicas realizadas sobre o modelo.

Os erros medidos durante os ensaios foram aceitáveis, ressaltando que os maiores erros encontrados foram nas medidas de torque nas faixas de rotação correspondentes ao começo do estol nas pás. Em todos os ensaios, o modelo reduzido apresentou vibrações significativas nos pontos de operação correspondentes ao inicio do estol nas pás. A faixa de velocidades para as quais este fenômeno foi observado corresponde aos 800-1200 rpm. Nas curvas de desempenho pode ser observado como para os valores de $\lambda$ referentes a estas velocidades de rotação o coeficiente de potência apresenta os maiores valores de erros, acarretados desde as medidas de torque.

Após os ajustes realizados sobre o modelo, foi observado que os valores encontrados de $C_{p}$ foram maiores aos esperados, e portanto, foram analisados os efeitos de bloqueio no rotor. A literatura sugere que para razões de bloqueio (BR) maiores que $10 \%$ é preciso aplicar alguma correção de bloqueio. Neste caso, $B R=13,6 \%$ e portanto, o método de correção de bloqueio de Bahaj et al. (2007) foi aplicado. As correções de bloqueio levam a uma diminuição dos resultados anteriormente obtidos, isto devido a que os dados experimentais medidos na turbina em condições de confinamento são maiores dos que em uma situação de fluxo livre seriam. O máximo valor do coeficiente de potência, após a correção de bloqueio, é $C_{p}=0,32$ para $\lambda=4,8$. Valores muito próximos aos encontrados na simulação numérica do modelo reduzido, $C_{p}=0,33$ para $\lambda=4,36$, comparação realizada para o caso de velocidade de escoamento no túnel de vento de $12 \mathrm{~m} / \mathrm{s}$. Portanto, os resultados experimentais obtidos no túnel de vento foram validados demonstrando confiabilidade na metodologia experimental utilizada.

Os dados experimentais obtidos no túnel de vento, foram velocidade de rotação, torque e velocidade do escoamento. Estes foram coletados usando o micro controlador ARDUINO. Na metodologia experimental, um fator chave foi o controle PID utilizado para manter a velocidade de rotação constante e conseguir estabilizar o sistema nos pontos de operação desejados. Sem este tipo de controle não foi possível conseguir estabilidade 
na zona pós estol devido às elevadas vibrações. O controle PID foi usado para regular o tempo de modulação (PWM) da carga conectada ao motor, atuante como um freio eletromagnético.

Finalmente, uma lei semi-empírica foi proposta para lograr a transposição de resultados de desempenho hidrodinâmico de um modelo operando em ar e seu protótipo em água. Portanto, a partir da curva de desempenho $C_{p}$ vs $\lambda$ obtida experimentalmente no túnel de vento para o modelo reduzido e da lei semi-empírica proposta foi obtida uma curva de desempenho para o protótipo operando em água. 


\section{Conclusões}

O presente trabalho teve como finalidade o estudo de turbinas de eixo horizontal, tanto eólicas como hidrocinéticas.

O objetivo principal deste estudo foi encontrar uma equação semi-empírica para realizar a transposição de resultados de desempenho obtidos experimentalmente a partir de um modelo reduzido ensaiado em túnel de vento para seu protótipo em água.

A equação proposta para a transposição de resultados relaciona os coeficientes de potência de modelo e protótipo com seus números de Reynolds e um fator de escala. Tanto os coeficientes de potência como o fator de escala foram calculados a partir das equações da metodologia BEM. Esta análise foi realizada para o ponto de projeto da máquina protótipo, correspondente a um $\alpha_{\text {opt }}=3,4$ e portanto, $\lambda=4,19$ nas condições de desenho do protótipo de $2,5 \mathrm{~m} / \mathrm{s}$ e $20 \mathrm{rpm}$.

O fator de escala, m, é calculado a partir de uma equação que relaciona os coeficientes de indução axial e radial para modelo e protótipo. Esses coeficientes foram calculados pelas equações do BEM, e dependem exclusivamente do número de Reynolds e do $\lambda$.

Com os dados experimentais obtidos para o modelo reduzido (ar) e usando a equação empírica proposta foi obtida uma curva de $C_{p}$ vs $\lambda$ para o protótipo (água). Os resultados obtidos da transposição para o protótipo foram validados com as simulações numéricas CFD e BEM. O valor máximo do coeficiente de potência na simulação CFD foi de 0,4 para $\lambda=4,44$, e no caso da transposição tem-se que $C_{p}=0,42$ para $\lambda=4,36$. Valores muito próximos que mostram que a lei encontrada tem capacidade de transpor os resultados experimentais de um modelo em ar para um protótipo em água.

No caso de turbinas hidrodinâmicas, fatores inerentes à hidrodinâmica do escoamento sobre pás girantes tais como transição laminar-turbulenta, descolamento da camada limite, entre outros, fazem com que os estudos de transposição de escalas, dependentes do número de Reynolds, não possam ser generalizados devido à complexidade dos fenômenos. Já que a similaridade dinâmica, baseada na equivalência entre os números de Reynolds entre modelo e protótipo, é quase impossível de ser reproduzida.

Portanto, a lei semi-empírica proposta neste trabalho para a transposição de escalas entre modelo-protótipo, foi validada apenas para o perfil aerodinâmico NACA 65(3)618 utilizado neste caso. Como foi comentado anteriormente, por problemas de similaridade dinâmica, leis semi-empíricas dependentes do número de Reynolds não podem ser generalizadas. Porém, cabe ressaltar, que a metodologia proposta é robusta já que é baseada nas equações da metodologia BEM, e a curva de desempenho obtida da transposição 
para o caso do protótipo em água foi validada por meio das simulações CFD e BEM.

Para trabalhos posteriores, sugere-se validar a lei semi-empírica proposta para outras turbinas com perfis aerodinâmicos diferentes. Assim como continuar os estudos de escalabilidade entre turbinas, para se possível encontrar uma lei que possa ser generalizada. No caso de outras turbinas, o fator de escala, m, deverá ser novamente calculado a partir das equações da metodologia BEM para o problema em questão. 


\section{Referências}

ABBOTT, I. H.; DOENHOFF, A. E. V.; STIVERS, L. S. Report No 824. Summary of airfoil data. [S.l.], 1945. Citado 2 vezes nas páginas 28 e 73.

ADARAMOLA, M.; KROGSTAD, P. Experimental investigation of wake effects on wind turbine performance. Renewable Energy, 36:2078-2086,, 2011. Citado na página 8.

AKON, A. F. Measurement of Axial Induction Factor for a Model Wind Turbine. Tese (Doutorado) - University of Saskatchewan, 2012. Citado na página 3.

ANDRIAMPARANY, T. IMPLEMENTATION OF A BLADE ELEMENT MOMENTUM CODE FOR THE DESIGN AND ANALYSIS OF HYDROKINETIC ROTOR. [S.l.], 2015. Citado na página 25.

BAHAJ, A. et al. Power and thrust measurements of marine current turbines under various hydrodynamic flow conditions in a cavitation tunnel and a towing tank. Renewable Energy, v. 32, n. 3, p. 407 - 426, 2007. ISSN 0960-1481. Disponível em: $<$ http://www.sciencedirect.com/science/article/pii/S0960148106000516>. Citado 4 vezes nas páginas $9,50,68$ e 85 .

BARNSLEY, M.; WELLICOME, J. Final report on the 2nd phase of development and testing of a horizontal axis wind turbine test rig for the investigation of stall regulation aerodynamics. [S.l.], 1990. Citado na página 50.

BATTEN, W. et al. The prediction of the hydrodynamic performance of marine current turbines. Renewable Energy, v. 33, n. 5, p. 1085 - 1096, 2008. ISSN 0960-1481. Disponível em: < http://www.sciencedirect.com/science/article/pii/S0960148107002133>. Citado na página 9.

BERTAGNOLIO, F. et al. Wind turbine airfoil catalogue. [S.l.], 2001. Citado na página 28.

BOtTASSO, C. L.; CAMPAGNOLO, F.; PETROVIC, V. Wind tunnel testing of scaled wind turbine models: Beyond aerodynamics. Journal of Wind Engineering and Industrial Aerodynamics, v. 127, p. 11 - 28, 2014. ISSN 0167-6105. Disponível em: <http://www.sciencedirect.com/science/article/pii/S0167610514000269>. Citado 4 vezes nas páginas 10, 64, 68 e 70 .

BURTON, T. et al. Wind Energy Handbook. [S.l.]: John Wiley \& Sons, LTD, 2001. Citado 2 vezes nas páginas 13 e 16.

CAMPAGNOLO, F. WIND TUNNEL TESTING OF SCALED WIND TURBINE MODELS: AERODYNAMICS AND BEYOND. Tese (Doutorado) - POLITECNICO DI MILANO, 2013. Citado 5 vezes nas páginas 2, 8, 10, 35 e 64 .

CHEN, T.; LIOU, L. Blockage corrections in wind tunnel tests of small horizontal-axis wind turbines. Experimental Thermal and Fluid Science, v. 35, n. 3, p. 565 - 569, 2011. ISSN 0894-1777. Disponível em: <http://www.sciencedirect.com/science/article/pii/ S0894177710002438>. Citado 2 vezes nas páginas 50 e 68. 
CONNOR, J. C. andG. et al. Development of a contra-rotating tidal current turbine and analysis of performance. In: EWTEC, Southampton, UK. [S.l.: s.n.], 2007. Citado na página 9.

DOMAN, D. A. et al. Tow-tank testing of a $1 / 20$ th scale horizontal axis tidal turbine with uncertainty analysis. International Journal of Marine Energy, v. 11, p. 105 - 119, 2015. ISSN 2214-1669. Disponível em: < http://www.sciencedirect.com/science/article/pii/ S2214166915000259>. Citado 2 vezes nas páginas 9 e 10.

DRELA, M. XFOIL: An analysis and design system for low Reynolds number airfoilS. [S.l.]: Low Reynolds Number Aerodynamics. Lecture Notes in Engineering, Spring-Verlag, New York, 1989. Citado na página 28.

GLAUERT, H. Wind Tunnel Interference on Wings, Bodies and Airserews. [S.l.], 1933. Citado 2 vezes nas páginas 9 e 50.

GLAUERT, H. The elements of aerofoil and airscrew theory. In: Cambridge University Press, Cambridge, England. [S.l.: s.n.], 1959. Citado na página 3.

HAND D.A. SIMMS, L. F. D. J. J. C. S. S. M.; LARWOOD, S. Unsteady Aerodynamics Experiment Phase VI: Wind Tunnel Test Configurations and Available Data Campaigns. [S.1.], 2001. Citado na página 7.

HANSEN, M. O. L. Aerodynamics of Wind Turbines. 2. ed. [S.l.]: Earthscan Publications Ltd, 2008. 181 p. (978-1-84407-438-9). Citado 7 vezes nas páginas 3, 16, 18, 19, 20, 22 e 24 .

HESS, J. L.; SMITH, A. M. O. Calculation of potential flow about arbitrary bodies. [S.l.], 1966. Citado na página 28.

IEA. IEA STATISTICS. KEY RENEWABLES TRENDS. Excerpt form: Renewables Information. [S.1.], 2015. Citado 2 vezes nas páginas 1 e 2.

JO, C. hee et al. Performance of horizontal axis tidal current turbine by blade configuration. Renewable Energy, v. 42, p. 195 - 206, 2012. ISSN 0960-1481. International Symposium on Low Carbon and Renewable Energy Technology 2010 (ISLCT 2010).

Disponível em: <http://www.sciencedirect.com/science/article/pii/S0960148111004617>. Citado na página 9.

KHAN, M. et al. Hydrokinetic energy conversion systems and assessment of horizontal and vertical axis turbines for river and tidal applications: A technology status review. Applied Energy, v. 86, n. 10, p. 1823 - 1835, 2009. ISSN 0306-2619. Disponível em: <http://www.sciencedirect.com/science/article/pii/S0306261909000713>. Citado na página 2 .

KHAN, M.; IQBAL, M.; QUAICOE, J. River current energy conversion systems: Progress, prospects and challenges. Renewable and Sustainable Energy Reviews, v. 12 , n. 8, p. 2177 - 2193, 2008. ISSN 1364-0321. Disponível em: < http: //www.sciencedirect.com/science/article/pii/S136403210700069X>. Citado 2 vezes nas páginas 5 e 6. 
KINSEY, T. et al. Prototype testing of a hydrokinetic turbine based on oscillating hydrofoils. Renewable Energy, v. 36, n. 6, p. 1710 - 1718, 2011. ISSN 0960-1481. Disponível em: <http://www.sciencedirect.com/science/article/pii/S0960148110005549>. Citado 2 vezes nas páginas 2 e 4 .

KULUNK, E. Aerodynamics of wind turbines. [S.l.: s.n.], 2011. Citado na página 21.

LANZAFAME, R.; MESSINA, M. Bem theory: How to take into account the radial flow inside of a 1-d numerical code. Renewable Energy, v. 39, n. 1, p. 440 - 446, 2012. ISSN 0960-1481. Disponível em: <http://www.sciencedirect.com/science/article/pii/ S0960148111004514>. Citado na página 28.

LEE, C. S. et al. Classification of airfoils by abnormal behavior of lift curves at low reynolds number. In: 24TH INTERNATIONAL CONGRESS OF THE AERONAUTICAL SCIENCES (ICAS). [S.l.: s.n.], 2004. Citado na página 28.

MAALAWI, K. Y.; BADAWY, M. T. A direct method for evaluating performance of horizontal axis wind turbines. Renewable and Sustainable Energy Reviews, v. 5, n. 2, p. 175 - 190, 2001. ISSN 1364-0321. Disponível em: <http://www.sciencedirect.com/science/ article/pii/S1364032100000174> . Citado na página 30.

MAGANGA, F. et al. Experimental characterisation of flow effects on marine current turbine behaviour and on its wake properties. IET Renewable Power Generation, v. 4, p. 498, 2010. Citado na página 9.

MANWELL, J. F.; MCGOWAN, J. G.; ROGERS, A. L. Wind energy explained, theory, design and application. In: John Wiley and Sons, Chichester, England. [S.l.: s.n.], 2002. Citado na página 3.

MASON-JONES, A. et al. Non-dimensional scaling of tidal stream turbines. Energy, v. 44, n. 1, p. 820 - 829, 2012. ISSN 0360-5442. Integration and Energy System Engineering, European Symposium on Computer-Aided Process Engineering 2011. Disponível em: < http://www.sciencedirect.com/science/article/pii/S0360544212003891>. Citado na página 9.

MCWILliam, M. K. Development of a Wind Tunnel Test Apparatus for Horizontal Axis Wind Turbine Rotor Testing. Tese (Doutorado) — University of Waterloo, 2008. Citado 2 vezes nas páginas 3 e 9 .

MENDES, R. C. F. ESTUDO DO FATOR DE INDUÇÃO AXIAL EM TURBINAS DE EIXO HORIZONTAL. Dissertação (Mestrado) — Universidade de Brasília, 2015. Citado 2 vezes nas páginas 10 e 48 .

MENTER, F. Zonal two equation k-w turbulence models for aerodynamic flows. in: Fluid dynamics and co-located conferences. American Institute of Aeronautics and Astronautics,, 1993. Citado na página 57.

MENTER, F. R. Two-equation eddy-viscosity turbulence models for engineering applications. AIAA Journal, American Institute of Aeronautics and Astronautics, v. 32, $n$. 8, p. 1598-1605, ago. 1994. ISSN 0001-1452, 1994. Citado na página 57.

MIKKELSEN, R.; SøRENSEN, J. Modelling of wind tunnel blockage. In: Proceeding of the 2002 Global Windpower Conference and Exhibition. [S.l.: s.n.], 2002. Citado 2 vezes nas páginas 9 e 50. 
MILEY, S. A catalog of low Reynolds number airfoil data for wind turbine applications. [S.1.], 1982. Citado na página 28.

MILNE, I. et al. Blade loads on tidal turbines in planar oscillatory flow. Ocean Engineering, v. 60, p. 163 - 174, 2013. ISSN 0029-8018. Disponível em: $<$ http://www.sciencedirect.com/science/article/pii/S0029801812004465>. Citado na página 9 .

MO, J.-O.; LEE, Y.-H. Cfd investigation on the aerodynamic characteristics of a small-sized wind turbine of nrel phase vi operating with a stall-regulated method. Journal of Mechanical Science and Technology, Korean Society of Mechanical Engineers, v. 26, n. 1, p. 81-92, 2012. ISSN 1738-494X. Disponível em: <http://dx.doi.org/10.1007/s12206-011-1014-7>. Citado 4 vezes nas páginas 10, 57, 59 e 62 .

MONTEIRO, J. P. et al. Wind tunnel testing of a horizontal axis wind turbine rotor and comparison with simulations from two blade element momentum codes. Journal of Wind Engineering and Industrial Aerodynamics, v. 123, Part A, p. 99 - 106, 2013. ISSN 0167-6105. Disponível em: <http://www.sciencedirect.com/science/article/pii/S0167610513001967>. Citado 2 vezes nas páginas 8 e 69.

MONTGOMERIE, B. Methods for Root Effects, Tip Effects and Extending the Angle of Attack Range to +-100deg, with Application to Aerodynamics for Blades on Wind Turbines and Propellers. [S.l.], 2004. Citado na página 28.

MOSHFEGHI, M.; SONG, Y. J.; XIE, Y. H. Effects of near-wall grid spacing on sst $\mathrm{k}-\mathrm{w}$ model using \{NREL $\}$ phase $\{\mathrm{VI}$ \} horizontal axis wind turbine. Journal of Wind Engineering and Industrial Aerodynamics, v. 107-108, p. 94 - 105, 2012. ISSN 0167-6105. Disponível em: < http://www.sciencedirect.com/science/article/pii/S016761051200089X>. Citado 3 vezes nas páginas 10, 59 e 62 .

MYERS, E. L.; GALLOWAY, P. W.; BAHAJ, A. S. Experimental and numerical results of rotor power and thrust of a tidal turbine operating at yaw and in waves. In: WREC, Sweden. [S.l.: s.n.], 2011. Citado na página 9.

OGGIANO, L. $\{\mathrm{CFD}\}$ simulations on the $\{\mathrm{NTNU}\}$ wind turbine rotor and comparison with experiments. Energy Procedia, v. 58, p. 111 - 116, 2014. ISSN 1876-6102. Renewable Energy Research Conference, \{RERC\} 2014. Disponível em: $<$ http://www.sciencedirect.com/science/article/pii/S1876610214017834>. Citado 2 vezes nas páginas 10 e 59 .

PECHLIVANOGLOU, G. The Effect of Distributed Roughness on the Power Performance of Wind Turbines. Tese (Doutorado) - Berlin University of Technology, 2010. Citado na página 64 .

RYI, J. et al. Blockage effect correction for a scaled wind turbine rotor by using wind tunnel test data. Renewable Energy, v. 79, p. 227 - 235, 2015. ISSN 0960-1481. Selected Papers on Renewable Energy: \{AFORE\} 2013. Disponível em: $<$ http://www.sciencedirect.com/science/article/pii/S0960148114007873>. Citado 4 vezes nas páginas $9,27,50$ e 68 .

SANDERSE, S. P. V. d. P. B.; KOREN, B. Review of computational fluid dynamics for wind turbine wake aerodynamics. Wind Energ. 2011; 14:799-819, 2011. Citado na página 57. 
SCHAFFARCZYK, A. Introduction to Wind Turbine Aerodynamics. [S.l.]: Springer, 2014. Citado 2 vezes nas páginas 7 e 8 .

SCHEPERS, J. et al. Final report of IEA Annex XIV : Field Rotor Aerodynamics. [S.l.], 1997. Citado na página 7.

SILVA, P. A. S. F. e. ESTUDO NUMÉRICO DE TURBINAS HIDROCINÉTICAS DE EIXO HORIZONTAL. Dissertação (Mestrado) — Universidade de Brasília, 2014. Citado 5 vezes nas páginas $3,10,60,61$ e 62 .

SORENSEN, N. N.; MICHELSEN, J.; SCHRECK, S. Navier-stokes predictions of the nrel phase vi rotor in the nasa ames $80 \mathrm{ft}$ x $120 \mathrm{ft}$ wind tunnel. Wind Energy, v. 5, p. 151-169, 2002. Citado 2 vezes nas páginas 10 e 57.

VERMEER, L.; SøRENSEN, J.; CRESPO, A. Wind turbine wake aerodynamics. Progress in Aerospace Sciences, v. 39, n. 6-7, p. 467 - 510, 2003. ISSN 0376-0421. Disponível em: <http://www.sciencedirect.com/science/article/pii/S0376042103000782>. Citado na página 8.

VITERNA, L.; CORRIGAN, R. Fixed pitch rotor performance of large horizontal axis wind turbines. [S.l.], 1982. Citado na página 28.

WHALE, J. et al. A study of the near wake structure of a wind turbine comparing measurements from laboratory and full-scale experiments. Solar Energy, v. 56, n. 6, p. 621 - 633, 1996. ISSN 0038-092X. Disponível em: <http://www.sciencedirect.com/science/article/pii/0038092X96000199>. Citado na página 8. 


\section{APÊNDICE A - Caracterização geométrica da pá}

A seguir apresentam-se o aerofólio usado nas pás, NACA 65(3)618, e o modelo tridimensional das mesmas. O modelo tridimensional foi criado no software Solidworks usando a ferramenta 'Loft' a partir dos dados de distribuição de corda, ângulo de torção e raio apresentados nas Tabela 3 e Tabela 4, para protótipo e modelo respectivamente.

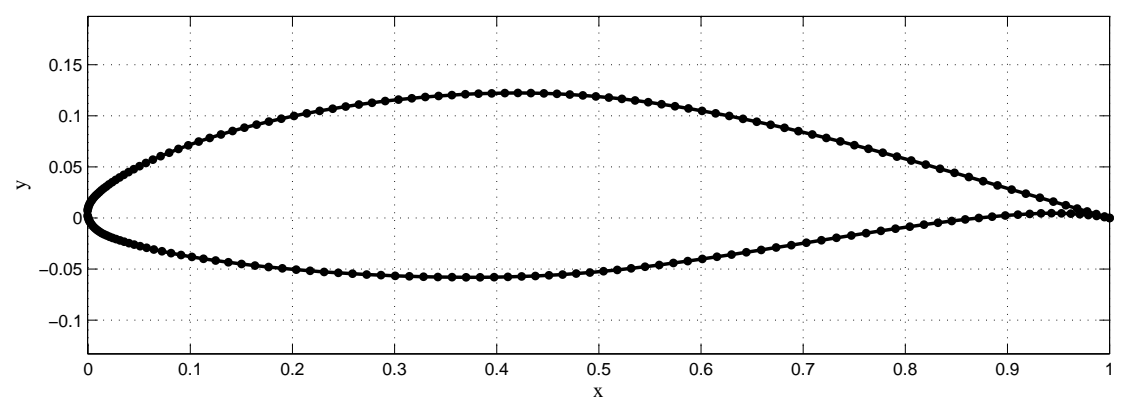

Figura 55 - Aerofólio NACA 65(3)618 usado nas pás

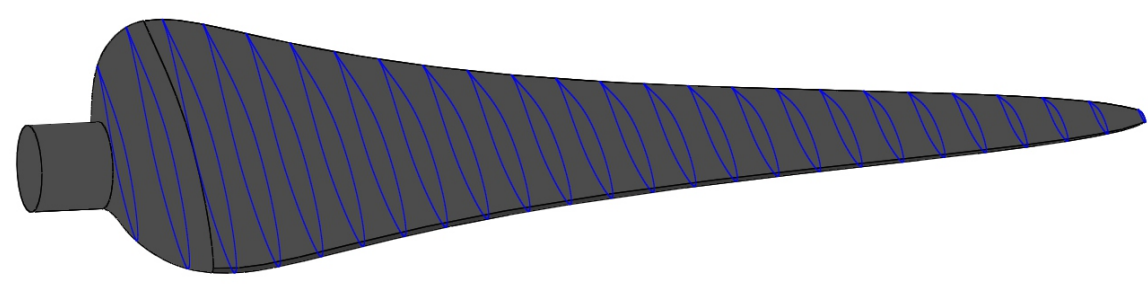

Figura 56 - Modelo tridimensional da pá 
Tabela 3 - Dados da geometria da pá para o protótipo

\begin{tabular}{ccc}
\hline Raio[m] & Corda $[\mathrm{m}]$ & Torção[rad] \\
\hline 0,600 & 0,426 & 0,669 \\
0,869 & 1,224 & 0,556 \\
1,139 & 1,362 & 0,467 \\
1,408 & 1,302 & 0,397 \\
1,678 & 1,200 & 0,341 \\
1,947 & 1,098 & 0,297 \\
2,216 & 1,006 & 0,260 \\
2,486 & 0,924 & 0,231 \\
2,755 & 0,851 & 0,206 \\
3,024 & 0,785 & 0,185 \\
3,294 & 0,725 & 0,167 \\
3,563 & 0,669 & 0,151 \\
3,833 & 0,612 & 0,138 \\
4,102 & 0,551 & 0,126 \\
4,371 & 0,479 & 0,115 \\
4,641 & 0,382 & 0,106 \\
5,000 & 0,112 & 0,095 \\
\hline
\end{tabular}

Tabela 4 - Dados da geometria da pá para o modelo. Escala 1/20.

\begin{tabular}{ccc}
\hline Raio[m] & Corda $[\mathrm{m}]$ & Torção[rad] \\
\hline 0,030 & 0,021 & 0,669 \\
0,043 & 0,061 & 0,556 \\
0,057 & 0,068 & 0,467 \\
0,070 & 0,065 & 0,397 \\
0,084 & 0,060 & 0,341 \\
0,097 & 0,055 & 0,297 \\
0,111 & 0,050 & 0,260 \\
0,124 & 0,046 & 0,231 \\
0,138 & 0,043 & 0,206 \\
0,151 & 0,039 & 0,185 \\
0,165 & 0,036 & 0,167 \\
0,178 & 0,033 & 0,151 \\
0,192 & 0,031 & 0,138 \\
0,205 & 0,028 & 0,126 \\
0,219 & 0,024 & 0,115 \\
0,232 & 0,019 & 0,106 \\
0,250 & 0,006 & 0,095 \\
\hline
\end{tabular}




\section{APÊNDICE B - Caracterização do perfil de velocidades do túnel de vento}

O objetivo de caracterizar o perfil de velocidades do túnel de vento é conhecer o comportamento do escoamento a montante da turbina. A seção escolhida para caracterizar o perfil de velocidades localiza-se na frente do modelo reduzido, a $750 \mathrm{~cm}$ da entrada da câmara de testes, já que o interesse do estudo reside em conhecer a uniformidade do fluxo que será escoado pelo rotor.

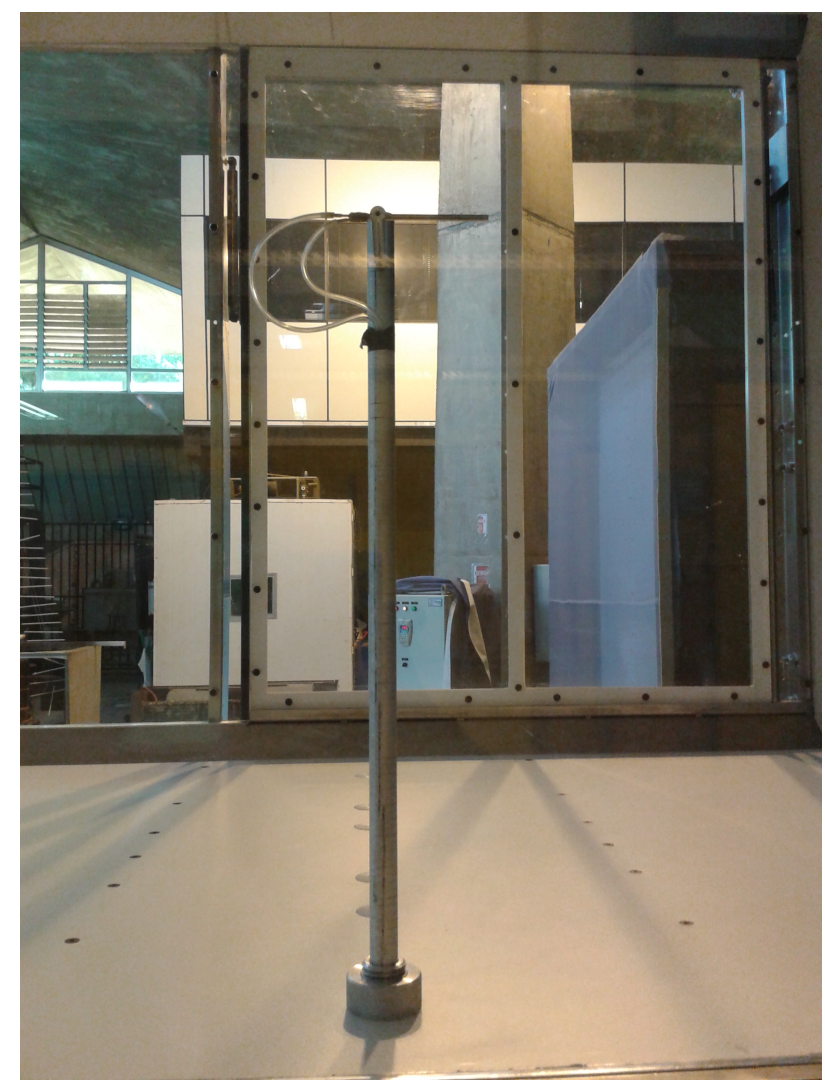

Figura 57 - Haste móvel e tubo de Pitot usados na medida dos perfis de velocidade

As medidas de velocidade foram tomadas a partir de um tubo de Pitot conectado a um manômetro de coluna inclinada de resolução $0,05 \mathrm{~mm}$ e fundo de escala $12,5 \mathrm{mmH}_{2} \mathrm{O}$. A temperatura e pressão foram tomadas durante o ensaio para o cálculo da densidade através da Equação 3.2 e posteriormente, a velocidade foi obtida pela Equação B.1, tal que

$$
u=\sqrt{\frac{2 \Delta P}{\rho}}
$$


O tubo de Pitot foi colocado no topo de uma haste móvel no interior do túnel de vento sendo posicionado em diferentes pontos da seção escolhida (Vide Figura 57). Adotando um sistema de coordenadas cartesianas localizado no ponto médio da superfície inferior do túnel, foram realizadas 10 medidas na horizontal e 6 na vertical, totalizando 60 pontos.

O perfil de velocidades foi caracterizado para duas velocidades médias do escoamento, $8,8 \mathrm{~m} / \mathrm{s}$ e $12,9 \mathrm{~m} / \mathrm{s}$. Cada perfil foi medido três vezes para garantir confiabilidade e repetibilidade nos dados obtidos.

Na Figura 57 apresentam-se as velocidades medidas ao longo da linha central para as duas velocidades, $8,8 \mathrm{~m} / \mathrm{s}$ e $12,9 \mathrm{~m} / \mathrm{s}$.

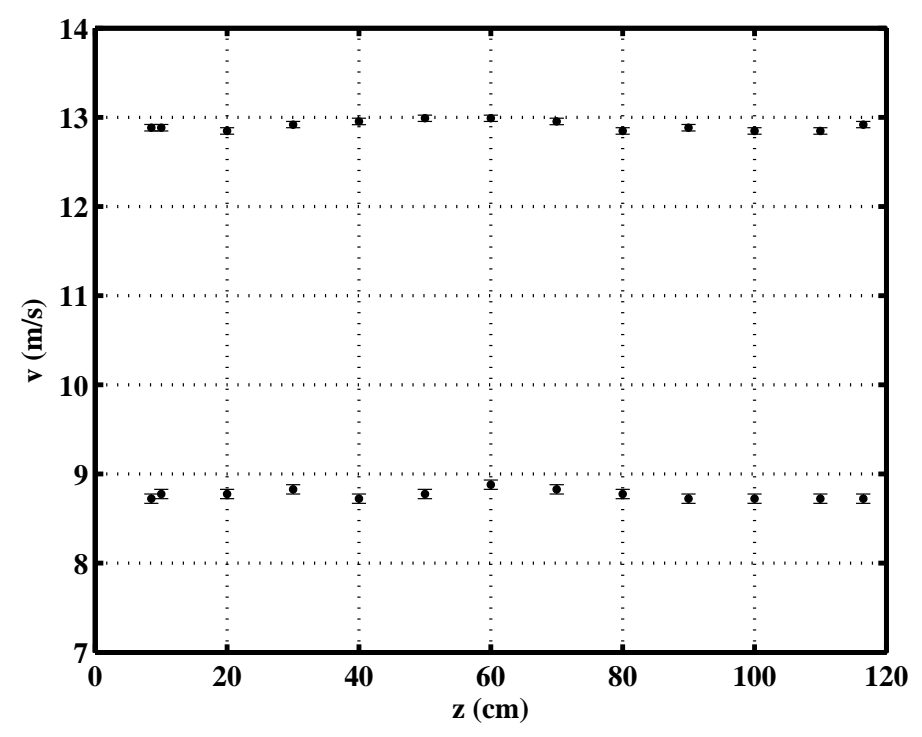

Figura 58 - Perfil de velocidade na linha central para as velocidades média de $8,8 \mathrm{~m} / \mathrm{s}$ e $12,9 \mathrm{~m} / \mathrm{s}$ 


\section{APÊNDICE C - Estimação da intensidade de turbulencia no túnel de vento}

Para uma descrição adequada do escoamento no interior do túnel, além de conhecer o perfil de velocidade em uma seção, é importante obter uma estimação das flutuações de velocidade para ter uma melhor caracterização do fluxo de ar no interior do túnel. Isto é feito a partir da estimação da intensidade de turbulência.

A intensidade de turbulência é uma medida adimensional da energia das flutuações de velocidade $u^{\prime}$, e foi definida pelo cociente entre o valor das flutuações da velocidade e a velocidade média $u$ de referência.

As medidas foram realizadas com um anemômetro de fio quente de ponta esférica, sistema miniCTA da DANTEC DYNAMICS, conectado a um osciloscópio. Em primeiro lugar o anemômetro é calibrado usando um tubo de Pitot fixo no túnel de vento conectado a um manômetro de coluna inclinada. Do osciloscópio tomamos as medidas de média e flutuação do sinal de velocidade medido pelo anemômetro. Após a calibração do anemômetro, o valor obtido no osciloscópio em vóltios (V) é correlacionado com a velocidade $(\mathrm{m} / \mathrm{s})$. Obtendo assim a intensidade de turbulência no interior do túnel de vento.

Na Figura 60 observa-se a montagem experimental no túnel de vento para caracterizar a intensidade turbulenta.
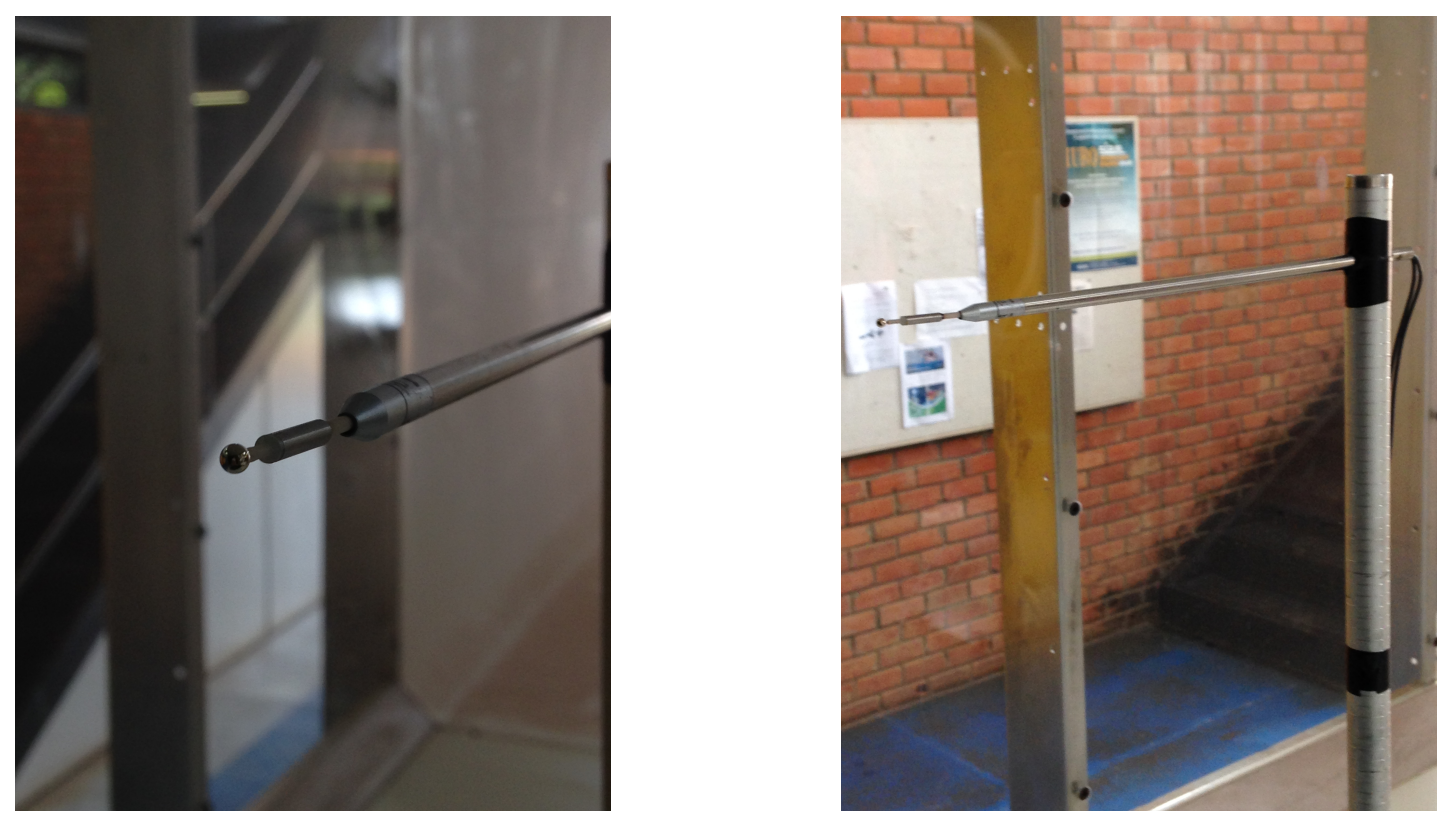

Figura 59 - Montagem experimental do anemômetro de fio quente para medição da intensidade de turbulência 
Foram realizadas medidas da intensidade de turbulência para várias velocidades de escoamento no interior do túnel de vento. Na Figura 60 são apresentadas as medidas de intensidade de turbulência realizadas.

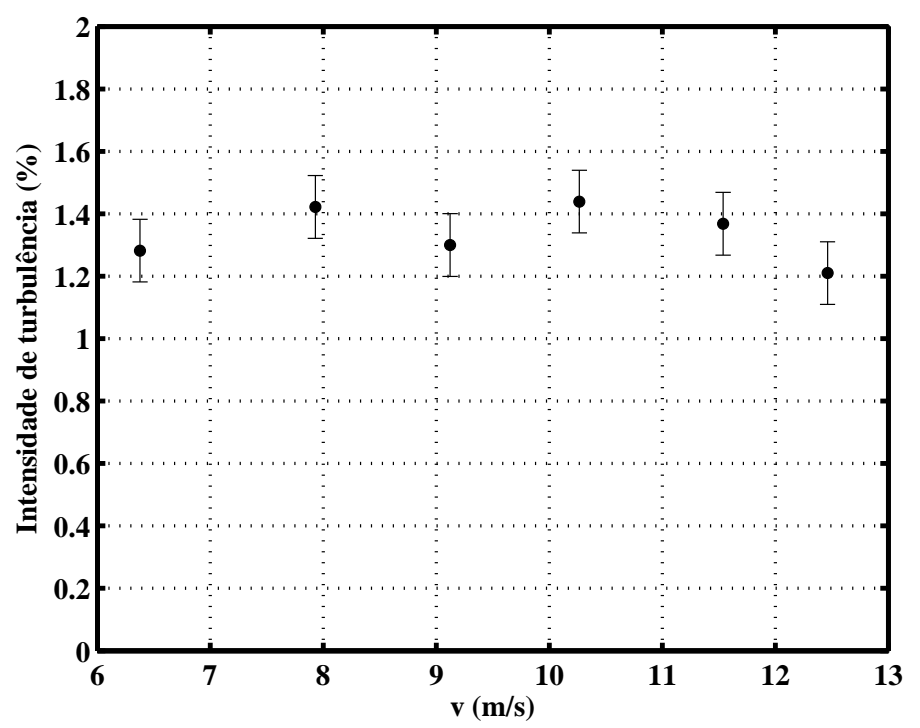

Figura 60 - Intensidade de turbulência para diferentes velocidades do escoamento 


\section{APÊNDICE D - Calibração do túnel de vento e dos sensores}

Na Figura 61 apresenta-se a calibração realizada para o túnel de vento. Nesta relacionam-se os valores de velocidade de rotação do motor do túnel de vento com a velocidade do escoamento medida por meio do manômetro de coluna inclinada. Os valores de velocidade de rotação do motor foram fornecidos pelo inversor.

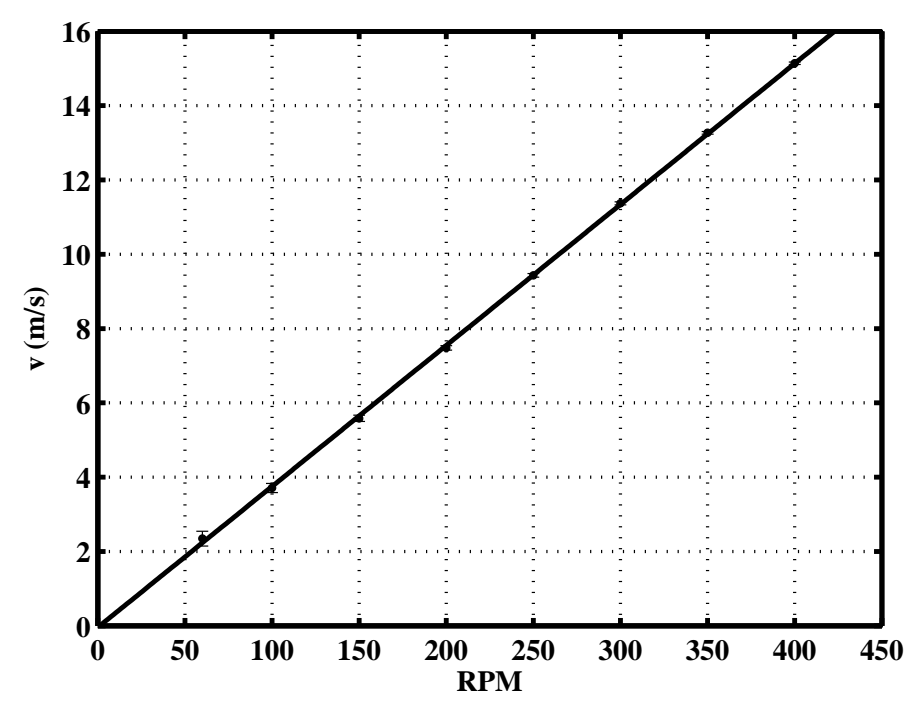

Figura 61 - Calibração do túnel de vento $y=0,079 x-0,045$

Nas Figura 62 e Figura 63 podem ser observadas as calibrações realizadas para o anemômetro de fio quente e a célula de carga. O anemômetro de fio quente foi calibrado através do tubo de Pitot instalado no túnel de vento. Com ajuda de um osciloscópio foram obtidos os valores de tensão proporcionados pelo anemômetro. Estes valores foram correlacionados com os valores de velocidade obtidos por meio do tubo de Pitot. A célula de carga foi calibrada usando um sistema de pesos padrão conhecidos. 


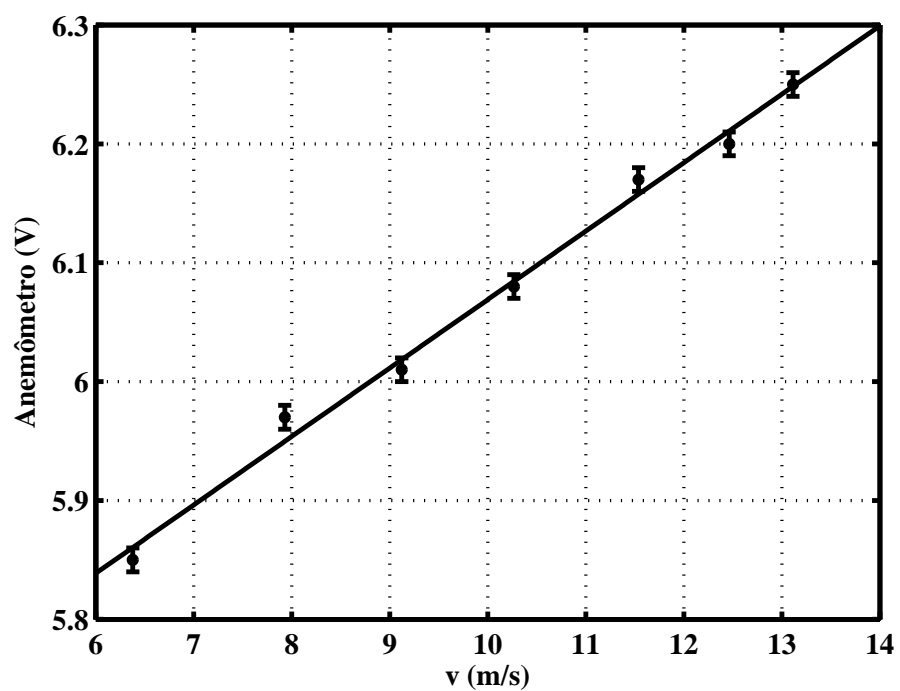

Figura 62 - Calibração do anemômetro de fio quente $y=0,058 x+5,49$

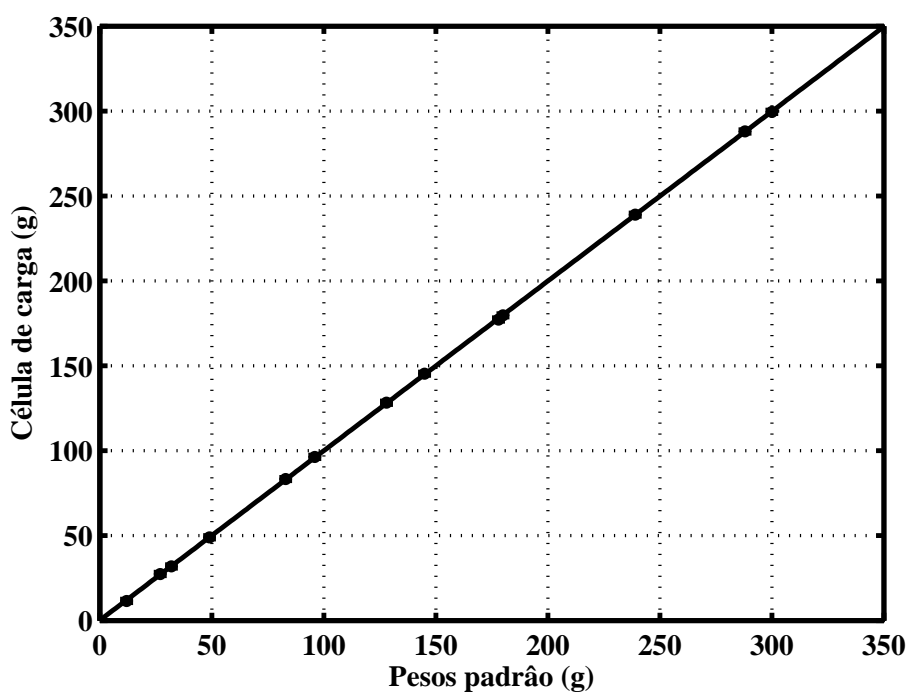

Figura 63 - Calibração da célula de carga $y=0,998 x+0,125$ 


\section{APÊNDICE E - Propagação de incertezas}

A seguir apresenta-se o estudo de propagação de incertezas associado às medidas tomadas durante os ensaios experimentais neste trabalho. As incertezas vem dadas pela soma das incertezas instrumentais e aleatórias.

As incertezas instrumentais são determinadas como: o valor da menor escala medida pelo instrumento, no caso de instrumento digital, ou pela metade do valor da escala, no caso de instrumento analógico.

Por outro lado, as incertezas aleatórias vem dadas como o desvio padrão $(\delta)$ calculado sobre o conjunto de ensaios realizados nas mesmas condições.

Todas as incertezas dos ensaios são escritas em função das incertezas dos seguintes instrumentos: sensor de temperatura $(\mathrm{T})$, sensor de pressão $(\mathrm{P})$, manômetro $(\Delta P)$, célula de carga $(\mathrm{F})$ e sensor indutivo de proximidade $(\omega)$.

$$
\begin{gathered}
T=\bar{T} \pm \delta T ; \\
P=\bar{P} \pm \delta P ; \\
\Delta P=\overline{\Delta P} \pm \delta \Delta P ; \\
F=\bar{F} \pm \delta P ; \\
\omega=\bar{\omega} \pm \delta \omega ;
\end{gathered}
$$

As incertezas medidas pelo sensores digitais de temperatura e pressão são propagadas no cálculo da densidade, já que,

$$
\rho=\frac{P n}{R T}
$$

Portanto, a incerteza da densidade vem dada por

$$
\delta \rho=\frac{n}{R} \sqrt{\left(\frac{1}{T}\right)^{2} \delta P^{2}+\left(\frac{-P}{T^{2}}\right)^{2} \delta T^{2}}
$$

onde,

$$
\delta T=0,1 .
$$

$$
\delta P=0,01 .
$$


A incerteza medida pelo manômetro de coluna inclinado e a incerteza calculada para a densidade são propagadas no cálculo da velocidade.

$$
u=\sqrt{\frac{2 \Delta P}{\rho}} .
$$

Portanto,

$$
\delta u=2 \sqrt{\left(\frac{1}{\rho}\right)^{2} \delta \Delta P^{2}+\left(\frac{-\Delta P}{\rho^{2}}\right)^{2} \delta \rho^{2}}
$$

onde,

$$
\delta \Delta P=0,05
$$

A medida to torque é determinada pelo produto da medida de força (célula de carga) multiplicada por um braço de comprimento $x$, sendo que

$$
\tau=x F
$$

A incerteza da distância vem dada pela escala do paquímetro utilizado para medição $0,01 \mathrm{~mm}$.

A incerteza da medida de força realizada pela célula de carga vem dada pelo desvio padrão obtido do conjunto de medidas realizadas.

$$
\delta \tau=\sqrt{(F)^{2} \delta_{x}^{2}+(x)^{2} \delta F^{2}}
$$

A potência mecânica gerada pela turbina vem dada por,

$$
P_{\text {mec }}=\tau \omega .
$$

e sua incerteza,

$$
\delta P_{m e c}=\sqrt{(\omega)^{2} \delta \tau^{2}+(\tau)^{2} \delta \omega^{2}}
$$

onde a incerteza da medida de velocidade de rotação realizada pelo sensor indutivo de proximidade vem dada pelo desvio padrão obtido do conjunto de medidas realizadas.

A potência disponível do escoamento,

$$
P_{d i s}=\frac{1}{2} \rho\left(\pi R^{2}\right) u^{3}
$$


as incertezas da densidade e velocidade já foram calculadas e a incerteza da medida do raio vem dada pela incerteza do paquímetro, 0,01mm.

Portanto, a incerteza da potência disponível vem dada por,

$$
\delta P_{\text {dis }}=\frac{\pi}{2} \sqrt{\left(R^{2} u^{3}\right)^{2} \delta \rho^{2}+\left(2 \rho R u^{3}\right)^{2} \delta R^{2}+\left(3 \rho R^{2} u^{2}\right)^{2} \delta u^{2}}
$$

Finalmente, apresentam-se as incertezas propagadas no cálculo de $\lambda$ e de $C_{p}$.

$$
\begin{gathered}
\lambda=\frac{\omega R}{u}, \\
C_{p}=\frac{P_{m e c}}{P_{d i s}}, \\
\delta \lambda=\sqrt{\left(\frac{R}{u}\right)^{2} \delta \omega^{2}+\left(\frac{\omega}{u}\right)^{2} \delta R^{2}+\left(\frac{-\omega R}{u^{2}}\right)^{2} \delta u^{2}} \\
\delta C_{p}=\sqrt{\left(P_{m e c}\right)^{2} \delta P_{d i s}^{2}+\left(\frac{-1}{P_{d i s}^{2}}\right)^{2} \delta P_{m e c}^{2}}
\end{gathered}
$$

